\title{
PRINCIPLES OF VEHICLE SUSPENSION.
}

By H. S. ROWELL (MEMBER).

\section{Part I.--INTRoductory.}

THE importance of the problem of suspension is manifest when it is remembered that its solution would lead to:-

1. Greater comfort of passengers.

2. Less damage to goods, or, alternatively, cheaper packing.

3. Reduced chassis stresses permitting:

(a) Reduction of weight and first cost.

(b) Reduction of repairs and maintenance.

4. More constant and uniform contact of road and tyre, thus reducing:

(a) Tyre bill.

(b) Engine and transmission stresses.

(c) Dust.

(d) Ruad wear and consequent taxation.

The nature of the problem is primarily dynamical, since it is concerned with the motions of masses and the forces which produce or change those motions. In the passenger vehicle, however, the element of comfort enters, and involves considerations of physiology and psychology which are not amenable to exact calculation. If a vehicle were required to carry eggs or watches, the acceleration which an egg or a watch could support under various conditions of packing could be determined and the vehicle designed to suit any prescribed road and speed. Altematively, and more practically, for any given road, speed and suspension, the minimum packing necessary could be determined, and this is the economic attitude and practice. A trader sends his wares by various oonveyances and finds in the long run by expensive experience the nature and amount of packing required in each case, e.g., goods train, passenger train, motor lorry, errand boy, etc.

Tho difficulties and limitations of the problem are many, and it is important that they should be kept in mind, since they affeat the interpretation of any solution. The following are among the more important:-

1. Tho load varios in:

(a) Nature.

(b) Position.

(o) Amount. 
2. Spring friotion varies with time and among springs of different manufacture.

3. The form of the road varies widely. For any one type of road a vehicle can be designed, but it is difficult to meet all conditions with one solution. For example, on some roads we have small irregularities as on cobbles, on tar macadam a wave form frequently occurs, while on plain or old tarred macadam in bad condition abrupt gaps, called pot-holes, may be encountered. Extreme conditions gave rise to the tank.

4. Tyres vary in:

1. Size.

2. Quality, and

3. Inflation.

5. The speed of a vehicle varies widely.

6. The standard of comfort is unknown and it is not precisely determinate. Obviously, it varies with the temperament and physical condition of the passenger.

7. Joints of various kinds wear slack and alter the conditions usually for the worse.

As the suspension problem is pre-eminently concerned with the passenger vehicle, it is desirable to consider the end in view, namely, comfort. Unless a problem can be clearly stated it cannot be clearly solved, and therefore we are driven to enquire into the nature of comfort.

\section{PART II.-COMroRT.}

The view has been put forward* that discomfort is to be expecterl in proportion to the rate of change of acceleration, or at least that rate of chango of acceleration is the important criterion. It is maintained that if the rate of change of acceleration is kept small, say, $1 \mathrm{ft}$. per seo. per sec. per sec., there will be little discomfort. It is not clear precisely to what part of the systen. the term aoceleration applies, whether it is the wherls, the car body, the centre of mass of the passenger or of his stomach, or of his brain, but it is clear that the law advocated cannot be a general law. While it is not suggested that Mr. Wimperis put forward this criterion as a complete generalisation of wide application, it is oonsidered desirable to neutralise the undue emphasis that he has lent to this view.

Thus, for example, suppose a man starts from rest with a rate of change of acceleration of $1 \mathrm{ft}$. per sec. per sec. per sec., which Mr. Wimperis says is comfortable, then in less than $5 \frac{1}{2}$ minutes the force exerted on every part of the man's body is ten times its weight. As an example, the average man's brain would be pressed against its caing with a force of between 30 and $40 \mathrm{lb}$, and a

* See Proc. I.A.E., Vol. VII., p. 476. 
12-stone passenger would be acted on by a force of $15 \mathrm{cwt}$. It is difficult to imagine that such conditions would be comfortable.

A further example may be given. Suppose a ship or a gardien. swing to move with harmonic motion.

$$
\mathrm{S}=\mathrm{A} \sin n t
$$

The velocity of the motion is given by

$$
v=\dot{\mathrm{S}}=n \mathrm{~A} \cos n t
$$

and the acceleration by

$$
\ddot{\mathrm{S}}=-n^{2} \mathrm{~A} \sin n t=-n^{2} \mathrm{~S} \text {. }
$$

The rate of change of acceleration is

$$
\ddot{\mathrm{S}}=-n^{3} \mathrm{~A} \cos n t==-n^{2} v \text {. }
$$

Putting these equations into words, we may, disregarding signs, say that the acceleration is proportional to the distance from mid-point, and the rate of change of acceleration is proportional to the velocity. Those who have been on a rolling ship or on a garden swing will admit that the most uncomfortable part of the motion is at the extreme, where the rate of change of acceleration is zero. On the other hand, at mid-swing, where the rate of change of acceleration is a maximum, the discomfort is a minimum.

Comfort is not a dynamical quantity, and it is unlikely that it can be correlated with dynamical equations however complex; certainly, simple dynamical statements of comfort are to be suspected. Comfort in locomotion is a branch of æsthetics, probably related in some degree through the mind to the other branches which are concerned more directly with the sensations of sight and sound.

Consider, for example, sea-sickness, a malady as old as or older than science. No satisfactory remedy has been found for all peoplo. Some require an opiate, others a tonic or stimulant, others again find nothing of use. The theory has been advanced that sea-sickness is due to the changing impressions on the vision due to the relative motion of the seascape, but this is discounted by. the fact that blind persons are not immune, nor is darkness any. protection. Dynamical theories have hitherto been equally unsuccessful. Discomfort at sea, however, has been greatly reduced in recent years by the introduction of massive ships with wellbalanced engines, and there is a parallel to this in the motor car.

It would be risky to define comfort as the absence of sensation, but certainly discomfort can be associated with various sensations, and, in fact, may be described as unpleasiant sensation. Physiologists and philosophers have attempted to deduce laws connecting. sensation and stimuli, but with indifferent success. E. H. Weber $(1795-1878)$ in the law that bears his name stated that the appreciable increment of a stimulus bears a constant ratio to the stimulus. Thus, if $\mathrm{S}$ be a stimulus and $d \mathrm{~S}$ the increment which can be just appreciated, then

$$
d \mathrm{~S} / \mathrm{S}=\text { constant }=\mathrm{K} \text {. }
$$


Professor W. D. Halliburton in his handbook of Physiolagy gives tho following values of $\mathrm{K}$, which, needless to say, vary for different persons according to training and temperament:-

$\begin{array}{lll}\text { Light } \ldots \ldots \ldots \ldots \ldots \ldots \ldots . . . \ldots & \text { about } & 0.01 \\ \text { Noise ................ } " & 0.33 \\ \text { Cutaneous pressure ... } & 0.03\end{array}$

Weight

$$
0.014,0.025
$$

for various parts of the body.

The meaning of these constants is simply explained by an example. If the average man were supporting a weight of $5 \mathrm{lb}$., and he could just detect the addition or subtraction of one-tenth of $1 \mathrm{lb}$., so, on Weber's law, if he were supporting a weight of $50 \mathrm{lb}$. he would be able just to detect a variation of $1 \mathrm{lb}$.

G. T. Fechner's (1801-1887) law may be deduoed by integration from Weber's law. Thus, if $d \gamma$ is the increased sensation due to $d \mathrm{~S}$, then when $d \gamma$ is small $d_{\gamma}=d \mathrm{~S} / \mathrm{S}$, so that $\gamma=\log \mathrm{S}+\mathrm{C}$, or the sensation varies as the logarithm of the stimulus. It need hardly be added that Fechner's law has its limitations. When the stimulus becomes excessive, unconsciousness or death may supervene. Fechner's law, however, recoived considerable verification from Sir Francis Galton, and it does express inter alia the everyday fact that the pangs of tooth-ache increase at a diminishing rate. The fallacy in the law is that a unit of sensation is inconceivable.

While we may dismiss as impossible and therefore impracticable any attempt to express sensation or discomfort in mathematical terms, it is of interest and value to examine briefly some of the general features of the problem.

The idea of a muscular sense was originated by Kelvin and Tait in their treatment of dynamics, and it has been examined more fully since by physiologists under the better term motorial or kinæsthetio sense. Thus, apart from cutaneous sensations which can be eliminated by local anæsthetics, and apart from any effort of the will, there is some sense of movement against force which is of complex origin. This cannot be ascribed entirely to the muscles, since the joints also play a part. According to Professor Starling (Elements of Physiology), in some joints a movement of 0.25 degrees is felt, while in others at least 1.4 degrees is necessary. Joints in compression are more sensitive than those in tension, probably because the nerves are in better contact.

Pain in the viscera, according to Professor Halliburton, is not produced by handling or even by eutting or burning; it appears to be associated with excessive action, stretching and inflammation. In locomotion, whether on a ship, or horse, or train, or motor car, it is clear that the internal organs are subject to varying forces and accelerations, and thus yielding amongst themselves there is increased action. This is the secret of horseback exercise for the liver, a prescription the value of which is inversely as the proficiency of the rider, and it explains the value of motoring in cases of anæmia. It must also be clear that various organs, since they 
are variously suspended and have various masses, have various free periods of oscillation. Thus, it may be supposed that sea-sickness or motoring discomfort could be ascribed to unison between the free periods of the viscera and those of the ship. Hence may spring the reason that some travellers prefer a meal before a sea voyage, while others prefer to go without. Herein may lie the reason why some people dislike orossing the Channel with its short choppy seas, while other people have different and slower seas as antipathies. Here may be the explanation of personal preference for certain ships or motor cars. Vibratory massage applied to the back or arms or face may give a soothing and pleasant sensation, whereas the dentist's drill applied to a tooth with smaller forces is unpleasant. A motor car was designed with a very soft suspension of low frequency, and several passengers who tried it complained of sea-sickness; a well-known man affirms that he dislikes standing inside a motor bus because the hairs in his ears are set in vibration and tickle him; one well-known car, the susfension of which is agreeable to most adults, is known in one locality to produce sickness in dogs and children.

The quantitative relation between physical energy or force and the resulting sensation will probably remain a mystery for a very long time, for the units necessary for comparison could not conceivably be of a comparable kind. But this fundamental hiatus does not preclude qualitative comparison. For example, waves of light, of heat and of sound produce three distinct kinds of sensation, and while on accepted modern views these three kinds of waves do not all oecur in the same medium, they are of distinctly diffenent frequencies, and different sense organs have been developed or evolved for their discrimination. It is worthy of remark that heat and light waves, while of a kindred nature, require different sense organs for their appreciation, but, viewed through analogy, there is little surprising in this. For example, we may consider the engine indicator, which in one form or another is familiar to every engineer. The indicator is, in a sense, a specia: sensory apparatus through which the engineer becomes aware of the fluctuations of pressure in an engine cylinder, and when the frequency of the fluctuations varies the indicator must be modified; for high-speed engines a high-speed indicator is essential. The analogy with our senses is olear. Heat waves, which are of comparatively low frequency, can be perceived through the nerves of the skin; light waves, of higher frequency, require the delicate apparatus of the eye for their perception.

In the suspension problem we have forces of various frequencies. What is their effect? Suppose a man suddenly walks down a step which he had forgotten and he lands on his heel, he does not feel the shock in his stomach, but in his bones, head, spinal-column, eto. When a man goes to a town after living in the country he suffers for a while pains in his shins and headaches on account of the shocks due to walking on hard pavements. After a while 
he becomes hardened and he usually changes his gait. In the same way, when using a pneumatic hammer or travelling in a motor omnibus or lorry with solid tyres, there is a high-frequency vibration or chatter which is felt more in the bones than elsewhere. On the other hand, when a ship is rolling, or when a car is bouncing, or on a swing or switchback railway, the main sensation is one of rising or falling of the viscera, often ascribed solely to the stomach. Some people say they do not mind a ship rolling, others cannot endure the pitching. Is this due mainly to the different frequency?

Just as we are sensible of vibrations of various frequencies by means of different sense organs-eyes, skin and ears-so vibrations of slower orders become manifest to us through various parts of our bodies. Just as there is a resonance theory of audition, so we may consider a resonance theory of sea-sickness or of locomotive discomfort generally. When a car has a frequency exceeding 140 per minute it jars badly, and we have unpleasant vibrations in our frame. When a car has a frequency of less than 80 , some people are sea-sick. The theory is only a partial one, because the human being has a mind and is subject to imagination, association and reflex sensations; some people are sea-sick before a ship leaves her moorings.

There are one or two other aspects of discomfort in motoring which may be mentioned. Sensation always outlasts stimulus; thus a rapidly-flickering light appears continuous, and the impacts of sound waves produce the sensation of a continuous impression. Something of this kind occurs in motoring, especially in motor cycling; even on very good roads where no bumps are experienced, a rider may feel sore and stiff after a long journey. Apart from the main vibrations of the machine and rider, there are subsidiary vibrations of much higher frequency in the frame, ete., which are never noticed except through the final sensation of fatigue. Adaptation and use also play a part. Just as sailors and horsemen become oblivious to what other people regard as acute discomforts, so hardened motorists never experience the sensation of the first ride in a car. Because most cars are tested by professional drivers, who have not only the esprit de corps of their firm, but the acquired hardiness of their trade, it may be that the last elements of comfort will remain elusive until manufacturers keep an intelligent invalid on their testing staffs.

Allied to the consideration of adaptation or use is variety or suddenness of change in the nature of motion or discomfort, and it is in this connection that the criterion of rate of change of acceleration may possibly find some justification. When anyone first enters a boiler shop the sudden increase of noise is unpleasant, but those who are working there daily soon cease to notice it, and so with a cold bath and many other daily experiences. In a motor car travelling over roads of normal quality, the passenger, after a while, settles down, and may even be soothed by the steadily 
recurring disturbance. Let the character of the roud change suddenly, or, what is almost equivalent, let the speed of the car be changed, and the passenger notices a difference in his condition unti! his system is adapted or used to it. Railway travel affords good examples of this, especially in the transition from straights to curves and vice versâ. The unpleasantness of rolling when a car is rounding a corner is probably due to variety or change in addition to the sensation, by association, of instability or insecurity. There is probably a curious mixture of psychology and physiology in the fact that one shock is not nearly so objectionable as repeated shocks. In the car this justifies friction.

Apart from mere discomfort, but related to it, is the extreme condition of suffering or injury. Many motor cyclists have had to sell their machines because "they could not stand the vibrat:on." Others on occasion have experienced vomiting and diarrhœea and nervous troubles. One ardent rider was regularly ill after a ride until he adopted oversize tyres. Without presuming to be too definite on such a problem, it may be stated that one important thing to avoid is solid shock or knock. Now, the main causes of the solid kind of shock are, bad spring friction due either to rough plates or rust or excessive nip, slack shackles and pins, inadequate tyres and hard cushions. The remedies are fairly obvious, and will be analysed more fully later. It may be emphasised here that in seeking to avoid knock or shock, designers may proceed to the other extreme and produce a suspension which causas seasickness, or at any rate gives an impression of flabbiness or insecurity. Moreover, no man can easily judge a suspension and say that it will suit all other men.

It is permissible to speculate a little on evolutionary lines. For hundreds of centuries men and women have been walking erect, and no doubt the internal organs have in a measure become adapted to the erect posture and to the shocks produced by walking. The leg is a double pendulum with two natural periods and modes of ribration, and these correspond somewhat to the speeds of walking and running. If there is anything in a resonance theory of sea-sickness or locomotion discomfort, and if we assume that our organs have suited themselves to the shocks of walking, we may enquire into the frequency of these shocks. If we assume a paos of $30 \mathrm{in}$., then the number of steps per minute is 35 times the miles per hour, so that when we walk at the speeds shown in the Table below, the body and its organs receive shocks per minute as shown.

$\begin{array}{lrrrrrrr}\text { Speerl ir miles per hour } \ldots & 2 \cdot 5 & \ldots & 3 \cdot 0 & \ldots & 3 \cdot 5 & \ldots & 4 \cdot 0 \\ \text { Shocks per minute ........... } & 87 & \ldots & 105 & \ldots & 122 & \ldots & 140\end{array}$

It is remarkable that these frequencies coincide very nearly with the range of practicable and comfortable frequencies in cars.

Dr. Lanchester, some eightesn years ago, gave the valuable. rule that a car would be comfortable if it had a natural frequenoy 
of between 90 and 100 per minute. There seems little doubt that this rule is a good guide, though in theory it is not quite sound because among several reasons a motor car can have six or more distinat natural frequencies. Moreover, many have used Dr. Lanchester's rule without complete success, and others, the bulk of the automobile industry, use it too slavishly. The fact remains that 90 to 100 swings per minute, as recommended by Lanchester, is equivalent in frequency to a wallking speed of between 2.5 and 3.0 miles per hour, a very comfortable pace indeed. The further fact remains that walking is a healthy and comfortable exercise which encourages peristaltic and other actions without injury or discomfort, and, while proof is impossible, the inferences indicated above are attractive to the imagination.

The foregoing is naturally a matter more of suggestion than of demonstration, but it may lead designers and experimental engineers to give more conscious attention to the human and personal clement in motoring, an element which is complex and of infinite variations. Before passing to the less difficult but by no means simple dynamios of the subject, it may be well to summarise the more important ideas in the preceding argument. Thus, we have observed that:-

1. The suspension problem is very important.

2. The problem cannot be stated definitely or simply.

3. There is no satisfactory standard of comfort. The criterion of rate of change of acceleration is manifestly unsatisfactory.

4. Discomfort is probably due to quasi-resonance. Highfrequency vibrations affect the bones, while low-frequency vibrations affect the tissues and organs. Walking frequencies are comfortable.

5. Habit and use play an important part and should be considered by experienced motorists before judging a suspension. Knock or solid shock is the most important thing to avoid.

\section{Part III.-Dynamics of a Single Body--The Block Cart.}

The dynamics of a motor car may be approached in various ways. We may with advantage proceed from the simple to the complex. Thus, in the first place assume that a vehicle has no springs and that its mass is concentrated in a point. This is an assumption beloved of mathematicians because it makes calculations as simple as they can be; it reduces the dynamics of life to the so-called dynamics of a particle. Moreover, assume that the road contour is rigid and represented by an equation of the type:-

$$
y=(h / 2)(1-\cos . t t 2 \pi / \lambda) \ldots \ldots \ldots \ldots \text { i } 1)
$$

where $v$ is the speed of the vehicle and $t$ is time. The othier quantities are shown in Fig. 1. 
The acceleration of the particle while following the road contour is obtained by differentiating equation (1) twice thus:-

$$
\ddot{y}=\left(4 \pi^{2} v^{2} h^{\prime} / 2 \lambda^{2}\right) \cos v t 2 \pi / \lambda \text {. }
$$

The reaction of the road being $R$ and the weight of the particle being $W$ we have

$$
\mathrm{R}=\mathrm{W}(1+\ddot{y} / g)=\mathrm{W}) 1+\left(4 \pi^{2} \ell^{2} h / 2, g \lambda^{2}\right) \cos r t 2 \pi / \lambda i \ldots
$$

This equation is important to road engineers and tyre purchasers. It shows the relative importanoe of weight, speed, height and wave length of the hump. It shows that for any ordinary road speed, speed is the governing factor, and for practical purposes we may say that the pressure on the road varies as the square of the speed, a result eonfirmed by expensive experiments in America.

The equation (1) may be regarded as a term of a Fourier series, and thus the foregoing conclusions apply to any form of raad irregularity subject to the interpretation of wave length. The effects of speed may be shown with much generality and clearness by simple vector methods, se Fig. 2. The momentum $M$ of the

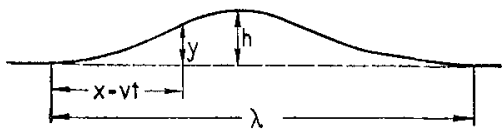

FIG. 1.

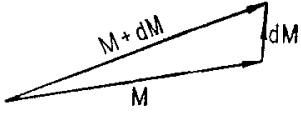

Fig. 2.

vehicle increases by $d \mathrm{M}$ in the time $d t$. For a given angular change, $d t$ is inversely as $v$, and since $M$ varies as $v$ the rate of change of momentum varies as $v^{2}$, i.e., the reaction on any given roarl varies as the square of the speed.

Other deductions of interest follow from this result. Thus, the road reaction is proportional to the weight, and by looking for the conditions under which road reaction is zero, we have the well-known effect of bounce or leaving the road. The vertical aceeleration upwards is given by (2) and the reaction $R$ by (3). Putting $R=0$ we have the condition for leaving the road.

$$
-\ddot{y} \geqslant g
$$

or

or writing

$$
\begin{aligned}
-\cos t t 2 \pi / \lambda & \geqslant 2 g \lambda^{2} / 4 \pi^{2} v^{2} h \quad \ldots \ldots \ldots \ldots . \\
2 \pi v / \lambda & =p \\
-p^{2} \cos p t & \geqslant 2 g / h \ldots \ldots \ldots \ldots \ldots \ldots \ldots
\end{aligned}
$$

From this we see that the higher the speed or the shorter the wave length or the higher the hump, so is the "take off" earlier and the angle of projection steeper. Thus, the body bounces higher and comes down again with greater force on the road. 
This can be put in symbols very easily. The gradient of the road from equation (1) is

$$
(\pi h / \lambda) \sin v t 2 \pi / \lambda=\tan \phi, \text { say } \ldots \ldots \ldots
$$

Thus, if $u$ be the vertical velocity we have under ordinary raad conditions

$$
u^{2}=v^{2} \tan ^{2} \phi=v^{2} \pi^{2} / h^{2} / \lambda^{2}-g \lambda^{2} / 4 \pi^{2} r^{2}=2 g H \ldots
$$

where $H$ is the height of bounce.

From equation (4) it is clear that no bounce can occur unless $v^{2} 7 g \lambda^{2} / 2 h \pi^{2}$, and thus the limiting bouncing speed varies as the wave length and inversely as the square root of the height of the hump.

The influence of the various terms in (6) can be brought out by arithmetic if certain values are assumed. The important variable is speed, because this can be controlled by the driver or by law. Assume $\lambda=2 \mathrm{ft}$. and $h / \lambda=1 / 10$ then $2 g \mathrm{H}=v^{2} / \pi^{2} / 100-g^{2} / \pi^{2} v^{2}$.

\begin{tabular}{ccccccccc}
\hline $\mathrm{V}$ ft. per sec. $\ldots$ & $5 \cdot 7$ & $\ldots$ & 10 & $\ldots$ & 20 & $\ldots$ & 30 \\
$2 g \mathrm{H} \ldots \ldots \ldots \ldots \ldots \ldots \ldots$ & $0 \cdot 0$ & $\ldots$ & 8.82 & $\ldots$ & $\mathbf{3 9} \cdot 22$ & $\ldots$ & $\mathbf{8 8 . 7}$ \\
$\mathrm{H}$ inches $\ldots \ldots \ldots \ldots \ldots$ & $0 \cdot 0$ & $\ldots$ & $\mathbf{1 . 5 4}$ & $\ldots$ & $7 \cdot 3$ & $\ldots$ & $\mathbf{1 6 . 5}$
\end{tabular}

In equation (3) we have the value of the reaction at the road surface.

This is a maximum when $t=0$, i.e., where the hump begine, and a minimum at the crest of the hump. Thus we see roughly why road waves are formed and why they progress. With traffio moving at speods sufficient to cause bouncing the effects are still worse, as the wheel does not touch the crest and comes down with a bang on the other side. With bituminous surfaces which can flow, the road is squeezed up, and with almost all surfaces there must be serious abrasion, as the heavy wheels impinge on the road after they have been accelerated while off the road.

\section{Conclusions.}

Before proceeding further we may collect and summarise results. Assuming a rigid body of small dimensions on a smooth rigid road, we see that the stresses on the noad vary as the square of the speed, and inversely as the square of the wave length of the road irregularity. Further, the road stresses vary directly as the weight and almost directly as the height of the hump. When the speed exceeds a certain value, the body bounces or leaves the road, and the bouncing speed varies as the wave length of the road irregularity and inversely as the square root of the height of the hump. The height of bounce varies practically as the square of the speed. It will appear later that the effect of springs on a vehicle is to reduce its virtual inertia in regard to road irregularities, and it is clear that the effect of increasing whel diameter 
is to increase the virtual wave length of the road obstacle. The practical results so far apparent are, therefore:-

1. With heavy wheels the speeds must be limited.

2. Road irregularities are aggravated and not smoothed out by fast traffic. This follows from consideration of bounce.

3. Increased wheel diameter smooths out the road, and, but for increased mass, would always be good.

\section{Part IV.-Simple Sprung System of two Masses-The SPRING Cart.}

Suppose, now, that instead of a single mass, we have two masses $m_{1}$ and $m_{2}$ connected by a spring (see Fig. 3), the mass of which may be ignored or allocated in part to each of the masses $m_{1}$ and $m_{2}$. Let $s$ be the stiffness of the spring in lb. per foot. and let. $x_{1}$ and $x_{2}$ be the heights of $m_{1}$ and $m_{2}$ measured from their equilibrium positions when they are at rest on the level part of

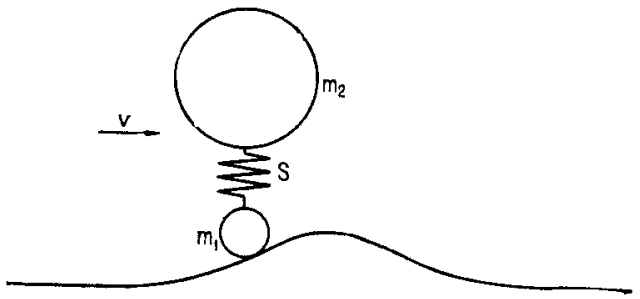

FIG. 3.

the road. Then we have the Newtonian equation of motion of $m_{2}$ $m_{3} \ddot{x}_{2}+s\left(x_{22}-x_{1}\right)=0$

The conclusions to be drawn from this equation are:-

1. The motion of the upper mass is governed by

(a) The ratio $s / m_{2}$.

(b) The motion of $m_{1}$.

2. The motion of $m_{2}$ is not directly affected by the magnitude of $m_{1}$ but by the motion of $m_{1}$, nor is it indireatly affected at low speeds.

It should be noted that the condition (1a) was implied by Dr. F. W. Lanchester eighteen years ago, when he prescribed a natural frequency of about 90 up and down oscillations per minute. The physical significance of equation (7) is that the motion of a car body is independent of the sprung mass of the car provided that the ratio of spring stiffness to sprung mass is constant. From this Dr. Reissner has argued that a light car might be as comfortable as a heavy car. This would be correct if a car could be truly

ROWELI. 
represented so simply as in Fig. 3. As a matter of fact, the treatment of motor-car suspensions as two masses connected by. a spring is only a crude approximation, which, while somewhat better than our first method wherein the car was treated as a single particle, is very far from being correct.

Re-arranging (7) we have:-

$$
\ddot{x}_{2}+s x_{22} / m_{22}=s x_{1} / m_{2}
$$

or assuming a path for the axle as before, i.e., assuming

$$
\begin{aligned}
& x_{1}=y=(h / 2)(1-\cos v t 2 \pi / \lambda) \\
& \ddot{x}_{2}+s x_{2 /} / m_{2}=\left(s h / 2 m_{2}\right)(1-\cos v t 2 \pi / \lambda) .
\end{aligned}
$$

For convenience we may write $2 \pi v / \lambda=p$ and $\sqrt{ }\left(s / m_{2}\right)=n$, and thus we see that the mass $m_{2}$ has a natural frequency of $n / 2 \pi$ and it is subjected to a forced vibration of frequency $p / 2 \pi$

The most general solution of $(8 \mathrm{a})$ is

$$
x_{2}=\mathrm{A} \cos n t+\mathrm{B} \sin n t+(h / 2)\left[1-\left\{\left(n^{2} /\left(n^{2}-p^{2}\right)\right\} \cos p t\right] .\right.
$$

wherein the constants $\mathrm{A}$ and $\mathrm{B}$ are arbitrary and depend on initial conditions. Thus, when $t=0, x_{2}=0=x_{2}$ from which

$$
\begin{aligned}
& \mathrm{A}=h p^{2 / 2}\left(n^{2}-p^{2}\right) \text { and } \mathrm{B}=0, \text { so that } \\
& \left.x_{2}=1^{2}+\left(p^{2} \cos n t-n^{2} \cos p t\right) /\left(n^{2}-p^{2}\right)\right\} h / 2 \ldots \ldots \ldots(10) \\
& \dot{x}_{.2}=(n \sin p t-p \sin n t) h p n / 2\left(n^{2}-p^{2}\right) \ldots \ldots \ldots \ldots \ldots(10 \mathrm{a}) \\
& x^{2}=(\cos p t-\cos n t) h p^{2} n^{2} / 2\left(\mathrm{n}^{2}-p^{2}\right) \ldots \ldots \ldots \ldots \ldots(10 \mathrm{~b})
\end{aligned}
$$

These are the equations of position, velocity, and acceleration for $m_{2}$ while passing over the hump. At the end of the hump, when $p t=2 \pi$, we have a free vibration of frequency $n / 2 \pi$, the amplitude and phase of which are determined from equations (10) and (10a). Thus we have from (10) (cos $\left.n t_{0}-1\right) h p^{2} / 2\left(n^{2}-p^{2}\right)=$ $\mathrm{C} \cos n t_{0}+\mathrm{D} \sin n t_{0}$ and from $(10 \mathrm{a})\left[h p^{2 / 2}\left(n^{2}-p^{2}\right)\right] \sin n t_{0}=$ $\mathrm{C} \sin n t_{0}-\mathrm{D} \cos n t_{0}$ where $n t_{0}=2 \pi n / p$.

Solving these two equations for $\mathrm{C}$ and $\mathrm{D}$ and substituting, we find that the equation after the hump is

$$
\begin{aligned}
& x_{2}=-\left[h p^{2} / 2\left(n^{2}-p^{2}\right)\right] 2 \sin (\pi n / p) \sin (n t-\pi n / p) \ldots(11) \\
& x_{2}=-\left[h p^{2} n / 2\left(n^{2}-p^{2}\right)\right] 2 \sin (\pi n / p) \cos (n t-\pi n / p) \ldots(11 \mathrm{a}) \\
& \ddot{x_{2}}=\left[h p^{2} n^{2} / 2\left(n^{2}-p^{2}\right)\right] 2 \sin (\pi n / p) \sin (n t-\pi n / p) \ldots(11 \mathrm{~b})
\end{aligned}
$$

The equations (10) and (11) give the motion during and after the hump. Before drawing deductions from these equations, it is desirable to consider the special case when $n=p$, so-called resonance, which makes the expressions assume an indeterminate form, 0 lo. By differentiation of (10) regarding $n$ or $p$ as independent and equating $n$ to $p$ we have:-

$$
\begin{aligned}
& x_{.2}=[1-\cos n t-(n t / 2) \sin n t] h / 2 \ldots \ldots \ldots(12) \\
& \ddot{x}_{2}=(\sin n t-n t \cos n t) h n / t \ldots \ldots \ldots \ldots \ldots(12 \mathrm{a}) \\
& \ddot{x_{2}}=\left(n^{3} t \sin n t\right) h / 4 \ldots \ldots \ldots \ldots \ldots \ldots \ldots \ldots \ldots \ldots
\end{aligned}
$$

These are the equations passing over the hump. Thereafter we have a free vibration of the form $x_{2}=\mathrm{E} \cos n t+\mathrm{F} \sin n t$ where 
$\mathrm{E}$ and $\mathrm{F}$ can be determined as before-from (12) $\mathrm{E}=0$ and from (12a) $\mathrm{F}=-\pi h / 2$.

Thus, the equations after the obstacle in the case of resonance $\operatorname{are}$

$$
\begin{aligned}
& x_{2}=-(\pi h / 2) \sin n t \ldots \ldots \ldots \ldots \ldots(13) \\
& x_{2}=-(n \pi h / 2) \cos n t \ldots \ldots \ldots \ldots \ldots(13 \mathrm{a}) \\
& x_{2}=\left(n^{2} \pi h / 2\right) \sin n t \ldots \ldots \ldots \ldots(13 \mathrm{~b})
\end{aligned}
$$

The foregroing conclusions assume that $m_{1}$, representing the wheel and axle masses, follows the road; so long as this is the case the following deductions may be made.

From equation (10) we see that the chassis motion is compounded of two harmonics of frequencies $n / 2 \pi$ and $p / 2 \pi$; this might be expected from the standard dynamics of forced vibrations.

From equations (11) we see that the motion of the chassis after the obstacle depends on the ratio of $n$ to $p$. Thus, when $n / p$ is any whole number greater than unity, there is no motion of the chassis after the obstacle. This may be expressed roughly by stating that a hard or stiff suspension with large $n$ will bump badly on an obstacle, but it is less likely to oscillate afterwards than a soft or flexible suspension with small $n$. This result has a parallel theorem in the dynamics of poppet valves.

From equation (12) we see that when a car period coincides with that of the road waves, the amplitude of the oscillation increases with the time and is a linear function thereof so long as the waves continue. For one wave alone we see from equations (13) that the amplitude after the obstacle is $\pi$ times the mean height of the obstacle.

When the car period is much longer than that of the road waves, i.e., when $p$ is much greater than $n$, we see from equations (10) that there is little disturbance of the chassis during one hump. This follows by writing equation (10) in the form

$$
x_{2}=\left\{1+\left[\cos n t-\left(n^{2} / p^{2}\right) \cos p t\right] /\left(1-n^{2} / p^{3}\right)\right\} / 2
$$

and even for $p / n$ humps in succession the amplitude is approximately the mean height of the hump. In this lies the justification for the suspension of low frequency. This point may be further emphasised by referring to equation (11), which gives the motion after the hump. Writing $p / n=r$, i.e., the road waves are $r$ times as rapid as the natural oscillations of the loar, we have the amplitude of the chassis as

$$
\left\{h r^{2} / 2\left(1-r^{2}\right)\right\} 2 \sin \left(180^{\circ} / r\right) .
$$

For example, if a car travelled at 20.5 miles per hour or $30 \mathrm{ft}$. per sec., and it had a natural frequency of 90 per minute or 1.5 per second, then road waves of $1 \mathrm{ft}$. pitch or wave length would have a frequency of 30 and $r$ would be 20 . Thus, the amplitude of the chassis after passing over one such obstacle would be

$$
(h / 2)(400 / 399) \sin 6 \text { degrees }=(h / 2), 9 \cdot 5
$$

$30(2)$ 
or with road waves $2 \mathrm{ft}$. long $r=10$, and the amplitude of the chassis would be

$$
(h / 2)(100 / 99) \sin 18 \text { degrees }=(h / 2) / 3 \cdot 2 .
$$

\section{Road Stress.}

The stress at the road surface in addition to the weight of the vehicle is $S=m_{1} \ddot{x}_{1}+m_{2} \ddot{x}_{2}$; when values of $\ddot{x}_{1}$ and $\ddot{x}_{2}$ are substituted from foregoing equations we have instructive results. 'Thus, using equation (10b), we have the road stress during the motion over the hump

(10c) $\mathrm{S}=\left(p^{2} h / 2\right)\left[\left\{m_{1}+m_{2} n^{2} /\left(n^{2}-p^{2}\right)\left\{\cos p t-\left\{m_{2} n^{2} /\left(u^{2}-p^{2}\right)\right\} \cos n t\right]\right.\right.$ and after the hump we have

(1!c) $\mathrm{S}=\left\{m_{2} p^{2} n^{2} h / 2\left(n^{2}-p^{2}\right)\right\} 2 \sin (\pi n / p) \cdot \sin (n t-\pi n / p)$

From both of these equations we see that the road stress in addition to weight varies as the square of the speed and as the height of the hump, and inversely as the square of the road wave length. When $p / n$ is large the unsprung mass is an important factor in road stress.

In the case of resonance we have during the hump

$$
\left.\left.(12 \mathrm{e}) \mathrm{S}=p^{2} h / 2\right) ; m_{1} \cos p t+\left(m_{.2} p t / 2\right) \sin p t\right\}
$$

From which we see that the sprung mass is more important than the unsprung mass.

And after the hump we have

$$
\text { (13c) } \mathrm{S}=\left(m_{2} p^{2} h \pi / .\right) \sin p t
$$

from which we see that the same law of speed squared, hump, and wave length apply, and that the sprung weight is important.

Under conditions of resonance it is the total weight of the vehicle, or, more exaotly, the sprung mass, which is important. For ordinary English roads and speeds we may say that unsprung. mass decides road stress, and in rough country or under Colonial conditions the total car weight and sprung mass become important.

\section{Holding the Road.}

A wheel leaves the road when the downward forces acting on it are not great enough to hold it in contact. When a weight is running on a curved path, we know that a force must be exerted on the weight towards the centre of curvature of the path in order to balance the so-called centrifugal force. When a car runs over a hump we have a similar state of things, and unless the downward forces are great enough the wheel will leave the road. If a carr were a rigid body as we supposed before, the matter would be a simple and obvious one, but where we have masses connected by springs the problem is complicated. Thus, if we have two masses with a spring between, and the system is in oscillation, then the upper mass may pull the spring and extend it and thus lift the 
lower mass off the road. The problem is too complex for words, and thus we are compelled to use symbols and mathematical operations which are merely a short-hand used to express concisely ideas which otherwise would become unwieldy.

Let $m_{1}$ be the mass of the wheel and axle and $m_{2}$ the mass of the chassis portion concerned; using the same symbols as before, we have the total downward forces on the wheel and axle as

$$
F=m_{2} y+s\left(x_{1}-x_{2}\right)+m_{1} g
$$

Now, if the wheel follows the road it has an upward acceleration $\ddot{x}_{1}$ or a downward acceleration $-\ddot{x}_{1}$. Thus, if the downward force is less than $-m_{1} \ddot{x}_{1}$ it will not be able to hold the wheel to the road and jumping will occur. The condition, then, for jumping is that

$$
m_{2} g+s\left(x_{1}-x_{2}\right)+m_{1} y<-m_{1} \ddot{x}_{1}
$$

hut if $\delta$ is the statio deflection, we have

$$
\begin{gathered}
\delta / g=m_{2} / s=1 / n^{2} \text { and } \\
s\left(\delta+x_{1}-x_{2}\right)+m_{1} g<-m_{1} \ddot{x}_{1}
\end{gathered}
$$

remembering that$$
x_{1}=(h / 2)(1-\cos p t)
$$$$
x_{2}=(h / 2)\left\{1+\left(p^{2} \cos n t-n^{2} \cos p t\right) /\left(n^{2}-p^{2}\right)\right\}
$$

and $\ddot{x}_{1}=\left(p^{2} h / 2\right)$ cos $p t$ we have by substitution, the condition of jumping is

$$
x_{2} \geq x_{1}+m_{1} \ddot{\delta} x_{1} / m_{2} g+\delta+m_{1} g / s \ldots \ldots \ldots \ldots(15 \mathfrak{c})
$$

or $x_{2}>h / 2-(h / 2) \cos p t\left(1-p^{2} m_{1} \delta / m_{2} g\right)+\delta\left(1+m_{1} / m_{2}\right)$

Thus. $(h / 2)\left[1+\left(p^{2} \cos n t-n^{2} \cos p t\right) /\left(n^{2}-p^{2}\right)\right]$

$$
>h / 2-(h / 2) \cos p t\left(1-p^{2} m_{1} \delta / m_{2} g\right)+\delta\left(1+m_{1} / m_{2}\right)
$$

From which we have

$$
\begin{aligned}
& \left(2_{\delta} / h\right)\left(1+m_{1} / m_{2}\right) \leqslant \cos p t\left[1-p^{3} m_{1} \delta / m_{2} g-n^{2} /\left(n^{2}-p^{2}\right)\right] \\
& \quad+\cos n t\left\lceil p^{2} /\left(n^{2}-p^{2}\right)\right] .
\end{aligned}
$$

putting $p^{2} / n^{2}=r^{2}$ wo have the condition for jump

$$
\begin{array}{r}
(2 \delta / h)\left(1+m_{1} / m_{2}\right) \leqslant \cos \mu t\left[1-r^{2} m_{1} / m_{2}-1 /\left(1-r^{2}\right)\right] \\
\quad+\cos p t / r\left[r^{2} /\left(1-r^{2}\right)\right] \ldots \ldots \ldots \ldots \ldots \ldots \ldots
\end{array}
$$

In the case of resonance we have $x_{2}$ from (12) and the condition is

$$
\begin{aligned}
(h / 2): 1 & -\cos n t-(n t / 2) \sin n t ;>h / 2-(h / 2) \cos p t\left[1-p^{2} m_{1} \delta_{2} m / g\right] \\
& +\delta\left(1+m_{1} / m_{2}\right) \ldots \ldots \ldots \ldots \ldots \ldots \ldots \ldots \ldots \ldots \ldots \ldots(1 i)
\end{aligned}
$$

and therefore jumping occurs when

$$
(2 \delta / h)\left(1+m_{1} / m_{3}\right) \leqslant-(n t / 2) \sin n t-\left(m_{1} / m_{2}\right) \cos n t \ldots(17 a)
$$

Thus, with resonance $m_{1} / m_{2}$ is not so important, and this is obvious from other considerations. Reverting to equation (16) and making. $r$ large, then for jump to occur

$$
2 \delta / h\left(1+m_{1} / m_{2}\right) \leqslant \cos p t\left(1-r^{2} m_{1} / m_{2}\right)+1 .
$$


or the condition for no jump is that

$$
\begin{aligned}
& 2_{\delta} / h \geq\left\{\cos p t\left(1-r^{2} m_{1} / m_{2}\right)+1\right\} /\left(1+m_{1} / m_{2}\right) \\
& \text { say } r^{2} m_{1} /\left(m_{1}+m_{2}\right)
\end{aligned}
$$

The equations are easily interpreted either for hillocks or hollows, the latter by making $h-v e$.

We see the importance generally of low unsprung weight and soft springs.

\section{Spring Stress.}

The question is often asked whether, when a car begins to oscillate violently, due to resonanoe, it is better from the wear and tear point of view to speed up or slow down. In the vehicle considered in this section, it is better to slow down. This is apparent from equations (12c) and (13c), which give road and wheel stross.

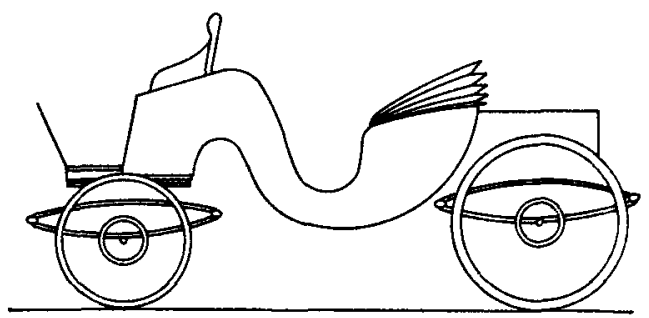

Fig. 4.

Moreover, if $\mathrm{P}$ is the spring stress in addition to static loading, we find that $\mathrm{P}=s\left(x_{1}-x_{2}\right)$.

$$
\mathrm{P}=(s h / 2)\left[p^{2} /\left(n^{2}-p^{2}\right)\right](\cos p t-\cos n t)
$$

when $n=p$ (the resonance condition) we have

$$
\mathrm{P}=(s h / 2) p t \sin p t \ldots
$$

Equation (18a) gives the worst condition. If the car is accelerated so that $p$ is much greater than $n$ we have a deflection of the spring equal to, or less than, the height of the hump. This assumes that there is no jumping of the wheel, which is hardly allowable at high speeds. On the other hand, we see from equation (18) that slowing down will reduce the added spring stress very rapidly until at rest it becomes, of course, zero.

\section{Part V.-Doubly-Sprung Wagon-Victorian Brougham and THE RaILWAY WagON.}

Assume now that we have two axles each connected separately by a spring or springs with the body, see Fig. 4. This separate 
springing of vehicles was the epoch-marking invention of Obadiah Elliot (1801), by which unsprung weight was reduced and permissible or safe speeds increased. Previously the perch-pole of great mass inherited from the so-called Ancient Britons tied the axles together and formed the back-bone of the four-posted frame from which the body was slung by leathern straps carried over quarter-elliptio springs. At high speeds on bad roads the leathern straps must have been severely tried, and it is likely that this was the origin of the saying "Hell for leather," and not, as is commonly supposed, the harness and traces.

Dynamically, this type of vehicle may be represented by Fig. 5, where the body is shown mounted on springs of stiffness $s_{1}$ and $s_{2}$ horizontally distant $a$ and $b$ respectively from the centre of gravity of the car body. It need hardly be added that this dynamical equivalent applies only to motion in the plane of motion of the car. Rolling will be dealt with later.

We have seen already that there is no uniformity in roads or

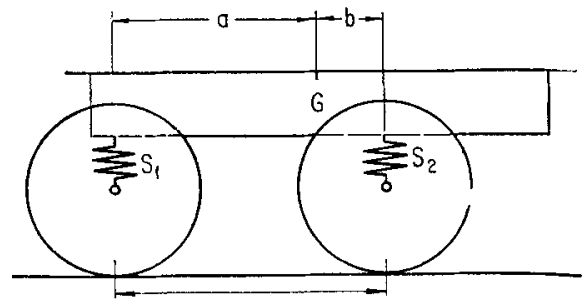

Fra. 5.

speeds or in many other things, and thus it is not feasible to attempt too much deduction. The sound method appears to be, to study as far as possible the dynamical properties of the car, to become conversant with the various kinds of motion which are natural to it, and then fior any one road or other set of conditions make what compromises are possible. We shall therefore examine the motions of the car body when not acted upon by forces other than its weight, and we shall find that there are certain natural periods or modes of free vibration.

It is convenient to measure all displacements from the equilibrium position, and we may either consider the displacements $x$ and $y$ of the car body just above the axles, or we may use $z$, the displacement of the centre of gravity of the body, and $\theta$, the angle through which the body has pitched or rotated in the plane of travel. There are advantages in both notations, and therefore the equations of motion for both sets of co-ordinates are set out.

First, we take $x$ and $y$, the amount the body sinks over the front and rear axle respectively. Thus, using $M$ for the mass, 
and $k$ for the radius of gyration of the body, and $L$ for the wheel base, the equations of motion are:-

$$
\left.\begin{array}{l}
(b \ddot{x}+a \ddot{y}) \mathbf{M} / \mathrm{L}+s_{1} x+s_{3} y=0 \\
(\ddot{x}-\ddot{y}) \mathbf{M} k^{2} / L+s_{1} a x-s_{2} b y=0
\end{array}\right\}
$$

We see that in general the motion $x$ is not independent of the motion $y$.

Similarly, using $z$ and $\theta$, for the sinking of the centre of gravity and the tilt of the body, we have as equations of motion

$$
\left.\begin{array}{l}
\mathbf{M} z+z\left(s_{1}+s_{2}\right)+\theta\left(s_{1} a-s_{2} b\right)=0 \\
\mathbf{M} k^{2} \ddot{\theta}+z\left(s_{1} a-s_{2} b\right)+\theta\left(s_{1} a^{2}+s_{2} b^{2}\right)=0
\end{array}\right\}
$$

From which again we see that the heaving motion $z$ is not in general independent of the pitching motion $\theta$.

Writing

$$
\begin{aligned}
& \tilde{z}=\mathrm{A} \cos (n t+\epsilon) \\
& \theta=\mathrm{B} \cos (n t+\epsilon) \\
& x=\mathrm{O} \cos (n t+\epsilon) \\
& y=\mathrm{D} \cos (n t+\epsilon) \\
& \alpha=\left(s_{1}+s_{2}\right) / \mathrm{M} \\
& \beta=\left(s_{1} a-s_{2} b\right) / \mathrm{M} \\
& \gamma=\left(s_{1} a^{2}+s_{2} b^{2}\right) / \mathrm{M}
\end{aligned}
$$

we have the following two sets of equations:-

$$
\begin{aligned}
& \mathrm{C}\left(s_{1}-n^{2} b \mathrm{M} / \mathrm{L}\right)+\mathrm{D}\left(s_{2}-n^{2} a \mathrm{M} / \mathrm{L}\right)=0 \\
& \left.\mathrm{C}\left(s_{1} a-n^{2} k^{2} \mathrm{M} / \mathrm{L}\right)+\mathrm{D}\left(-s_{2} b+n^{2} k^{2} \mathrm{M} / \mathrm{L}\right)=0\right\} \\
& \left.\begin{array}{ll}
\mathrm{A}\left(a-n^{2}\right)+\mathrm{B} \beta & =0 \\
\mathrm{~A} \beta & +\mathrm{B}\left(\gamma-n^{2} k^{2}\right)=0
\end{array}\right\}
\end{aligned}
$$

eliminating $\mathrm{A}, \mathrm{B}, \mathrm{C}, \mathrm{D}$, we have the frequency equations:-

$$
\begin{aligned}
& n^{4}-n^{2}\left\{\left(s_{1}+s_{2}\right) / \mathbf{M}+\left(s_{1} a^{2}+s_{2} b^{2}\right) / \mathbf{M} k^{2}\right\}+s_{1} s_{2} \mathbf{L}^{2} / \mathbf{M}^{2} k^{2}=0 \ldots \ldots \\
& n^{4}-n^{2}\left(\alpha+\gamma / k^{2}\right)+\left(a \gamma-\beta^{2}\right) / k^{2}=0 \ldots \ldots \ldots \ldots \ldots \ldots \ldots \ldots
\end{aligned}
$$

It will be seen that equations (21) and (21a) are identical if the values of $\alpha \beta \gamma$ are substituted, and this, of course, might be expected from the general theory of finite systems of more than one degree of freedom, i.e., frequencies are independent of the co-ordinates chosen.

The first deductions from equations (21) and (21a) are:-

(a) The sum of the roots in $n^{2}$ is, $a+\gamma / k^{2}$ or $\left(s_{1}+s_{2}\right) / \mathrm{M}+\left(s_{1} a^{2}+s_{2} b^{2}\right) / \mathrm{M} k^{2}$

(b) The product of the roots in $n^{2}$ is, $a \gamma-\beta^{2}$ or $s_{1} s_{2} \mathrm{~L}^{2} / \mathrm{M}^{2} k^{2}$

From this we see that the mean frequency, so to speak, varies as the square root of the wheel-base divided by the radius of gyration or inversely as the square root of the mass.

(c) The difference of the roots in $n^{2}$ is,

$$
(1 / \mathbf{M}) \sqrt{ }\left\{\left(s_{1}+s_{2}\right)^{2}+\left(s_{1} a^{2}+s_{2} b^{2}\right)^{2} / k^{4}+2\left(s_{1} a-s_{2} b\right)^{2} / k^{2}-2 s_{1} s_{2} \mathrm{~L}^{2} / k^{2}\right\}
$$


or from (21a)

$$
\left(1 / k^{2}\right) \sqrt{ }\left\{\left(a k^{2}-\gamma+2 k \beta\right)^{\prime}\left(a k^{2}-\gamma-2 k \beta\right) i\right.
$$

The condition for equal roots of the equation (21a) is that

$$
\left(\alpha k^{2}+\gamma\right)^{2}-4 k^{2}\left(\alpha \gamma-\beta^{2}\right)=0
$$

or

so that

$$
\left(\alpha k^{2}-\gamma\right)^{2}+4 k^{2} \beta^{2}=0
$$

and

$$
\beta=0=s_{1} a-s_{2} b
$$

$$
a=\gamma / k^{2} \text { or }\left(s_{1}+s_{2}\right) / \mathbf{M}=\left(s_{1} a^{2}+s_{2} b^{2}\right) / \mathbf{M} k^{2}
$$

The plain meaning of this condition is that the vertical resultant of the spring reactions must vanish or pass through the centre of gravity, and then the bouncing frequency must equal the pitching frequency. When $\beta$ is not equal to zero, bouncing and pitching are always co-existent and interdependent. It should be noted that either of the conditions $\beta=0$ and $\alpha=\gamma_{i} k^{2}$ is not sufficient for equality of the roots, but when both are satisfied we find by substitution in (20a) that the motion is indeterminate. Examples of this may be seen in certain double pendulums, in the spherical pendulum and in the vibrations of square plates. When the roots are not equal we may obtain the ratios of $A$ to $B$ and $C$ to $D$. Thus

$$
\begin{aligned}
& \mathrm{A} / \mathrm{B}=\beta /\left(n^{2}-a\right) \text { and } \\
& \mathrm{C} / \mathrm{D}=\left(s_{2}-n^{2} a \mathrm{M} / \mathrm{L}\right) /\left(n^{2} b \mathrm{M} / \mathrm{L}-s_{1}\right)
\end{aligned}
$$

Since $B$ is an angle, it is more natural to visualise $C / D$, which is the ratio of the motion over the front axle to that over the rear axle, and since there are two values of $n^{2}$ in the solution of the quadratics (21) and (21a), there are two values of the amplitude ratios $\mathrm{A} / \mathrm{B}$ and $\mathrm{C} / \mathrm{D}$.

The two values of $n^{2}$ and/or the corresponding values of the amplitude ratios define a mode, and thus we say that the simple car of Fig. 5 can vibrate in two distinet natural modes. Usually these two modes are superimposed, and using suffixes to denote the modes, we have the complete natural motion of the simple car in the equations

$$
\begin{aligned}
& z=\mathrm{A}_{1} \cos \left(n_{1} t+\epsilon\right)+\mathrm{A}_{2} \cos \left(n_{2} t+\epsilon\right) \\
& \theta=\mathrm{B}_{1} \cos \left(n_{1} t+\epsilon\right)+\mathrm{B}_{2} \cos \left(n_{2} t+\epsilon\right) \\
& x=\mathrm{C}_{1} \cos \left(n_{1} t+\epsilon\right)+\mathrm{C}_{2} \cos \left(n_{2} t+\epsilon\right) \\
& y=\mathrm{D}_{1} \cos \left(n_{1} t+\epsilon\right)+\mathrm{D}_{2} \cos \left(n_{2} t+\epsilon\right)
\end{aligned}
$$

A remarkably simple relation can be deduced for the ratios $A_{1} / B_{1}$ and $A_{2} / B_{2}$. Thus, from (21a) we have

$$
n^{2}=\left(k^{2} a+\gamma \pm \mathrm{R}\right) / 2 k^{2}
$$

from (22a), we have

$$
\text { where } \mathrm{R}=\sqrt{ }\left\{\left(k^{2} \alpha+\gamma\right)^{2}-\left(\alpha \gamma-\beta^{2}\right)+k^{2}\right\}
$$

$$
\begin{gathered}
\mathrm{A}_{1} \mathrm{~A}_{2} / \mathrm{B}_{1} \mathrm{~B}_{2}=\beta^{2} /\left(n_{1}{ }^{2}-\alpha\right)\left(u_{2}^{2}-\alpha\right) \\
=4 k 4 \beta^{2} /\left\{\left(\gamma-\alpha k^{2}\right)^{2}-\left(\alpha k^{2}+\gamma\right)^{2}+\left(\alpha \gamma-\left(\beta^{2}\right) 4 k^{2}\right\}\right.
\end{gathered}
$$


Thus:-

$$
\mathrm{A}_{1} \mathrm{~A}_{2} / \mathrm{B}_{1} \mathrm{~B}_{2}=-k^{2}
$$

Thus the product of these amplitude ratios is minus the radius of gyration squared, and is independent of the weight of the car and of the position of the axles.

Or if we take the $x$ and $y$ co-ordinates, we have from (22) the product of the amplitude ratios

$$
\begin{gathered}
\mathrm{C}_{1} \mathrm{C}_{2} \mathrm{D}_{1} \mathrm{D}_{22}=\left(s_{2}-n_{1}^{2} a \mathrm{M} / \mathrm{L}\right)\left(s_{2}-n_{2}^{2} a \mathbf{M} / \mathrm{L}\right) /\left(n_{1}^{2} b \mathrm{M} / \mathrm{L}-s_{1}\right) \\
\left(n_{2}^{2} b \mathbf{M} / \mathrm{L}-s_{1}\right)
\end{gathered}
$$

wherein we write $\mathrm{R}$ and $n^{2}$ as above, and the product of the amplitude ratios reduces to

$$
\mathrm{C}_{1} \mathrm{C}_{2} / \mathrm{D}_{1} \mathrm{D}_{2}=-s_{2} / s_{1} \ldots \ldots \ldots \ldots \ldots
$$

Or in words, the product of these amplitude ratios is minus the inverse ratio of the spring stiffnesses, which is also independent of axle position and car weight.

From these results the author was led to a new theorem on the double pendulum, which was published in "Nature," 28th July, 1921, and in the "Philosophical Magazine" for August, 1922, he gave an extension of the theorem to energy partition, which

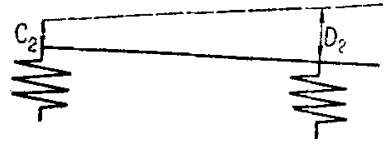

Fia. 6.

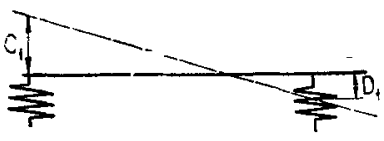

Fig. 7.

is of vital importance in the suspension of vehicles. These two theorems are embodied in Appendix A.

It should be added here, what is obvious and easily seen in the double pendulum, that the negative sign in the product of the amplitude ratios is due to the two distinct normal modes. In one mode $z$ and $\theta$ have the same sign, and in the other they ar opposed. Or, using $x$ and $y$ as co-ordinates, we see in Fig. 6 that in one mode $x$ and $y$ have the same sign, whereas in Fig. 7 they are opposed, as in pitching.

The justification for introducing these now conceptions, the product of the amplitude ratios and the energy partition, into suspension dynamics lies in the fact that they give simple views of complex phenomena, and they assist greatly in calculations both directly and as a check. An example will make this work clear.

We take a car of $9 \mathrm{ft}$. wheel-base, with sprung weight of $966 \mathrm{lb}$. The centre of gravity is $5 \mathrm{ft}$. behind the front axle and $4 \mathrm{ft}$. in front of the rear axle. The radius of gyration of the 
sprung part is $\sqrt{ } 13$. Using the notation in the foregoing, we have

$$
a=5 \mathrm{ft} . \quad b=4 \mathrm{ft} . \quad L=9 \mathrm{ft} . \quad k^{2}=13 \mathrm{ft}^{2} .
$$

$M=30$ slugs. $s_{1}=2,400 \mathrm{lb}$. per ft. $s_{2}=1,600 \mathrm{lb}$. per ft.

These stiffnesses correspond to static deflections at the front and rear axles of

$$
\delta_{1}=2.15 \text { in. and } \delta_{2}=4.0 \text { in. respectively. }
$$

These dimensions are all normal for present-day practice of moderate-quality cars.

From these assumed values we obtain

$$
\begin{array}{rlrl}
a & =133 \cdot 3 & a l^{2} & =1,733 \cdot 3 \\
\beta & =186 \cdot 67 & \alpha k^{2}+\gamma & =4,586 \cdot 6 \\
\gamma & =2,853 \cdot 3 & \alpha k^{2}-\gamma & =-1,120 \cdot 0 \\
\beta^{2} & =34,844 \cdot 4 & & \\
4 k^{2} \beta^{2} & =1,811,909 & \alpha\left(k^{2}-\gamma\right)^{2} & =1,254,400
\end{array}
$$

The solution of (21a) is

$$
\left.n^{2}=\left[\alpha k^{2}+\gamma \pm \sqrt{ } !\left(\alpha k^{2}-\gamma\right)^{2}+4 k^{2} \beta^{2}\right\}\right] / 2 k^{2} \ldots \ldots \ldots
$$

or substituting numerical values

$$
\begin{aligned}
n^{2} & =10^{2}(1.764 \pm 0.673) \\
& =10^{2}(2.438 \text { or } 1.091)
\end{aligned}
$$

whence $n=15.6$ or 10.45 radians per second, or multiplying by 9.55 to give complete oscillations per minute, we have $N_{1}=150$ and $\mathrm{N}_{2}=100$ per minute.

Thus the ear chosen in the example has two natural frequencies, 150 and 100 , and it will vibrate in either or both 'combined, according to circumstances. It is desirable to enquire into the rmplitudes of the motion in each mode.

From equation (22a) we have

$$
\begin{aligned}
\mathrm{A} / \mathrm{B}=\beta /\left(n^{2}-\alpha\right) \text { and since } \beta & =186 \cdot 67 \\
\alpha & =133 \cdot 3 \\
n^{2} & =243 \cdot 8 \text { or } 109 \cdot 1
\end{aligned}
$$

we have

$$
\begin{array}{r}
\mathrm{A} / \mathrm{B}=1.689 \text { or }-7.714 \text {, the product of which is } \\
-13 \text { or }-k^{2} \text { as in equation }(24 \mathrm{a}) .
\end{array}
$$

The physical meaning of these numbers is this:--In the first mode, the centre of gravity of the sprung weight oscillates $1.689 \mathrm{ft}$. for every radian of pitching motion, or $0.355 \mathrm{in}$. per degree. In this mode the ratio is positive, which means that the centre of gravity is sinking as the car nose-dives.

In the second or slower mode the centre of gravity of the sprung weight oscillates $7.714 \mathrm{ft}$. per radian of pitching motion, or $1.62 \mathrm{in}$. per degree. In this mode the ratio is negative, which means that the centre of gravity is rising as the car nose-dives.

Broadly and roughly, the two modes may be visualised by saying. that in the first and quicker mode the car is bouncing on its front 
springs about the rear axle, and in the second and slower mode it bounces on the rear springs about the front axle.

This point is brought out more elearly by using the $x y$ coordinates. Thus from equation (22) we have

$$
\mathrm{C} / \mathrm{D}=\left(s_{2}-n^{2} a \mathrm{M} / \mathrm{L}\right) /\left(n^{2} b \mathrm{M} / \mathrm{L}-s_{1}\right)
$$

substituting the various values given above, and using $n^{2}=243 \cdot 8$ or $109 \cdot 1$, we have

$$
\begin{gathered}
\mathrm{C} / \mathrm{D}=5\left(96-n^{2}\right) / 4\left(n^{2}-180\right) \\
\mathrm{C}_{1} / \mathrm{D}_{1}=-2 \cdot 896 \text { and } \mathrm{C}_{2} / \mathrm{D}_{2}=0 \cdot 231
\end{gathered}
$$

the product of which is $-2 / 3$ or $-s_{2} / s_{1}$, as in equation $(24)$.

The physical meaning of these results is that the assumed car when vibrating in the quicker mode is mostly pitching, and the downwards deflection over the front axle is 2.896 times the upwards deflection over the rear axle. So that if the front wheels met an obstacle, and the body were foreed 2.89 in. upwards in step with this mode, the rear springs would be deflected downwards by $1 \mathrm{in.}$ In the second or slower mode we may say that the car is bouncing, the two deflections are in step or phase and the front deflection is always 0.23 of the rear deflection, the rear deflection being 4.35 times the front deflection. The interpretation of energy partition will be dealt with later.

The foregoing arithmetical excursion has possibly served two purposes. On the one hand, it may have relieved the monotony of symbols and, on the other hand, it gives tangible point and confirmation to the algebra. The various masses, lengths, and spring stiffnesses assumed are in keeping with ordinary practice, and the results deduced may be verified in everyday experience. Before returning to more fundamental questions, we may look at some matters of direct practical interest.

Dr. Lanchester* gave a method of finding the natural period of bouncing of a car, in which he suggested that three or four men should stand in the car and move together in approximate unison with the car. This method may be very useful in practioe, but it is fundamentally unsound and may lead to incorrect results. The method is unsound for at least two reasons:--

1. A car in its simplest conception has two periods in the plane of motion, as we have seen. It will be shown later that it has at least six.

2. In an elastic system with friction, such as exists in a car, the resonance range is wide, and if the men jumped out of phase the apparent frequency might be altered, i.e., if the real frequency were 100 , it would be easy to produce a forced frequency of 90 or 110 .

A better method which is used (not in its best form) in two or three factories is to force the car at the front to oscillate, and then force it at the back. The rule used is that forcing at the back should give 90 oscillations per minute, and forcing at the

- See Proc. I.A.E., Vol. TI., p. 193. 
front should give 110. The error in this method, as carried out in one factory at least, is that the car still has two degrees of freedom and consequently two frequencies. The error is not usually! serious, but it ean be appreciable. In one car which is very well sprung; the data derived from the works tests indicate that the sprung. mass has a negative moment of inertia, which is, of course, impossible.

A much better method is to jamb or remove the front springs and bounoe the ear, and then jamb the rear springs and bounce the car. In this way the sprung mass is contrained and one idegree of freedom is removed. These frequencies when determined are very useful, and they may now be investigated.

Suppose the front spring $s_{1}$ jambed so that the car can bounce on the rear spring about the front axle as a hinge. Then the equation of motion is

$$
\mathbf{M}\left(a^{2}+k^{2}\right) \ddot{\theta}+s_{2}(a+b)^{2} \theta=0 \ldots \ldots \ldots \ldots
$$

so that the constrained frequency on the rear spring is

$$
{ }_{c} n_{2}=\mathrm{L} \sqrt{ }\left\{s_{2} /\left(a^{2}+k^{2}\right) \mathrm{M} ; \ldots \ldots \ldots \ldots\right.
$$

by symmetry the constrained frequency on the front spring is

The ratio of these is

$$
{ }_{c} n_{1}=\mathrm{L} \sqrt{ }\left\{s_{1} /\left(b^{2}+k^{2}\right) \mathbf{M}\right\} \ldots \ldots \ldots \ldots \ldots
$$

From which we have

$$
{ }_{c} n_{9} / c n_{1}=\sqrt{ }\left\{s_{9}\left(b^{2}+k^{2}\right) / s_{1}\left(a^{3}+k^{2}\right)\right\} \ldots \ldots \ldots
$$

or if we write

$$
l_{i}^{2}=\left(b^{2} s_{2,} c n_{1}{ }^{2}-a^{2} s_{1} c n_{2}{ }^{2}\right) /\left(s_{1} c n_{2}{ }^{2}-s_{2} \circ n_{1}{ }^{2}\right) \quad \ldots \ldots
$$

we have

$$
s_{1} / s_{2}=\sigma \text { and }{ }_{c} n_{1} / c n_{2}=\nu,
$$

$$
k^{2}=\left(b^{2} \nu^{2}-a^{2} \sigma\right) /\left(\sigma-\nu^{2}\right) \ldots \ldots \ldots \ldots \ldots
$$

Two important points spring from this part of the work. In the first place, equations (30) and (31) give a handy method of finding the effective moment of inertia of the sprung mass, probably the best method available. Where spring stiffnesses are in doubt, for various reasons, it may be expedient to take off the wheels and swing the body as a pendulum, but this, as a rule, is only practicable for small cars, and it involves some possible error in working back to the instantaneous centre of motion. Here it may be added that the determination of the position of the centre of gravity is easily found with a weighing machine. For the distances $a$ and $b$, each pair of wheels may be run on to a platform scale, and for the height of the centre of gravity, which is not always necessary in this work, one pair of wheels is lifted about $2 \mathrm{ft}$. above the platform scale, while the other pair are on the scale.

The other point of importance springs from the equation (29). If ${ }_{c} n_{1}$ and ${ }_{c} n_{2}$ are known, the ratio of the spring stiffnessies may be determined. 
Thus, from (29) we have

$$
s_{1} / s_{2}={ }_{c} n_{1}{ }^{2}\left(b^{2}+k^{2}\right) /{ }_{c} n_{2}{ }^{2}\left(a^{2}+k^{2}\right) \ldots \ldots \ldots \ldots
$$

There is a superstition in the industry that ${ }^{-} n_{1}$ should be 110 , and $n_{3}$ should be 90 . This is probably a fairly sound rule, and if it is embodied in equation (32) we have

$$
s_{1} / s_{2}=1.49\left(b^{2}+k^{2}\right) /\left(a^{2}+k^{2}\right) \ldots \ldots \ldots \ldots
$$

and if we substitute the values of $a b$ and $k$ used before, we have $s_{1} / s_{2}=1 \cdot 14$, or the front springs should be about 14 per cent stiffer than the rear springs.

Since $k^{2}$ is usually less than $a^{2}$ or $b^{2}$, the effect of varying $k^{2}$, due to slight shift of the axles, may be ignored. This is seen by differentiating (33) from which

$$
\left.d\left(s_{1} / s_{2}\right)=!\left(a^{2}-b^{2}\right) /\left(a^{2}+k^{2}\right)^{2}\right\} d k^{2}
$$

so that it is neasonable to consider the case where $a=b$, and then we see that $s_{1} / s_{2}=1 \cdot 49$, say, the front springs would be 50 per cent stiffer than the rear springs.

It is of interest here to compare the constrained and natural frequencies. If we use equations (27) and (28), and compare with the roots of equation (21), we see that there is no simple relation. If, however, we substitute numerical values in equations (27) and (28), and compare with the natural frequencies of the assumed aar, we have fairly close agreement. Thus, from (27)

$$
\text { c. } n_{1}^{2}=\mathrm{L}^{2} s_{1} /\left(b^{2}+k^{2}\right) \mathrm{M}=223 \cdot 7
$$

and ${ }_{c} n_{2}^{2}=\mathrm{L}^{2} s_{2} /\left(a^{2}+k^{2}\right) \mathrm{M}=113 \cdot 7$

The natural frequencies squared were $243 \cdot 8$ and $109 \cdot 1$.

Those interested in this subject will see here a parallel of the stationary property noticed by Lagrange and developed by Lord Rayleigh.

Returning now to more general questions and examining equations (19) and (19a), we notice again two important and distinct facts. In (19a) we see that if $s_{1} a=s_{2} b$ or $\beta=0$ in equations (20a), the vertical motion of the centre of gravity is independent of pitching motion. We have then the equations

$$
\left.\begin{array}{l}
\mathrm{A}\left(\alpha-n^{2}\right)=0 \\
\mathrm{~B}\left(\gamma-l^{2} n^{2}\right)=0
\end{array}\right\} \ldots \ldots \ldots \ldots \ldots
$$

from which the two frequencies in radians per sec. are

$$
n_{1}=\sqrt{ } a=\sqrt{ }\left\{\left(s_{1}+s_{2}\right) / \mathbf{M}\right\}=\sqrt{ }(\Delta / g)
$$

where $\Delta$ is the static deflection of the centre of gravity and

$$
n_{2}=\sqrt{ }\left(\gamma / k^{2}\right)=\sqrt{ }\left\{\left(s_{1} a^{2}+s_{2} b^{2}\right) / \mathbf{M} k^{2}\right\}
$$

Now the condition $s_{1} a=s_{2} b$ is clearly satisfied when $s_{1}=s_{2}$ and $a=b$, and this is the condition in railway carriages. The important questions arise:-Are railway carriages well sprung? Is it desirable to have the pitching motion independent of the bouncing motion? To the first question no precise reply need be expected. To the second question there is a statistical answer. The condition $s_{1} a=s_{2} b$ is a natural relation which might appeal to any 
draughtsman who tried to design a suspension. The fact that no car except a railway wagon seems to embody this relation, appears to suggest that this simple condition, akin to the "theorem of momentis in statics," is not important in motor-car design. It can be shown, however, that this condition is not necessarily undesirable.

We have seen above that $s_{1} a=s_{2} b$ makes pitching independent of bouncing, and we noticed before that when

$$
k^{2}\left(s_{1}+s_{2}\right)=s_{1} a^{2}+s_{2} b^{2}
$$

the roots of the frequency equation are equal, and the pitching and bouncing frequencies are the same. This condition of equal roots has been much discussed by mathematicians, the greatest of whom, Lagrange, and many others, fell into the error of taking the solution $(\mathrm{A}+\mathrm{B} t) \cos n t$ as in ordinary linear differential equations. E. J. Routh gave the correct treatment, and discussed the conditions under which the amplitude should increase with time. These conditions do not exist in the average car, and yet there is strong prejudice amongst designers against using equal frequencies. It is difficult to give a reasaned answer as to why this should be so, for at first sight it might appear that equal roots would be an advantage, since there would be but one resonance speed. One explanation that might be given is that the evidence against using equal frequencies is extremely vague and ill-founded. Few designers know the frequencies of their cars; almost none know the moments of inertia. The true explanation may be psychological rather than dynamical. We have observed that equal roots mean indeterminate motion, as in the spherical pendulum, and thus a car so sprung that it can oscillate in an infinite variety of ways may be extremely difficult to get used to. Car comfort, certainly motor-cycle comfort, is largely a matter of inurement. A further explanation is given later.

Another important fact arises from equation (19). We have examined the conditions under which the vertical motion of the centre of gravity is independent of the tilting motion of the car. We may now ask, under what conditions is the deflection of one set of springs independent of that of the other set of springs? If in equations (19) we make $k^{2}=a b$, we find by addition and subtraction

$$
\left.\begin{array}{l}
\ddot{\mathbf{M}} \ddot{x}+s_{1} x \mathrm{~L} / b=0 \\
\mathrm{M}_{y}+s y \mathrm{~L} / a=0
\end{array}\right\} \ldots \ldots \ldots \ldots \ldots
$$

so that $n_{1}=\sqrt{ }\left(s_{1} \mathrm{~L} / b \mathrm{M}\right)$ and $n_{2}=\sqrt{ }\left(s_{2} \mathrm{~L} / a \mathrm{M}\right)$

These agree with the constrained frequencies in equations (27) and (28).

The question now arises, whether it is desirable that the deflection of the rear springs should be independent of that of the front springs? All the evidence available points to the fact that it is desirable in varying degree depending on conditions.

The $k^{2}=a b$ law is identical with the well-known rule for the 
compound pendulum, and it is curious that this simple dynamical equation should not have been applied to vehicles before. The nearest approach to it so far as is known lies in a remark of Professor Reissner that the radius of gyration of the sprung mass should be half the wheel-base. This rule, while better than none, and while possibly very good in practice, can be shown to be irrational unless the centre of gravity of the sprung mass is midway between the axles, in which case it coincides with that given above, and, since the centre of gravity of most cans lies very nearly midway between the axles, Professor Reissner's rule is strong confirmation of our deductions from equations (34). The beauty of the $k^{2}=a b$ law can be easily perceived by simple experiments with a walking stick or bar suspended on two springs. The results are so striking that the observer is led to doubt or even denounce nearly all present-day design, for the wheel-bases of nearly all vehicles are longer than would be given by the $k^{2}=a b$ equation. Why is this? Why have salesmen boomed long wheelbases so persistently without any reference to what is carried above the springs? The explanation of the discrepancy is very complicated; in brief, it is because a car is a vehicle and not simply a suspended bar. A car has to be steered, and the dynamical conditions for steering and skidding are different from those for mere suspension. Moreover, a car suspension is an elastie and not an impulsive system, and one of the most important factors in suspensions is damping. A car designed on the $k^{2}=a b$. principle would require springs possessed of much friction, as. in lorries and railway wagons, where the law is closely approached. The full explanation of the importance of wheel-base effects on damping lies in Appendix A, and it is sufficient here to remark that the prevalenoe of spring lubrication is largely a result of the striving after a long wheel-base, which latter is imposed to a certain extent by fashion, body access, doors, etc. The fact that a long wheel-base is not essential may be exemplified by a famous car of $7 \mathrm{ft}$. 6 in. wheel-base which is unequalled and noted for "holding the road," and by a racing car which would not hold the track at Brooklands until the wheel-base was shortened. It is still more definitely indicated in motor cycles, which are more nearly impulsive systems. A cycle designed on the $k^{2}=a b$ law will leap a humped bridge and come down on both wheels, whereas other cycles will land on one wheel only and run on that wheel for some little distance. This deduction is based on a remark by Mr. J. L. Norton regarding the motor cycle Tourist Trophy races.

One line of thought which led to the $k^{2}=a b$ law may be of interest.

Suppose a car as shown in Fig. 8 to be mounting an obstacle. The front wheels are forced upwards, the body is tilted and the rear springs are compressed. If the car is travelling at such a speed that the rear wheel reaches the obstacle while the rear spring 
is compressed, there is obviously a harsher bump, and if it is going so slowly that the rear spring is in prosess of restoration, then the rear wheel arrives at the obstacle with the body swinging upwards, so that while the bump is probably more gentle, the upward swing of the body is reinforoed as in resonance conditions. On the other hand, if the $k^{2}=a b$ law is applied, each axle arrives at an obstacle with springs unaffected by the deflections at the other axle, and the problem is reduced almost to that of Part VI.*

In any case, it is instructive to see the effects of speed on a vehicle with two axles. If $\mathrm{V}$ be the speed of the car in $\mathrm{ft}$. per see., and $L$ the wheel-base, then an obstacle will react on the car twice, once at each axle, and the interval between the two reactions will be $t=\mathrm{L} / \mathrm{V}$ seconds. Alternatively, the speed of the car to give impacts $t$ seconds apart will be $\mathrm{V}==\mathrm{L} / t$. The natural periodic times of the car being $T_{1}$ and $T_{2}$, we see that the action of the obstacle, whatever it may be, on either natural mode of vibration will be identical if $t$ is increased by a multiple of $T_{1}$ or $T_{2}$. Further, the general motion of the car as composed of the two harmonies of periods $T_{1}$ and $T_{2}$ will be equally influenoed by the obstacle if $t$ is increased by an interval which contains $\mathrm{T}_{1}$ and

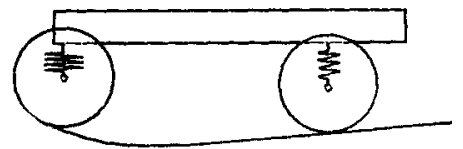

FIG. 8.

$\mathrm{T}_{2}$ an integral number of times. This is clear, because if the added interval is a multiple of $T_{1}$ and $T_{2}$ the car is in the same phase.

The following treatment is adapted from a paper by $P$. Lemaire (La Technique Moderne, January, 1921).

If $T_{1}$ and $T_{2}$ are the natural periods, there are two whole numbers $m_{1}$ and $m_{2}$ such that $m_{1} \mathrm{~T}_{1}=m_{2} \mathrm{~T}_{2}$. Thus, if the time interval be increased by intervals $m_{1} \mathbf{T}_{1}, 2 m_{1} \mathbf{T}_{1}$, etc., the effect ou the car of an obstacle should be kinematically the same. Thus, if a speed $\mathrm{V}=\mathrm{L} / t$ gives some characteristic of comfort or discomfort, the same characteristic will be in evidence at speods.

$$
\mathrm{L} /\left(t+m_{1} \mathrm{~T}_{1}\right) ; \mathrm{L} /\left(t+2 m_{1} \mathrm{~T}_{1}\right) ; \mathrm{L} /\left(t+3 m_{1} \mathrm{~T}_{1}\right) \text {, eto. }
$$

M. Lemaire pursues this aspect in detail, and proposes to deduce from a determined aomfortable speed, other comfortable speeds, but it seems doubtful if more than general ideas can be derived, because spring friotion would affect amplitude and phase, and sped affects shock. Moreover, his treatment is based on im-

$$
\text { * See later, p. } 485 \text {. }
$$

ROWELL. 
pulsive aotion, which, while approximately correct under certain conditions, is not generally valid because "an elastic system cannot support an impulse." His main result, however, is of great interest in that from quite a different angle he shows the fallacy of the long wheel-base which the author had indicated on other grounds some months before reading M. Lemaire's paper. Moreover, his analysis confirms the obvious fact of experience that for any car and obstacle there is a speed (or speeds) at which the motion will be violent and uncomfortable.

A numerical example will make clear M. Lemaire's treatment. In the car previously considered we found

$$
\mathrm{T}_{1}=0.4 \text { secs. and } \mathrm{T}_{2}=0.6 \text { secs. }
$$

Thus, we have $m_{1}=3$ and $m_{2}=2$, giving a grand interval of 1.2 secs. Suppose that for a given obstacle it was found that the car in question would negotiate that obstacle very comfortably at 18.4 miles per hour or $27 \mathrm{ft}$. per sec. The time interval between the two imprats for a 9 -ft. wheel-base would be $1 / 3$ sea., i.e., $t=1 / 3$. In words we may say that the phases of the motions are such that comfort or discomfort ensues when the rear axle is struck one-third of a second after the front axle or 1/3 \pm any number of times the grand interval. Thus, the speeds to give the same comfort over the same obstacle, assuming the car to approach it in the same state of rest or motion would be

$$
9 \div 1 / 3 ; 9 /(1 / 3+1 \cdot 2) ; 9 /(1 / 3+2 \cdot 4) \text {, etc. ft. per sec. }
$$

or $18.4,4,2 \cdot 25$, etc. miles per hour, a hyperbolic series.

The great advantage of numerical examples, apart from clarity, is the reality and proportion which ensues. In algebra the wheelbase may be represented by $L$ and there is no restriction, but if we take numbers we may not choose them far from practice. If $M$. Lemaire had given numerical illustrations of his algebra, which is extremely elegant and interesting, he would not have written his series of negative grand intervals. Theoretically, the phase conditions and the behaviour of the car are the same at lower speeds:-

$$
\mathrm{L} / t ; \mathrm{L} /\left(t+m_{1} \mathrm{~T}_{1}\right) ; \mathrm{L} /\left(t+2 m_{1} \mathrm{~T}_{1}\right) \text {, etc. }
$$

and at higher speeds:-

$$
\mathrm{L} /\left(t-m_{1} \mathrm{~T}_{1}\right) ; \mathrm{L} /\left(t-2 m_{1} \mathrm{~T}_{1}\right) ; \mathrm{L} /\left(t-3 m_{1} \mathrm{~T}_{1}\right) \text {, etc. }
$$

The second series is theoretically obvious and correct, but practically it is almost absurd, because in actual cars $m_{1}^{\prime} \mathrm{T}_{1}$ is nearly always much greater than $t$, so that negative velocities are indicated. This is seen by taking $\mathrm{L}$ as $9 \mathrm{ft}$. as before. We find for the range of speed from 6.1 miles per hour to 49 miles per hour $t$ ranges from 1 second to one-eighth of a second, and for the practical speed range $12 \cdot 2$ miles per hour to 49 miles per hour $t$ ranges from one-half to one-eighth of a second. Thus, for almost any car on the road $m_{1} T_{1}$ is greater than $t$ and the negative series is not practicable. The same is not always true of the motor oycle, which, when unsprung and with hard forks, can have a 
small grand interval. The possibility even here, however, is very small as the wheel-base of the motor cycle is usually shorter.

One very important point which appears to have escraped the notice of writers on this subject, is the relation between the two periods $T_{1}$ and $T_{2}$. M. Lemaire concludes that $T_{1}$ and $T_{2}$ should be large in comparison with the time required to travel over the length of the wheel-base, which is an argument for a short wheeIbase and slow springing, but the root of the matter lies in the grand interval $m_{1} \mathrm{~T}_{1}=m_{2} \mathrm{~T}_{2}$. It has been found by experienoe that it is bad to have $T_{1}$ and $T_{2}$ equal. Some reasons for this have been already discussed. But apart from these reasons, and very cogent, is the deduction which springs from M. Lemaire's method. If the periods $\mathrm{T}_{1}$ and $\mathrm{T}_{2}$ are so chosen that $m_{1}$ and $m_{2}$ are large, then the ranges of phase agreement, the grand intervals, are greatly increased. Thus,

$$
\begin{aligned}
& \text { if } \mathrm{T}_{1}=\mathrm{T}_{2}, m_{1}=m_{2}=1 \text { and } m_{1} \mathrm{~T}_{1}=\mathrm{T}_{1} \\
& \text { " } \mathrm{T}_{1}=0.9 \mathrm{~T}_{2}, m_{1}=10 \quad m_{2}=9 \quad, \quad, \quad=10 \mathrm{~T}_{1} \\
& " \mathrm{~T}_{1}=0.8 \mathrm{~T}_{2}, \eta n_{1}=5 \quad m_{2}=4 \quad, \quad "=5 \mathrm{~T}_{1} \\
& " \mathrm{~T}_{1}=0.5 \mathrm{~T}_{2}, m_{1}=2 \quad m_{2}=1 \quad, \quad,=2 \mathrm{~T}_{1}
\end{aligned}
$$

and so on.

It seems, then, desirable to have the natural frequencies not only unequal but also in a ratio which is only expressible by large whole numbers, $13 / 11,9 / 10,11 / 9$, eto. At the same time the ratio must not be too near unity or the change in loading of the car may affect the ratio adversely. Thus, in a light car it would be desirable to determine the frequency ratio with one man at the wheel and then with more passengers. In general, however, since loading will make $\mathrm{T}_{2}$ increase more rapidly than $\mathrm{T}_{1}$, it would be safe to arrange the ratio $\mathrm{T}_{2} / \mathrm{T}_{1}$ slightly greater than unity with one man at the wheel.

Suspension as a problem is bound up with other matters, and it is desirable that a brief note in regard to steering should be given.

The car, simply considered, is a pendulum with, so to speak, two knife-edges similar to that used by Capt. Kater in determinations of gravity. It is well known that if the knife-edges are properly placed, the periods can be adjusted. What is of more importanoe here, by suspending a ballistic pendulum correctly or by striking it at a certain point, all horizontal reaction at the point of suspension can be eliminated. Thus, if the car body be placed in a certain position relative to the axles, forces acting at one axle produce no reaction at the other. This general property of the pendulum, and indeed of all rigid bodies, holds also of the car body, but attention must be paid to the meaning of $k^{2}$.

In the suspension problem as usually understood, i.e., concerned with motions in a vertical plane, $k$ is the radius of gyration about a horizontal axis parallel to the axles. In the steering problem, $k$ is the radius of gyration about a vertical axis passing through the centre of gravity of the complete car, including wheels, etc.

$31(2)$ 
Here we see an explanation of what might seem to be a discrepancy between theory and practice. In some cars, notably the four-seater and two-seater open touring car of the light class, $k_{0}$, the radius of gyration for the body system about a certain horizontal transverise axis, is very much less than $7 k_{k}$, the radius of gyration of the entire car about a vertical axis through its centre of gravity, and herein lies one of the most formidable difficulties in light-car suspension. The springs of a car combined with the tyres make the $k^{2}=a b$ law unimportant exoept at high speeds or on bad roads. The car is not sensitive to its dynamics in this direotion. In steering, however, there is only the slight yield of tyres and shackles to ameliorate the kinetio reactions. Moreover, whereas in the vertical plane we have the road and Mother Earth to resist the impacts in the vertical plane, we have only lateral friotion to resist the transverse forces. On greasy roads this lateral friction is very small, and thus it is that designers have preferred safety to comfort.

They cannot, however, have both in all cases. The motor-bus designer should be happy bocause he has a high box-like body with a larger $k_{0}$ than in the ordinary vehicle-see Appendix B. Next in good fortune is the maker of the luxury car with a heavy saloon body, the height of which helps to make his suspension fit his steering. There is, however, one high-grade car which suffers lamentably on greasy roads, and this can only be accounted for by the subservience of the designer to the salesman with his wheelbase as a selling point. The light-car designer has the most difficult problem of all, and his solution will probably lie along lines of compromise. In any case, he cannot expect the same results as in the other grades. The motor cycle and combination are not handicapped in the same way, because, although the suspension is usually bad and harsh on account of unsprung weight, the masses are all well disposed and there are helpful effects in the gyroscopio action of the wheels and the pendulum motion of the inclined steering head, but the combination is not a straightforward problem.

Rolling, after what has gone before, requires only brief treatment, because, if we look at a car from the back or from the front, we have, as before, a body suspended on two springs. Sinoe the arrangement is usually symmetrical, we have the conditions similar to those in railway carriages, qua pitching, i.e., $s_{1} a=s_{2} b$; $s_{1}=s_{2}$. There are, however, important differences. In the motor car there are two kinds of rolling. There is the well known list as a car goos round a corner, and there is the lateral oscillation due to road inequalities, most important of which in this conneation are pot-holes, which often affect the off wheels, say, and not the near wheels, or vice versâ. Rolling on corners is a problem in itself, principally on acoount of the conventional front-wheel steering. Rolling of the second kind is not difficult so far as practical needs go. Probably the more important phase of this 
problem was dealt with by Dr. Lanchester in his paper already aited* under the head of side location. The other aspent of the problem has already been treated in this report; the equations (19), (20), (21), eto. all apply if $s_{1}$ is made equal to $s_{2}$ and $a=b=\mathrm{W} / 2$ where $\mathrm{W}$ is the width between the springs, and, naturally, the mean stiffness of the front and rear springs is used in plaon of $s_{1}$ and $s_{2}$.

A further point arises in connection with rolling due to road irregularities, but it is doubtful if it is of great importanoe. In most car bodies the centre of gravity is above the instantaneous centre of rotation, so that the body is like an inverted pendulum. The equation of motion is of the form

$$
\ddot{\phi}+\left(s_{3} w^{2}-\mathbf{M} g h\right) \phi=0
$$

from which we see that the height of the centre of gravity above the instantaneous centre must be balanced by spring stiffness.

There is, however, the very fortunate property of laminated springs that they have friotion. If a laminated spring is loaded

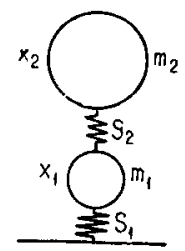

FIg. 9.

gradually and then unloaded gradually and a load-deflection diagram is taken, it will be found that the diagram is in the form of a loop-a so-called hysteresis loop. To defloct a Iaminated spring by one inch, say, requires a certain load, but before the spring will rebound a definite amount of load must be removed; this is due to friction. Thus, in rolling over towards the right, when the right-hand spring is compressed it exerts a force due to elasticity plus friction, while the left-hand spring exerts a force of elasticity minus friction. It is an old law that friction always opposes motion, and this is helpful in the kind of rolling motion here discussed.

\section{Part VI.-Systems in One Line.}

This aspect of the subject may be approached through the simplest case of two masses $m_{1}$ and $m_{2}$ connected by springs of stiffness $s_{1}$ and $s_{2}$ as in Fig. 9.

* See Proc. I.A.E., Vol. II., p. 193. 
If the system is disturbed it will vibrate, and the vibration set up will depend on the nature of the disturbanoe. The system has two natural frequencies, and it will vibrate in either of these or in a combination of both. If the disturbanee is periodic and repieated, there will be a forced vibration of period equal to the disturbance. For an isolated disturbance, the mode of vibration will partake of the character of the disturbance. As an example, we have the sound of detonation in, a cylinder-a system of infinite freedom which is disturbed by a very sudden blow, thus causing a note of high pitch.

In the problem let $x_{1}$ and $x_{2}$ be the displacements from equilibrium, thus the equations of motion are:-

$$
\left.\begin{array}{l}
m_{1} \ddot{x}_{1}+s_{1} x_{1}-s_{2}\left(x_{2}-x_{1}\right)=0 \\
m_{2} x_{2}+s_{1}\left(x_{2}-x_{2}\right)
\end{array}\right\}
$$

With a speed factor in we have:-

$$
\left.\begin{array}{l}
\mathrm{A}_{1}\left(s_{1}+s_{2}-m_{1} n^{2}\right)-\mathrm{A}_{2} k_{2}=0 \\
\mathrm{~A}_{1}\left(-s_{2}\right)+\mathrm{A}_{2}\left(s_{2}-m_{2} n^{2}\right)=0
\end{array}\right\}
$$

leading by elimination to the quadratio

$$
\left(s_{1}+s_{2}-m_{1} n^{2}\right)\left(s_{2}-m_{2} n^{2}\right)-\mathrm{s}_{2}^{2}=0
$$

The sum of the roots is

$$
\left(s_{1}+s_{2}\right) / m_{1}+s_{2} / m_{2}
$$

and the product of the roots is

$$
s_{1} s_{\mathrm{g}} / m_{1} m_{2}
$$

The amplitude ratios are obtained by substituting $n^{2}$ from (37) in (36) thus

where

$$
\mathrm{A}_{1} / \mathrm{A}_{2}=\left(s_{2}-m_{2} n^{2}\right) / s_{2}=1-n^{2} / \zeta_{2}{ }^{2}
$$

$$
\zeta_{2}=s_{2} / m_{2}
$$

from which it is clear that the ratio is negative when $n^{2}$ is large. The product of the amplitude ratios is $-m_{2} / m_{1}$ as in the double pendulum. A general discussion of this is given in Appendix A.

In the rear portion of a motor cycle we may assume as practical round numbers $m_{1}=m_{2}=5$, slugs; $s_{1}=10,000 \mathrm{lb}$. per ft. and $s_{2}=1,000 \mathrm{lb}$. per ft.

The frequencies are given by equation (37), thus, writing:-

$$
\begin{aligned}
& \lambda=n^{2} \\
& \lambda^{2}-2400 \lambda+4 \times 10^{5}=0 \\
& \lambda=2220 \text { or } 180 \\
& n_{1}=47 \text { and } n_{2}=13.4 \text { radians per sec. } \\
& \mathrm{N}_{1}=450 \text { and } \mathrm{N}_{2}=128 \text { vibrations per min. }
\end{aligned}
$$

The amplitude ratios in the two modes are $-10 \cdot 1$ and $0 \cdot 1$.

Putting this into words, we may say that when the system is vibrating in the quicker mode, the rider, if he were a rigid body 
clamped to the saddle, would have an amplitude one-tenth as great as that of the rear axle and in the opposite direation, whereas in the slower mode he would have an amplitude ten times as great as that of the rear axle. Here we have one explanation of the advantage of fast riding on a motor cycle. Apart from the stability, gyroscopic and otherwise, due to reasonable speeds, there is a surprising diffenence in comfort on bad roads. The problem is, of course, more complex than this discussion. The rider is not rigid and he is not seated over the axle; moreover, the frame and forks interact. Other influences are present sometimes, as, for instance, when a motor-cycle wheel leaves the road there is a snatching by the engine, whereas at high speeds the tyre impacts are rapid and the action appears to be more continuous. The, multi-cylinder engine versus the single-cylinder engine is a parallel.

TABLE I. $s_{2}=1000 \quad \xi_{2}=200$.

\begin{tabular}{|c|c|c|c|c|c|c|}
\hline \multirow{2}{*}{$m_{1}$} & \multicolumn{2}{|c|}{$s_{1}=32000$} & \multicolumn{2}{|c|}{$s_{1}=16000$} & \multicolumn{2}{|c|}{$s_{1}=8000$} \\
\hline & $n^{2}$ & $\mathbf{A}_{1} / \mathbf{A}_{2}$ & $n^{2}$ & $A_{1} / A_{2}$ & $n^{2}$ & $\mathbf{A}_{1} / \mathbf{A}_{2}$ \\
\hline 1 & 33006 & $-164 \cdot 0$ & 17012 & $-84 \cdot 0$ & 9023 & $-44 \cdot 0$ \\
\hline 5 & $\begin{array}{c}193 \cdot 9 \\
6606\end{array}$ & $\begin{array}{r}0.03 \\
-\quad 32.0\end{array}$ & $\begin{array}{c}188 \cdot 1 \\
3412\end{array}$ & $\begin{array}{r}0.06 \\
-16.0\end{array}$ & $\begin{array}{c}177 \cdot 3 \\
1825\end{array}$ & $\begin{array}{l}0.11 \\
-8 \cdot 1\end{array}$ \\
\hline & $193 \cdot 7$ & 0.031 & $187 \cdot 5$ & 0.062 & $175 \cdot 0$ & 0.125 \\
\hline 10 & 3306 & -15.5 & 1713 & $-7 \cdot 5$ & 929 & $-3 \cdot 6$ \\
\hline & 193.5 & 0.032 & $186 \cdot 7$ & 0.067 & $171 \cdot 4$ & 0.143 \\
\hline
\end{tabular}

It is important to consider wear and tear. In Part IF.. which applies to steel-tyred wheels, it was shown that speed should be decineased when oscillations become excessive, but in the above example the converse is indicated, for the following main reason. The reaction of the road is proportional to the vertical accelenation of the contre of gravity of the entire system. When the doubly-sprung vehicle is vibrating quickly the axle and passenger are moving in opposite directions, and thus the resultant acooleratior on the system is usually less. Heating and consequent destruction of the tyres is, of course, a different matter.

In the previous calculations we selected figures which. while practical, do not represent all practice. Tables I. and II. have therefore been calculated to show the effects of variations. The weight of the rider is assumed constant at $160 \mathrm{lb}$., which is rather heavy since some weight is taken by the foot-rests and handle-bars. Tho saddle stiffness is assumed as 1,000 lb. per $\mathrm{ft}$.. which is exceptionally good. and $3,000 \mathrm{lb}$. per ft., which is probably as 
bad as exists. The so-called unsprung weight of the machine is assumed to be $160 \mathrm{lb}$., which is a fair average, or $32 \mathrm{lb}$, which is light, corresponding to a spring frame, or $320 \mathrm{lb}$., which is abnormal. $s_{1}$ varies from 32,000 to $8,000 \mathrm{lb}$. per ft. which covers all usual tyre sizes and inflations.

Thus

$$
\begin{aligned}
& m_{2}=5 \\
& s_{2}=1000 \text { and } 3000 \quad \zeta_{2}=200 \text { and } 600 \\
& m_{1}=1,5 \text { or } 10 \\
& s_{1}=32000,16000,8000
\end{aligned}
$$

These Tables show the nature of the motion in a doubly-sprung system. They are applicable in an approximate way to a motor car or lorry. They show, what can be observed on any road, that

\begin{tabular}{|c|c|c|c|c|c|c|}
\hline & \multicolumn{2}{|c|}{$s_{1}=32000$} & \multicolumn{2}{|c|}{$s_{1}=16000$} & \multicolumn{2}{|c|}{$s_{1}=8000$} \\
\hline$m_{1}$ & $n^{2}$ & $\mathbf{A}_{1} / \mathbf{A}_{2}$ & $n^{2}$ & $A_{1} / A_{2}$ & $n^{2}$ & $A_{1} / A_{2}$ \\
\hline 1 & $\begin{array}{r}35052 \\
548\end{array}$ & $\begin{array}{c}-57 \cdot 4 \\
0.087\end{array}$ & $\begin{array}{r}19098 \\
502\end{array}$ & $\begin{array}{c}-32 \cdot 3 \\
0 \cdot 155\end{array}$ & $\begin{array}{r}11173 \\
427\end{array}$ & $-17 \cdot 6$ \\
\hline 5 & 7056 & -10.95 & 3913 & -5.52 & 2426 & -3.05 \\
\hline & 544 & 0.093 & 487 & 0.181 & 374 & $0 \cdot 327$ \\
\hline 10 & 3562 & -4.93 & 2039 & $-2 \cdot 4$ & 1461 & $-1 \cdot 43$ \\
\hline & 538 & 0.102 & 461 & 0.208 & 239 & 0.352 \\
\hline
\end{tabular}
for high-frequency vibrations such as are caused by ripples, the wheels may move up and down one hundred times as much as a

$$
\text { TABLE II. } s_{2}=3000 \quad \zeta_{2}=600 .
$$

car. All motorists know that at high speeds on rough roards the wheels may dance up and down and even leave the road while the car body is stationary except for tremor. The Tables show, moreover, the importance of low unsprung weight for high-speed travelling. Here, it may be noted that there is much confusion in the automobile world regarding the unsprung weight. Motor vehicles are usually regarded as one mass supported by springs on one other mass, whereas in fact a motor vehicle is an assemblage of masses connected and supported by various springs. The tyres are, in many modes of travelling, the most important springs of all, and it is obvious from the foregoing that in a rigid-framie motor oycle large tyres are essential. The same holds true of light cars, where the axle weight bears a rather high proportion to the body. A big car needs big tyres on account of wear and load-carrying capacity. A light car needs big tyres to absorb shocks; this is the solution of the problem of the suspension of the light rehicle. and in the long run, having regard to life 
and freedom from punctures, etc., large tyres are more economical than under-sized tyres.

From the doubly-sprung single mass we proceed to triple and multiplo springing, seo Fig. 10.

The equations of motion are:-

$$
\left.\begin{array}{lr}
m_{1} \ddot{x}_{1}+s_{1} x_{1}-s_{2}\left(x_{2}-x_{1}\right) & =0 \\
m_{2} \ddot{x}_{2}+s_{22}\left(x_{2}-x_{1}\right)-s_{3}\left(x_{3}-x_{2}\right) & =0 \\
m_{3} x_{3} & +s_{3}\left(x_{3}-x_{2}\right)-s_{4}\left(x_{4}-x_{3}\right)=0 \\
m_{4} \ddot{x}_{4} & +s_{4}\left(x_{4}-x_{3}\right)=0
\end{array}\right\}
$$

By addition of all the equations we have

$$
\Sigma m_{r} \ddot{x}_{r}+s_{1} x_{1}=0 \ldots \ldots \ldots
$$

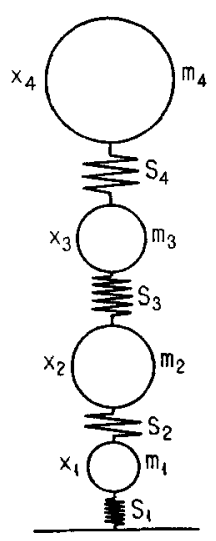

Fig. 10.

using a speed factor, we have

$$
\sum m_{r} \mathrm{~A}_{r}=s_{1} \mathrm{~A}_{1} / n^{2}
$$

or the sum of all the masses multiplied by their respective amplitudes is direotly as the amplitudes of the first mass - the axle, say $\rightarrow$ and inversely as the square of the frequency. Thus if $n$ be large, $\Sigma m_{r} \mathrm{~A}_{r}$ is small provided $s_{I}$ is reasonably small and $\mathrm{A}_{1}$ is not too great. Thus we see that some of the amplitudes will be small or negative, we also see the need for keeping $s_{1}$ small, i.e., for using soft tyres if the road reactions are to be kept small.

Using a speed factor in and assuming amplitudes $A_{1} A_{2} A_{3}$, etc. in the equations of motion, we have:-

$$
\begin{aligned}
& \mathrm{A}_{1}\left(s_{1}+s_{2}-m_{1} n^{2}\right) \\
& -\mathbf{A}_{2} s_{2} \\
& 0 \\
& -\mathbf{A}_{1} s_{3}+A_{2}\left(s_{2}+s_{3}-m_{2} n^{2}\right)-A_{3} s_{3} \\
& 0-\mathrm{A}_{2} s_{3}+\mathrm{A}_{3}\left(s_{3}+s_{4}-m_{3} n^{2}\right)-\mathrm{A}_{4} s_{4} \\
& 0 \quad 0 \\
& 0-\mathrm{A}_{3} s_{+} \\
& 0 \\
& +\mathrm{A}_{4}\left(s_{4}-m_{4} n^{2}\right) \\
& =0 \ldots \ldots \ldots \ldots(42)
\end{aligned}
$$


Eliminating the amplitudes, we have an equation for the frequencies in the form of a determinant thus:-

$$
\left.\begin{array}{cccc}
1+s_{2}-m_{1} n^{2} & -s_{2} & 0 & 0 \\
-s_{2} & s_{2}+s_{3}-m_{2} n^{2} & -s_{3} & 0 \\
0 & -s_{3} & s_{3}+s_{4}-m_{3} n^{2} & -s_{4} \\
0 & 0 & -s_{4} & s_{4}-m_{4} n^{2}
\end{array}\right\}=0 .(43)
$$

For some purposes this determinant is best transformed, by adding rows to their predecessors, into the form

$$
\begin{array}{cccc}
s_{1}-m_{1} n^{2} & -m_{2} n^{2} & -m_{3} n^{2} & -m_{4} n^{2} \\
-s_{2} & s_{2}-m_{9} n^{2} & -m_{3} n^{2} & -m_{4} n^{2} \\
0 & -s_{3} & s_{3}-m_{3} n^{2} & -m_{4} n^{2} \\
0 & 0 & -s_{4} & s_{4}-m_{4} n^{2}
\end{array} \mid=0 \ldots \text {. }
$$

This determinant is easily resolved into the other determinants. The main useful facts from (43) and (43a) are that the sum of the roots is

$$
\zeta_{1}+\xi_{2}+\zeta_{3}+\xi_{4} \text {, etc. }
$$

where $\zeta_{r}=\left(s_{r}+s_{r+1}\right) / m_{r}$ and the product of the roots is

$$
\left.\left(s_{1} s_{2} s_{3} s_{4} \ldots s_{r}\right) / m_{1} m_{2} m_{3} m_{4} \ldots m_{r}\right)
$$

The determinant (43) may be expanded into:-

$$
\left.\begin{array}{l}
\left(s_{1}+s_{2}-m_{1} n^{2}\right)\left(s_{2}+s_{3}-m_{3} n^{2}\right)\left(s_{3}+s_{4}-m_{3} n^{3}\right)\left(s_{4}-m_{4} n^{2}\right) \\
\quad+s_{2}^{2}\left\{s_{4}{ }^{2}-\left(s_{3}+s_{4}-m_{3} n^{2}\right)\left(s_{4}-m_{4} n^{2}\right) !\right. \\
\quad-\left(s_{1}+s_{2}-m_{1} n^{2}\right)\left\{s_{4}{ }^{2}\left(s_{2}+s_{3}-m_{9} n^{2}\right)+s_{3}{ }^{2}\left(s_{4}-m_{4} n^{2}\right\}=0\right.
\end{array}\right\}
$$

For motor-car purposes three masses are ample, and by removing the symbols with suffix 4 we have

$$
\left.\begin{array}{l}
\left(s_{1}+s_{2}-m_{1} n^{2}\right)\left(s_{2}+s_{3}-m_{2} n^{2}\right)\left(s_{3}-m_{3} n^{2}\right) \\
\quad-s_{2}^{2}\left(s_{3}-m_{3} n^{2}\right)-s_{3}^{2}\left(s_{1}+s_{2}-m_{1} n^{2}=0\right.
\end{array}\right\}
$$

or:-

$$
\begin{array}{r}
\left(\zeta_{1}-n^{2}\right)\left(\zeta_{2}-n^{2}\right)\left(\zeta_{3}-n^{2}\right)-\left(s_{2}{ }^{2} / m_{1} m_{3}\right)\left(\xi_{3}-n^{2}\right) \\
-\cdot\left(s_{3}{ }^{2} / m_{2} m_{3}\right)\left(\zeta_{1}-n^{2}\right)=0 \ldots \ldots \ldots \ldots
\end{array}
$$

Equation (44b) is, of course, a cubic in $n^{2}$, and for calculation purposes various artifices may be employed. Probably the best is to "split the roots." For example, equation (44b) may be written

$$
\left(\zeta_{1}-n^{2}\right)\left\{\left(\zeta_{2}-n^{2}\right)\left(\zeta_{3}-n^{2}\right)-s_{3}{ }^{2} / m_{2} m_{3}\right\}-\left(s_{2}{ }^{2} / m_{1} m_{2}\right)\left(\zeta_{3}-n^{2}\right)=0
$$

The roots of thie quadratic within $\{\ldots \ldots\}$ divide the roots of the eubic, and since two such quadratios can be formed, the range for guessing is narrowed down. After that, Newton's method, and, if need be, Horner's, can be used.

In order to show the nature of the results in a non-mathematical form, Table III. has been constructed from equation (44b) for various values of the masses and stiffnesses of a practical order. The char-a-bane, the big ear, the light car and the motor cycle 
Table III.

\begin{tabular}{|c|c|c|c|c|c|c|c|c|c|c|c|c|}
\hline Vehicle & & $\mathrm{S}_{r / 1000}$ & $m r$. & $\zeta r$ & $\delta^{\prime \prime}$ & $\mathrm{L}^{\mathrm{N}} / \mathrm{min}$ & $\mathbf{N}^{\prime}=9 \cdot \bar{\partial} 5 \sqrt{ } \lambda$ & $\lambda$ & $\mathbf{A}_{3} / \mathbf{A}_{1}$ & $\mathbf{A}_{2} / \mathbf{A}_{1}$ & $\mathbf{N}^{1} / \mathrm{L} \mathbf{N}$ & Remarks. \\
\hline $\begin{array}{l}\text { Char- } \\
\text { a- } \\
\text { banc. }\end{array}$ & $\begin{array}{l}1 \\
2 \\
3\end{array}$ & $\begin{array}{r}120 \\
24 \\
20\end{array}$ & $\begin{array}{r}60 \\
120 \\
100\end{array}$ & $\begin{array}{l}2400 \\
366 \cdot 7 \\
200\end{array}$ & $\begin{array}{l}0 \cdot 902 \\
3.542 \\
1 \cdot 932\end{array}$ & $\begin{array}{r}197 \cdot 6 \\
99 \cdot 7 \\
135 \cdot 0\end{array}$ & $\begin{array}{r}471 \cdot 5 \\
81 \cdot 1 \\
203 \cdot 9\end{array}$ & $\begin{array}{r}2438 \cdot 8 \\
71 \cdot 9 \\
455 \cdot 9\end{array}$ & $\begin{array}{l}0.0887 \\
9.091 \\
-3.799\end{array}$ & $\begin{array}{r}0.097 \\
5.820 \\
4.860\end{array}$ & $\begin{array}{l}2 \cdot 38 \\
0 \cdot 81 \\
1 \cdot 51\end{array}$ & \\
\hline $\begin{array}{l}\text { Big } \\
\text { Car. }\end{array}$ & $\begin{array}{l}1 \\
2 \\
3\end{array}$ & $\begin{array}{r}40 \\
6 \\
1\end{array}$ & $\begin{array}{l}20 \\
60 \\
10\end{array}$ & $\begin{array}{l}2300 \\
116 \cdot 7 \\
100\end{array}$ & $\begin{array}{l}0 \cdot 869 \\
4 \cdot 508 \\
3 \cdot 864\end{array}$ & $\begin{array}{r}201 \cdot 3 \\
88 \cdot 4 \\
95 \cdot 4\end{array}$ & $\begin{array}{r}459 \cdot 3 \\
74 \cdot 5 \\
113 \cdot 9\end{array}$ & $\begin{array}{r}2313 \cdot 5 \\
60 \cdot 8 \\
142 \cdot 3\end{array}$ & $\begin{array}{c}0.00204 \\
19 \cdot 048 \\
-16 \cdot 986\end{array}$ & $\begin{array}{l}-0.0451 \\
7 \cdot 4639 \\
7 \cdot 192\end{array}$ & $\begin{array}{l}2 \cdot 29 \\
0 \cdot 84 \\
1 \cdot 19\end{array}$ & \\
\hline $\begin{array}{l}\text { Light } \\
\text { Car } \\
\text { I. }\end{array}$ & $\begin{array}{l}1 \\
2 \\
3\end{array}$ & $\begin{array}{r}36 \\
4 \\
1\end{array}$ & $\begin{array}{l}10 \\
30 \\
10\end{array}$ & $\begin{array}{l}4000 \\
166 \cdot 7 \\
100\end{array}$ & $\begin{array}{l}0.536 \\
3.864 \\
3.864\end{array}$ & $\begin{array}{r}256 \cdot 3 \\
95 \cdot 4 \\
95 \cdot 4\end{array}$ & $\begin{array}{r}605 \cdot 1 \\
76 \cdot 1 \\
131 \cdot 6\end{array}$ & $\begin{array}{r}4013 \cdot 7 \\
63 \cdot 5 \\
189 \cdot 8\end{array}$ & $\begin{array}{c}0.000875 \\
26.96 \\
-10 \cdot 607\end{array}$ & $\begin{aligned}- & 0.0342 \\
& 9.8412 \\
& 9.525\end{aligned}$ & $\begin{array}{l}2 \cdot 36 \\
0 \cdot 80 \\
1 \cdot 38\end{array}$ & Luxurions cushions. \\
\hline $\begin{array}{l}\text { Light } \\
\text { Car } \\
\text { Ila. }\end{array}$ & $\begin{array}{l}1 \\
2 \\
3\end{array}$ & $\begin{array}{r}36 \\
4 \\
2\end{array}$ & $\begin{array}{l}10 \\
30 \\
10\end{array}$ & $\begin{array}{r}4000 \\
200 \\
200\end{array}$ & $\begin{array}{l}0 \cdot 536 \\
3 \cdot 964 \\
1 \cdot 932\end{array}$ & $\begin{array}{r}256 \cdot 3 \\
95 \cdot 4 \\
135 \cdot 0\end{array}$ & $\begin{array}{r}605 \cdot 1 \\
84 \cdot 1 \\
167 \cdot 7\end{array}$ & $\begin{array}{r}40139 \\
77 \cdot 6 \\
308 \cdot 5\end{array}$ & $\begin{array}{c}0.01822 \\
16.009 \\
-17.007\end{array}$ & $\begin{array}{l}-0.0347 \\
9.806 \\
9.229\end{array}$ & $\begin{array}{l}2 \cdot 36 \\
0 \cdot 88 \\
1 \cdot 24\end{array}$ & Medium cushions. \\
\hline $\begin{array}{l}\text { Tight } \\
\text { Car } \\
\text { IIa }_{1} \text {. }\end{array}$ & $\begin{array}{l}1 \\
2 \\
3\end{array}$ & $\begin{array}{r}66 \\
4 \\
2\end{array}$ & $\begin{array}{l}10 \\
30 \\
10\end{array}$ & $\begin{array}{r}7000 \\
200 \\
200\end{array}$ & $\begin{array}{l}0 \cdot 293 \\
3 \cdot 864 \\
1 \cdot 932\end{array}$ & $\begin{array}{r}347 \cdot 0 \\
95 \cdot 4 \\
135 \cdot 0\end{array}$ & $\begin{array}{r}799 \cdot 4 \\
86 \cdot 1 \\
168 \cdot 4\end{array}$ & $\begin{array}{r}7007 \cdot 8 \\
81 \cdot 2 \\
310 \cdot 9\end{array}$ & $\begin{array}{c}0 \cdot 000575 \\
29 \cdot 102 \\
-30 \cdot 120\end{array}$ & $\begin{array}{c}-0.0196 \\
17.297 \\
16.723\end{array}$ & $\begin{array}{l}2 \cdot 304 \\
0 \cdot 90 \\
1 \cdot 25\end{array}$ & As IIa. butharder tyres. \\
\hline $\begin{array}{l}\text { Light } \\
\text { Car } \\
\mathrm{IIa}_{2} .\end{array}$ & $\begin{array}{l}1 \\
2 \\
3\end{array}$ & $\begin{array}{r}16 \\
4 \\
2\end{array}$ & $\begin{array}{l}16 \\
30 \\
10\end{array}$ & $\begin{array}{r}2000 \\
200 \\
200\end{array}$ & $\begin{array}{l}1 \cdot 207 \\
3 \cdot 864 \\
1 \cdot 932\end{array}$ & $\begin{array}{r}170 \cdot 9 \\
95 \cdot 4 \\
135 \cdot 0\end{array}$ & $\begin{array}{r}430 \cdot 2 \\
79 \cdot 8 \\
165 \cdot 6\end{array}$ & $\begin{array}{r}2029 \cdot 4 \\
69 \cdot 9 \\
300 \cdot 7\end{array}$ & $\begin{array}{l}0.00802 \\
7 \cdot 494 \\
-8 \cdot 433\end{array}$ & $\begin{aligned} &- 0.0734 \\
& 4.825 \\
& 4.248\end{aligned}$ & $\begin{array}{l}2 \cdot 52 \\
0 \cdot 84 \\
1 \cdot 23\end{array}$ & As IIa, but softer tyres. \\
\hline $\begin{array}{l}\text { Light } \\
\text { Car } \\
\text { IIb. }\end{array}$ & $\begin{array}{l}1 \\
2 \\
3\end{array}$ & $\begin{array}{r}36 \\
4 \\
2\end{array}$ & $\begin{array}{r}10 \\
30 \\
5\end{array}$ & $\begin{array}{r}4000 \\
200 \\
400\end{array}$ & $\begin{array}{ll}0 \cdot 483 \\
3 & 38 \\
0 & 966\end{array}$ & $\begin{array}{l}270 \cdot 1 \\
102 \cdot 1 \\
191 \cdot 0\end{array}$ & $\begin{array}{r}605 \cdot 1 \\
91 \cdot 9 \\
218 \cdot 8\end{array}$ & $\begin{array}{r}4014 \cdot 0 \\
92 \cdot 6 \\
493 \cdot 4\end{array}$ & $\begin{array}{c}0 \cdot 00388 \\
1271 \\
-37 \cdot 544\end{array}$ & $\begin{array}{l}0.0352 \\
9.7685 \\
8.766\end{array}$ & $\begin{array}{l}2 \cdot 24 \\
0 \cdot 90 \\
1 \cdot 15\end{array}$ & $\begin{array}{l}\text { Medium cushions. } \\
\text { Light passengers. }\end{array}$ \\
\hline $\begin{array}{l}\text { Light } \\
\text { Car } \\
\text { II'. }\end{array}$ & $\begin{array}{l}1 \\
2 \\
3\end{array}$ & $\begin{array}{r}36 \\
4 \\
2\end{array}$ & $\begin{array}{l}10 \\
30 \\
15\end{array}$ & $\begin{array}{l}4000 \\
200 \\
133 \cdot 3\end{array}$ & $\begin{array}{l}0 \cdot 593 \\
4 \cdot 352 \\
2 \cdot 898\end{array}$ & $\begin{array}{r}243 \cdot 8 \\
88 \cdot 9 \\
110 \cdot 3\end{array}$ & $\begin{array}{r}605 \cdot 1 \\
75 \cdot 1 \\
153 \cdot 1\end{array}$ & $\begin{array}{r}4013 \cdot 9 \\
61 \cdot 9 \\
257 \cdot 5\end{array}$ & $\begin{array}{c}000120 \\
18 \cdot 376 \\
-\quad 8 \cdot 980\end{array}$ & $\begin{array}{r}-0.0349 \\
9.845 \\
9.356\end{array}$ & $\begin{array}{l}2 \cdot 48 \\
0 \cdot 84 \\
1 \cdot 39\end{array}$ & $\begin{array}{l}\text { Medium cushions. } \\
\text { Heavy passengers. }\end{array}$ \\
\hline $\begin{array}{l}\text { Light } \\
\text { Car } \\
\text { III. }\end{array}$ & $\begin{array}{l}1 \\
2 \\
3\end{array}$ & $\begin{array}{r}36^{\circ} \\
4 \\
4\end{array}$ & $\begin{array}{l}10 \\
30 \\
10\end{array}$ & $\begin{array}{l}4000 \\
266 \cdot 7 \\
400\end{array}$ & $\begin{array}{l}0536 \\
3.864 \\
0.966\end{array}$ & $\begin{array}{r}256 \cdot 3 \\
95 \cdot 4 \\
190 \cdot 9\end{array}$ & $\begin{array}{r}605 \cdot 1 \\
87 \cdot 6 \\
227 \cdot 6\end{array}$ & $\begin{array}{r}4014 \cdot 3 \\
84 \cdot 2 \\
568 \cdot 2\end{array}$ & $\begin{array}{c}0.00396 \\
12 \cdot 399 \\
-20 \cdot 396\end{array}$ & $\begin{aligned}-0.0357 \\
9.7896 \\
8.579\end{aligned}$ & $\begin{array}{l}2 \cdot 36 \\
0 \cdot 92 \\
1 \cdot 19\end{array}$ & Hard cushions. \\
\hline $\begin{array}{l}\text { Motor } \\
\text { Cycle. }\end{array}$ & $\begin{array}{l}1 \\
2\end{array}$ & $\begin{array}{l}90 \\
0.8\end{array}$ & $\begin{array}{l}3 \\
4\end{array}$ & $\begin{array}{c}3466 \cdot 7 \\
200\end{array}$ & $\begin{array}{l}0 \cdot 281 \\
1 \cdot 932\end{array}$ & $\begin{array}{l}354 \cdot 0 \\
335 \cdot 0\end{array}$ & $\begin{array}{l}563 \cdot 7 \\
129 \cdot 2\end{array}$ & $\begin{array}{r}3483 \cdot 0 \\
183 \cdot 7\end{array}$ & $\ddot{*}$ & $\begin{array}{r}-0 \cdot 0613 \\
12 \cdot 3112\end{array}$ & $\begin{array}{l}1 \cdot 59 \\
0 \cdot 96\end{array}$ & \\
\hline
\end{tabular}


are included, but most time has been spent on the light car, because it is important. The influence of tyres and cushions in the suspension problem is shown quantitatively.

A few words in explanation of the Table are necessary. The first column denotes the class of vehicle and the numerals in each cas nefer to masses in that vehicle. The second column gives the corresponding stiffnesses and the third column the masses. The fourth column gives an important dynamical quantity $\zeta$ which is the quotient derived from the stiffness of two springs and the mass between them. The fifth column gives the static deflection in inches of each spring due to the superincumbent loads on it. The sixth column markied $L^{N}$ represents the frequency per minute determined by the customary rules of automobile engineers who follow Dr. Lanchester. The seventh column marked $\mathrm{N}^{1}$ gives the truo frequency, which is derived from the eighth column by a simple relation. Thus $\lambda$ is in (radians per second) ${ }^{2}$, so that $\mathrm{N}^{1}$ in vibrations per minute is $9.55 \sqrt{ } \lambda$. Tisis 'T'able is commended to the attention of the practical man, who will see, in the figures for the light car, the effects of cushions, tyres and varying passenger loads.

The general dynamics of the suspension problem are lengthy and complioated, and an introductory sketch is given in Appendix 0. Here, however, a few words may be added which might have been appropriate at the end of that Appendix.

Firstly, it must be made clear that in this investigation friction has been ignored because it involves difficulties, and at the same time inust bo expressed the conviotion that friction is one of the most important factors in the problem. Consider a laminated spring of ten leaves. If there is no friction it can be shown that the stiffness is, say, $s$, but if the blades are definitely rusted together, it oan be shown that the stiffness is 100 times as great. There is no other factor in suspensions so important as friotion, and no other so difficult. It is the same in cushions and tyres, as will be shown later.

\section{Part Vit.-Vehicle Springs.}

The functions of springs on a car are essentially dynamical, and it is necessary to see olearly what these functions are:-

1. The spring must be strong enough.

2. It must be flexible enough.

3. It must have sufficient friction.

4. It must not have too much friction.

5. The friction must be of the right kind.

Thesc conditions are inter-related; they are necessary and indispensable for the following reasons:-

1. If the spring is not strong enough it will not perform its function of carrying or supporting its load.

2. If it is not flexible enough it will not efficiently perform its 
funation of absorbing shocks. By flexibility we mean adequate deflection without undue stress in the material.

3. If a spring had no friction the car would, apart from air friation, which is considerable, go on bouncing for ever, and, given only one obstacle on a journey, the remainder of the journey would be with oseillation.

4. If the friction is excessive, the virtual stiffness of the spring is momentarily increased and the riding is harsh and uncomfortable. The reason for this will be seen more olearly later.

5. If the friction is not of the right kind the absorption of energy may be harsh and impulsive, and the character of the motion may be changed.

It should be added here that there is no one definite relation that will fit all conditions. If a vehicle is to travel over rough ground, friction in the springs is an advantage for two reasons-strength and the capacity for being dead-beat. If a vehicle is to go over good roads friction is not required to anything like the same degree. This is one reason why motor-ar springs have far more initial nip than railway-carriage springs.

There are three principal ways of treating the laminated-spring. problem. There is the method of Professor Perry, by some called the classical treatment, presumably because it is seldom carefully read, in which the main idea is change of curvature of the plates. The method lends itself to offhand treatment by a mathematician, but it is of little use in practioe because springs are not ordemed. by curvature and they are not subject to pure couples. The effects of nip are not easily treated by this method, and this may have been the reason for Professor Perry's prejudice against nip.

The second method, and in many circumstances a good one in spite of the strictures of Landau and Parr, is in the main due to Reuleaux. In essence this method assumes the laminated spiring to be a kind of beam, and it professes to connect the behavioum of the spring with that of a simple beam by means of coefficients. The outstanding quality of the method is its humility and simplicity, and in the hands of a sceptic it should be safe and efficient. The risk lies in the blind use of the ooefficients under conditions to which they do not apply.

The method of Reuleaux is briefly this. Assume a cantilever beam of length $L$ and breadth $b$ and thickness $t$ with a load $W$ at the end. Then it is well known that the deflection of this cantilever is

$$
\delta=\mathrm{WL}^{3} / 3 \mathrm{EI}=4 \mathrm{WL}^{3} / \mathrm{E} b t^{3}
$$

If several such cantilevers are superposed, it is argued-clearly assuming no friction between them that the deflection will be inversely as the number of aantilevers. The deflection, then. for $n$ plates of equal size (see Fig. 11) would be

$$
\delta=4 \mathrm{WL}^{3} / \mathrm{Enbt}^{3}
$$


Reuleaux calculated that if the plates are shortened in equal steps (as in Fig. 12) the deflection will be 50 per cent greater, so that

$$
\grave{o}=6 \mathrm{WL}^{3} / \mathrm{En} b t^{3}
$$

Heldt (Gasoline Automobile, Vol. II. 1918), who follows Reuleaux, uses a factor to allow for the common practice of using more than one full length or master leaf, and he assumes that the dieHection in an actual spring is reduced by 15 per cent on account of friction His formula is thus

$$
\delta=(1.25 \text { to } 1.5)(0.85)+\mathrm{WL}^{3} / \mathrm{Enbt} t^{3}
$$

This is clearly crude, and it will be apparent later that it cannot be more than a rough approximation. The value of this method lies chiefly in comparisons of springs made in the same way and used under identical conditions. If springs of various sizes by one maker are to be compared, the formula gives a basis of comparison. It will be seen later that friction depends on the number of leaves, so that a fixed coefficient for friction is not advisable or permissible.

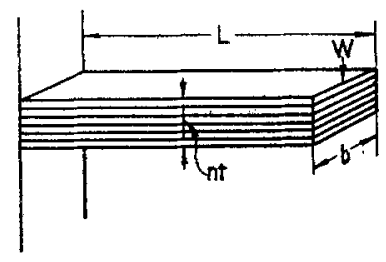

Fig. 11.

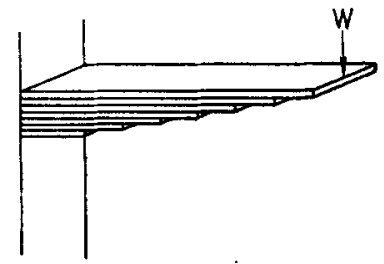

Fia. 12.

The strength of a spring is assumed on the Reuleaux-Heldt unethod to be directly proportional to the number of leaves, and no account is taken of friction which plays an important part in spring strength. If spring friction is excessive, a higher stress may be imposed on the top leaf, while the absence of friction may lead to increased stress in the lower leaves. The crude method inaugurated by Reuleaux is not to be recommended except in rough calculations.

Much the most comprehensive and rational treatment of laminated springs that has come to the author's knowledge is due to David Landau and Percy L. Parr in A New Theory of Plate Springs.* These papers occupy 97 printed octavo pages, and reference must thenefore be made to the originals for detail. In what follows a sketch of Landau and Parr's method is given, and a number of deductions are drawn which appear to have escaped their notice.

* See Journal, Franklin Institute, April and December, 1918, and January and February, 1919. 
The treatment considers for simplicity the cantilever or quarterelliptio spring, which is a unit in all plate springs. The following notation is almost identical with that in the paper quoted in order to make reference and comparison easy.

$\mathrm{L}_{1}=$ the length of the short leaf or first leaf.

$\mathrm{I}_{\mathrm{I}_{n}}=$ the length of the $n$th leaf.

$I_{n}=$ the moment of inertia of section of the $n$th leaf.

$\mathrm{R}_{n}=$ the reaction or load on the end of the $n$th leaf.

$x=$ the distance from fixed end to any section.

$M=$ bending moment at that section.

$y=$ deflection at that section.

$\delta_{n}=$ deflection at the end of the $n$th leaf.

$\mathrm{E}_{n}=$ modulus of elasticity of the $n$th leaf.

The basis of Landau and Parr's method is the well-known elastio equation

$$
\mathrm{EI} /\left(d^{2} y / d x^{2}\right)=\mathrm{M} \ldots \ldots \ldots \ldots \ldots \ldots(45)
$$

Referring to Fig. 13, which explains the above notation, it is

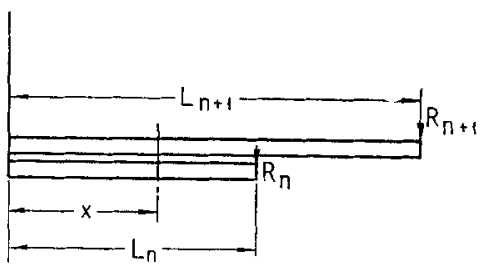

Fia. 13.

very clear that the bending moments for the different plates are expressed by the following equations:-For the $(n+1)$ th leaf when $x=\leqslant \mathrm{L}_{n}$

$$
\mathrm{M}=\mathrm{EI}_{n+1} d^{2} y / d x^{2}=\mathrm{R}_{n+1}\left(\mathrm{~L}_{n+1}-x\right)-\mathrm{R}_{n}\left(\mathrm{~L}_{n}-x\right) \quad \ldots(46)
$$

and when $x=\geq \mathrm{L}_{n}$

$$
\mathrm{M}=\mathrm{EI}_{n+1} d^{2} y / d x^{2}=\mathrm{R}_{n+1}\left(\mathrm{~L}_{n+1}-x\right) \ldots \ldots \ldots(46 \mathrm{a})
$$

Integrating these equations we get the slope $d y / d x$ and this must be the same at $x=\mathrm{L}_{n}$ where the two equations connect, thus:wher. $x \backslash \mathrm{I}_{n}$ from $(46)$

$$
\mathrm{EI}_{n+1} d y / d x=\mathrm{R}_{n+1}-\left(x \mathrm{~L}_{n+1}-x^{2} / 2\right)-\mathrm{R}_{n}\left(x \mathrm{~L}_{n}-x^{2} / 2\right) \ldots(47)
$$

and when $x \geq \mathrm{L}_{n}$ from (46a)

$$
\mathrm{EI}_{n+1} d y / d x=\mathrm{R}_{n+1}\left(x \mathrm{~L}_{n+1}-x^{2} / 2\right)-\mathrm{R}_{n}\left(\mathrm{~L}_{n}^{2} / 2\right) \ldots(47 \mathrm{a})
$$

If we integrate again we obtain the deflection at any point, and the constants of integration are governed by the fact that the deflection at $x=\mathrm{L}_{n}$ must be the same from both equations, thus:wher. $x \leqslant \mathrm{~L}_{n}$ from (47)

$$
\begin{array}{rl}
\mathrm{EI}_{n}+1 & y=\mathrm{R}_{n+1}\left(x^{2} \mathrm{~L}_{n+1} / 2-x^{3} / 6\right) \\
& -\mathrm{R}_{n}\left(x^{2} \mathrm{~L}_{n} / 2-x^{3} / 6\right) \ldots \ldots \ldots
\end{array}
$$


and here we observe that for $x=0, y=0$

when $x \geq \mathrm{L}_{n}$ from (47a)

$\mathrm{EI}_{n+1} y=\mathrm{R}_{n+1}\left(x^{2} \mathrm{~L}_{n+1} / 2-x^{3} / 6\right)-\mathrm{R}_{n}\left(x \mathrm{~L}_{n}^{2} / 2-\mathrm{I}_{n}^{3} / 6 \ldots(48 \mathrm{a})\right.$

Now putting $x=\mathrm{L}_{n}$ and $\mathrm{L}_{n+1}$ in (48a) we obtain the defleations $\delta_{n}$ and $\delta_{n+1}$ thus:-

$$
\begin{array}{r}
\mathrm{EI}_{n+1} \delta_{n}=\mathrm{R}_{n+1}\left(\mathrm{~L}_{n}^{2} \mathrm{~L}_{n+1} / 2-\mathrm{L}_{n}{ }^{3} / 6\right)-\mathrm{R}_{n} \mathrm{~L}_{n}^{3} / 3 \ldots(49 \\
\mathrm{EI}_{3+1} \delta_{n+1}=\mathrm{R}_{n+1} \mathrm{~L}_{n+1}^{3} / 3-\mathrm{R}_{n}\left(\mathrm{~L}_{n}^{2} \mathrm{~L}_{n+1} / 2-\mathrm{L}_{n}^{3} / 6\right) \ldots(49 a)
\end{array}
$$

If in (49a) we reduce the suffixes by unity we have an equation

$$
\mathrm{FI}_{n} \delta_{n}=\mathrm{R}_{n} \mathrm{~L}_{n}^{* 3 / 3}-\mathrm{R}_{n-1}\left(\mathrm{~L}^{2}{ }_{n-1} \mathrm{~L}_{n} / 2 \cdot-\mathrm{L}^{3_{n-1}} / \mathrm{h}\right) \ldots(50)
$$

Equating the values of $\delta_{n}$ given by equations (49) and (50) wo have:-

$$
\begin{aligned}
6 \mathrm{E}_{\delta n} & =\left\{\mathrm{R}_{n+1}\left(3 \mathrm{~L}_{n}^{2} \mathrm{~L}_{n+1}-\mathrm{L}^{3}{ }_{n}\right)-2 \mathrm{R}_{n} \mathrm{~L}_{n}{ }_{n}{ }^{1} / \mathrm{I}_{n+1}\right. \\
& =\left\{2 \mathrm{R}_{n} \mathrm{~L}^{3}{ }_{n}-\mathrm{R}_{n-1}\left(3 \mathrm{~L}_{n-1}^{2} \mathrm{~L}_{n}-\mathrm{L}_{n-1}{ }_{n-1}\right)\right\} / \mathrm{I}_{n} .
\end{aligned}
$$

Equation (51) is the basis of Landau and Parr's method. Making $n=1$ we may begin at the shortest leaf in the spring and work outwards thus for the first and second leaves:-

$$
\begin{aligned}
& \left\{\mathrm{R}_{2}\left(3 \mathrm{~L}_{1}{ }^{2} \mathrm{~L}_{2}-\mathrm{L}_{1}{ }^{3}\right)-2 \mathrm{R}_{1} \mathrm{~L}_{1}{ }^{3}\right\} / \mathrm{I}_{2}=2 \mathrm{R}_{1} \mathrm{~L}_{1}{ }^{3} / \mathrm{I}_{1} \\
& \text { or }\left\{\mathrm{R}_{2}\left(3 \mathrm{~L}_{2}-\mathrm{L}_{1}\right)-2 \mathrm{R}_{1} \mathrm{~L}_{1}\right\} / \mathrm{I}_{2}=2 \mathrm{R}_{1} \mathrm{~L}_{1} / \mathrm{I}_{1}
\end{aligned}
$$

If the plates are all of the same section $I_{1}=I_{2}$ and we have:-

$$
\mathrm{R}_{2} / \mathrm{R}_{1}=4 \mathrm{~L}_{1} /\left(3 \mathrm{~L}_{2}-\mathrm{L}_{1}\right)
$$

If $\mathrm{L}_{2}=2 \mathrm{~L}_{1}$, i.e., equal overlaps, we have

$$
R_{2} / R_{1}=4 / 5
$$

and if $R_{1}=R_{2}$, i.e., equal reactions, we have

$$
\mathrm{L}_{1}=3 \mathrm{~L}_{2} / 5
$$

All this is elementary beam theory, and it is extraordinary that no one should have applied it before, and all the more credit is due to Landau and Parr. We know that the gradient of bending moment is proportional to shearing force, and thus it is obvious at a glanoe that with equal spacing or equal overlaps the bending moment in the second leaf is greatest when $x=\mathrm{L}_{1}$ and it is then $=R_{2} L_{1}$. The maximum bending moment in the first leaf being: $R_{1} \mathrm{~L}_{1}$ is 25 per oent greater, i.e., $5 R_{2} \mathrm{~L}_{2} / 8$.

If $R_{1}=R_{2}$ we have the maximum bending monent in the second leaf $=2 R_{1} L_{1} / 3$ and in the first leaf it is $R_{1} L_{1}$ or 50 per cont greater, i.e., $3 \mathrm{R}_{2} \mathrm{~L}_{2} / 5$.

Thus with equal reactions the maximum bending moment is $0.6 \mathrm{R}_{2} \mathrm{~L}_{2}$ and with equal spacing it is $0.625 \mathrm{R}_{2} \mathrm{~L}_{2}$. It should bo added here, a point omitted entirely by Landau and Parr, that the existence of equal reactions presupposes pure couples at the clamping point--a condition difficult to visualise and not likely to oocur in practice.

In the papers cited the authors attack very vigorously the older theory, and rebut the idea that the strength of a spring is proportional to the number of leaves, and then they provide a number 
of excellent and laboriously calculated tables which almast prove themselves to be wrong.

Thus if $n$ be the total number of leaves and $p$ is the number of full-length leaves in the spring and $k$ is the number of steps, so that $n=k+p-1$, the strength $s$ of springs, according to Landau and Parr's tables, when the overlaps are equal, is:-

For one full-length leaf

$$
s=1+0 \cdot 614(n-1)
$$

For two full-length leaves

$$
s=2+0.617(n-2)
$$

For three full-length leaves

$$
s=3+0.620(n-3)
$$

For four full-length leaves

$$
s=4+0.624(n-4)
$$

For five full-length leaves

$$
s=5+0.625(n-5)
$$

For six full-length leaves

$$
s=6+0 \cdot 626(n-6) \text {. }
$$

These empirical equations neglect certain slight singularities which need not occur in practioe, so that for any equally-spaced leaves we may say with sufficient accuracy

$$
\begin{aligned}
& s=p+0.62(n-p) \text { or } \\
& s=0.38 p+0.62 n
\end{aligned}
$$

\begin{tabular}{|c|c|c|c|c|c|c|}
\hline$n$ & \multicolumn{3}{|c|}{ Reuleaux-Heldt. } & Landan \& Parr. & & Rowell. \\
\hline 1 & & 1 & & 1 & ..... & 1 \\
\hline 2 & & 2 & & $1 \cdot 6$ & ...... & $1 \cdot 62$ \\
\hline 4 & $\ldots \ldots$ & 4 & $\ldots \ldots$ & $2 \cdot 82$ & ...... & $2 \cdot 82$ \\
\hline 6 & $\ldots \ldots$ & 6 & ...... & $4 \cdot 04$ & ... & $4 \cdot 10$ \\
\hline 8 & $\ldots \ldots$ & 8 & $\ldots \ldots$ & $5 \cdot 27$ & ... & $5 \cdot 34$ \\
\hline 12 & $\ldots \ldots$ & 12 & $\ldots \ldots$ & $7 \cdot 734$ & ...... & $7 \cdot 82$ \\
\hline
\end{tabular}

So that spring strength does vary somewhat as $n$.

When $n=1, p=1$ we have the Reuleaux theory satisfied, otherwise there is disagreement. For example, assuning one masterleaf and $n=6$; by Landau and Parr's method the strength coefficient is 4.04 against the Reuleaux-Heldt figure of 6 , or in a small Table for $p=1$

Turning now to deflections, for which Landau and Parr gire a Table of coefficients, the results are very interesting. The Table of deflection coefficients seemed to give a set of hyperbolas, and thus by taking their reciprocals and calling them stiffnesses we get these relations for equal spacing. For one full-length leaf the stiffness $\sigma$ is

$$
\sigma=1.02+1.98 n
$$

For two full-length leaves

$$
\sigma=2 \cdot 0+2 \cdot 0 n
$$

For three full-length leaves

$$
\sigma=3.03+1.99 n
$$

ROWEL.T. 
For four full-length leaves

$\sigma=4 \cdot 0+202 n$

For five full-length leaves $\sigma=5 \cdot 0+2 \cdot 02 n$

For six full-length leaves $v=6.0+2.03 n$

and thus with sufficient accuracy for practice $\sigma=p+2 n$.

Applying this to an actual example, we have the deflection $\dot{\delta}=\mathrm{WL}^{3} /(\mathrm{p}+2 n) \mathrm{EI}$

put $n=6$ and $p=1$ and we have $\delta_{n}=\mathrm{WL}^{3} / 13 \mathrm{EI}=0.077 \mathrm{WI} / \mathrm{EI}$

whereas by the Reuleaux-Heldt formula we have $\delta_{2}=W^{3}\left(1.25\right.$ to $1.5 / / 18 \mathrm{EI}=0.0695$ to $0.0835 \mathrm{WL}^{3} / \mathrm{EL}$

We see, then, that the Reuleaux method, while misleading on strengths, is not far wrong as regards deflections. So far we have dealt mostly with springs of equal overlaps or equal spacing of leaves, but we saw from Landau and Parr's work that a spring designed to give equal reactions gives lower stresses in the plates. The overlaps needed to give equal reactions are worked out by Landau and Parr, and may be given thus. If the length of the shortest plate be taken as unity, then the lengths of all the plates are in the ratios:-

$$
1: 1.667: 2.2979: 2.9132: 3.5193: 4 \cdot 1194 \text {, etc. }
$$

and the overlaps, counting the shortest plate as the first overlap, are in the ratios:-

$1: 0.6667: 0.6312: 0.6153: 0.6061: 0.6001$, eto.

the 10 th plate has an overlap 0.5882

the 15th plate " , , 0.5822

and the 20th plate ", " $\quad 0.5792$

Thus the variation is small after six plates. The following series represents very nearly the overlaps for equal reactions:-

$$
1: \frac{6}{9}: \frac{7}{11}: \frac{8}{13}: \frac{9}{15}: \frac{10}{17}: \frac{10}{17}: \frac{10}{17} \text { etc. }
$$

When the spring is designed in this way, we find that it is stiffer than the spring with equal spacing, i.e., assuming each spring has the same overall size. By reducing Landau and Parr's Tables it is found that the stiffness coefficient can be represented very nearly by

$$
v=0.89 \eta+2.11 n
$$

so that the deflection of such a spring is

$$
\delta_{n}=\mathrm{WI} /(0 \cdot 89 p+2 \cdot 11 n) \mathbf{E I}
$$

The strength of the spring designed with equal reactions is little different from that with equal spacing. It is sometimes greater and sometimes less, and the difference is less than the probablo errors of manufacture. It is doubtful if the equal reaction spring is appreciably superior to that with equal spacing, though 
it must be added that Mr. Landau is a suecessful specialist with exceptional experience.

The second and third papers of Landau and Parr deal with special questions which are the province of the spring maker, and which no car designer should be asked to investigate or specify. Among these are tapering of ends. The methods used in the paper are somewhat open to question, because assumptions are made or implied which may not be realised in practice. On the other hand, the writers have compared their results with a large body of experimental and actual work. Their main conclusions are that plates which are tapered or reduced in width only are not appreciably different from square-ended plates. "Such tapering has no practical effect on the strengths. reactions, stresses or flexibilities of the springs." . . . "Taper in the thickness," on the other hand, "has an enormous effect." . . "A combination of the two tapers-in the width and in the thickness -is sometimes of much importance, but generally the effect of tapering the width is very much less than that of a taper in the

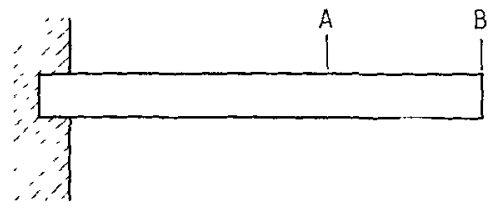

FIg. 14.

thickness." This, of course, is to be expected from the general properties of simple beams. Some recent experiments by the author promise a complete explanation.

Another important question dealt with by the authors mentioned is "nip." As a basis for a general method which they develop, a reciprocal theorem on deflections, due to Clerk Maxwell, is employed. This theorem states that in a beam, say, such as in Fig. 14, the deflection at $A$ due to a load at $B$ is the same as the deflection at $\mathrm{B}$ when the same load is moned to $\mathrm{A}$. By using this theorem a systematic method of calculating nip stresses is developed, but this in spite of all efforts is a laborious process and not amenable to any concise simple expression; it is a matter for the spring specialist and need not be considered here.

Arising from this method of calculating accurately the nip stresses, Messrs. Landau and Parr have arrived at very important results on spring life or fatigue. While it was held previouslynotably by Lemoine-that the elastic limit of the material was the deciding factor, Landau and Parr, applying the well-known work of Wöhler and Gerber, emphasise the importance of stress reversal which ocours on account of nip and flick. On this basis 
they have worked out the liability to break of the various plates in a typical spring of ten leaves. These relative weaknesses are shown graphically in Fig. 15, from which it will be seen that the upper and lower plates are the most vulnerable, and this is usual experience. The authors give a diagram, which is reproduced in Fig. 16, showing the relative liability to fracture of

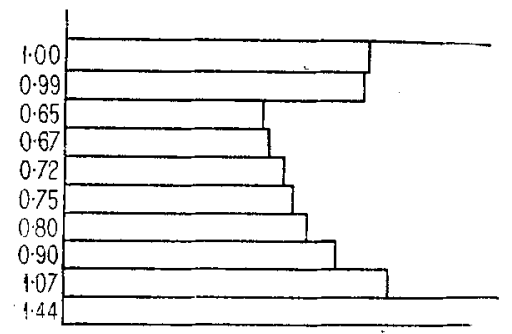

FIG. 15.

various plates in springs as deduced from more than 500 fractures, and this diagram agrees in form with the calculations of Fig. 15. The discrepancy between the two diagrams is not explained by. the authors. I am strongly of the opinion that it is due entirely. to friction between the plates which is not taken into ascount in their theory and which is extremely important in practice.

Spring friction is very much more important than most writers

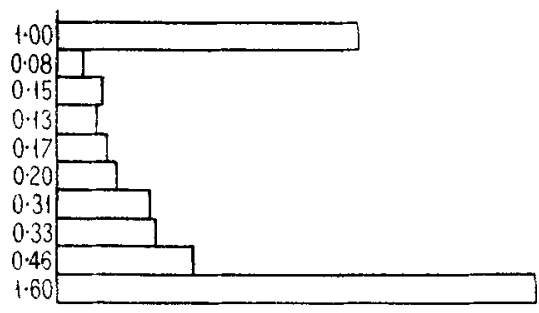

FIg. 16.

on springs seem to appreciate. It is most thoroughly esteemed by owner-drivers of light cars, who use various gaiter devices for protection against rust and for supply of lubrication. The nature, cause and effect of spring friction may be explained in the following way.

If a solid bar is set in vibration, as, for example, a tuning fork, and if the amplitude of the vibration is not so large as to cause 
the bar to be stressed beyond the elastic limit of the material, there is no discernible internal friction, etc., there is no damping. This has been very well known for years, and it became a scientifio fact as a result of Bairstow's :work an the elastic limit of steel and Dalby's indicator work on internal friction of strains. For a solid steel spring either a single plate, helix or torsional tube, the load-deflection curve is a straight line, and any mass attached to the spring vibrates with simple harmonic motion of constant amplitude.

If a solid steel spring be coupled to a dash-pot so that there is a fluid frietional resistance proportional to speed of deflection, the load-deflection diagram for slow motion or static tests is a straight line, and for quick maintained motions we have looped curves as in Fig. 17. In all cases they are elliptic curves. Any mass attached to the spring vibrates in smooth harmonic oscillations, of which the amplitudes decrease in geometrical progression; see Appendix D.

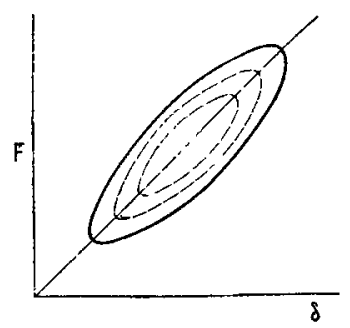

FIG. 17.

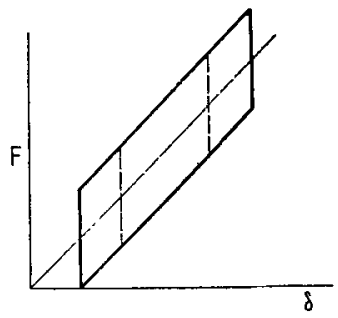

Frg. 18.

If now a spring of any sort be coupled to a solid friction. device, a dry guide on a dry slide-bar, say, the load-extension diagrams is altered in character and is of the form shown in Fig. 18. Any mass attached to such a spring vibrates in harmonic motions, of which the amplitudes decrease in arithmetical progression and of which the mid points change from one to the other side of the zero-sec Appendix E.

The conditions of Fig. 18 are realised in a light-car suspension with dry springs excessively nipped, and the conditions of Fig. 17 are realised in certain damped governors of the old Parsons type and $i_{i}$ an approximate way in the well-lubricated springs of high-grade cars when newly assembled.

There are one or two important variations on these main types. Consider, for instance, locomotive springs, which usually run dry and have very little nip. The friction between the plates is of the solid type and varies with the load. The diagram is of the 
form shown in Fig. 19, and this agrees with the experiments of Professor Dalby on Locomotive Springs.*

Then, again, consider motor-car springs, which, for obvious reasons of experience, are given much nip and are as a rule slightly better lubricated. The loop in this case is usually parallel with a more rounded corner in the returns as in Fig. 20. This difference in oharacter between motor-car springs and locomotive

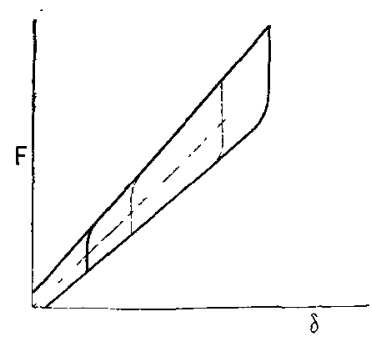

FIG. 19.

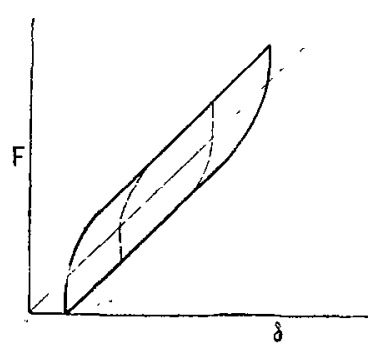

Fig. 20.

springs does not appear to have been noticed before. The explanation will be given in more detail later. Here, it should be emphasised that the loop diagram, sometimes called the hysteresis loop, for any one spring is a characteristic diagram which stands for any one spring as a human face for the man who wears it.

Another variation of interest is the so-called auxiliary spring.

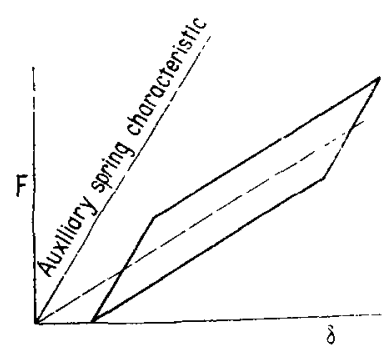

FiG. 21.

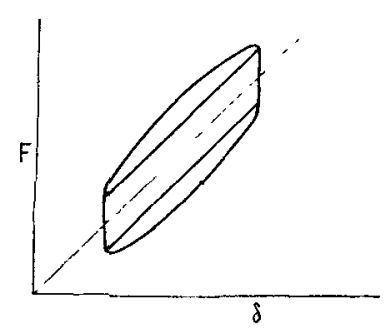

Fic. 22. .

This usually consists of one or more helical spring: in series with the main laminated springs, and it has the dynanical effeat of introducing flexibility or elastioity without friction. In the characteristic diagram it is easily represented because the load on the helical or auxiliary spring is practically the same as that on the main or laminated springs, and thus the deflections of the

* See Proc. Intt. C. E., Vol. CLXXXY., Part III. 
two springs are added together to give the total deflection of the system, see Fig. 21 and compare it with Fig. 18.

A further variation, and the last that we need consider before proceeding to generalisation, is the so-called shock-absorber, which as a rule merely adds fluid friction to the system. This is characterised by adding the diagrams in Figs. 17 and 18 , see Fig. 22, and it is obvious at a glance that shock-absorbers of this type aro useless on springs which already have much solid friction. Shock-absorbers of the fluid-friction type are useful as remedies on cars where the springs have insufficient nip or few leaves, in which case they may approach Fig. 17. They are useful in special circumstances, as in racing cars, but they are quite unnecessary as standard fittings to standard touring cars if care is used in designing the springs. Here it may be added that almost the same kind of opinion holds regarding auxiliary helical springs. These ase useful when nip is excessive or where leaves are many. or narrow where the main springs are unduly stiff. They are palliatives

In Mr. Baillie's interesting paper on "Springs,"* a number of" facts are recorded which are well worthy of thought. His attempt to analyse spring friction, though unsuccessful, is highly estimablo and original. On page 463 he states that the "decrement was measured as the ratio of one half oscillation to the next half oscillation." This point is explained in Appendix F. On page 464 of Mr. Baillie's paper, curves are given showing how the decrement varies with the amplitude, and Mr. Baillie says, "it is rather remarkable how rapidly the decrement increased as the oscillations got small." As a matter of fact, there is nothing remarkable in this phenomenon once solid friction is admitted. And this may. be realised by a little simple reasoning. Assume a spring to have a stiffness of $10 \mathrm{lb}$, per inch of deflection, and assume the friction loop is $20 \mathrm{lb}$. broad, i.e., within the region \pm 1 inch, there is no restoring force on the system. We may state the matter in this way; that a system with solid friction beoomes dead-beat as the friction zone is approached. The theory of the matter is given in Appendix E.

With these few preliminary notions we may turn to a more general analysis of the problem. As pointed out in the earlier parts, one of the main things to avoid in suspension springs is solid friction. The reason for this is that solid friction transforms a system from an elastic to an almost impulsive condition. Cor sider what happens in a spring of $n$ leaves. With no friction the stiffness varies as $n t^{3}$, where $t$ is the thickness. With solid friction the stiffness of the system at one part of the cycle varies as $n^{3} t^{3}$, so that in a 6 -leaved spring the stifiness is 36 times as great while the solid friction is being overcome. Thus, in a spring with much solid friction the chassis is for a certain interval

* See Proc. I.A.E., Vol. VII., p. 451. 
of time held to the axles by a very stiff connection, and if anly blow or impulse is received the system becomes impulsive and the theorem of mass ratios given in Appendix $J$ becomes not only of interest but really true and important. This is one explanation of the inferiority of light cars which has bothered so many people. It may be surmised in this connection that spring lubrication is more important for light cars than for heavy cars, and this is one reason why certain light cars achieve comparative success on helical springs.

Returning, again, to the general question of spring friction, which appears to have been but little studied, we may recall elementary facts. Firstly, friction always opposes motion. Secondly, there is a radical difference between solid friction and fluid friction. In solid friction there is a static resistance which must be overcome before motion can begin (this is why solid. friction is so bad in car springs, because light road shocks are not absorbed by the springs to any appreciable extent). In fluid friction, the slightest force suffices to cause motion. As the speed increases fluid friction increases rapidly, usually directly as the speed, whereas solid friction usually decreases as the speed increases, and this is probably due to the pumping in of an air film. Solid friction increases directly as the normal pressure, and fluid friction, since it varies as the thinness of the fluid film, also: follows somewhat the same law: The energy absorbed by friction depends on the normal pressure and on the relative motion; this is the important factor in car springs.

Suppose we have two springs of geometrically similar shape and of dimensions in the ratio $\lambda$. Each spring has the same number of plates, and all angles are the same. Let deflections be imposed in the ratio $\lambda$ and the springs still remain similar. The relative motion of the plates is also in the ratio $\lambda$. If, now, we make the deflections equal, it is clear that the relative motion of the plates is inversely as the lengths $\mathrm{L}$ of the springs. Further, if there are $n$ plates in a spring, the number of rubbing surfages is $n-1$, and thus, since the normal pressure between leaves varies as load $\mathrm{W}$ plus nip $\mathrm{N}$, the frictional work of the spring varies as $((\mathrm{W}+\mathrm{N})(n-1)) \mu / \mathrm{L}$ where $\mu$ is the coefficient of friction. According to Landau's paper on "The Commercial Testing of Leaf Springs," Gelorges Marié deduced an equation for friotional work in the form

$$
2 \mu(n-1) t / L
$$

where $t$ is the thickness of each plate. The equation of Marié agrees approximately with that deduced above.

For practical purposes it is sufficient to remember that frictional work increases with the number of plates and is inversely. as the length of the spring, and therefore to get smooth riding we need few leaves and long springs or exceptionally good lubrication.

The relative value of flat and cambered springs is seen by considering the ratio of deflection to the relative motion of the plates. 
Highly-cambered springs give much relative motion and therefore much friction for a given deflection. Thus, for smooth riding the spring:s should be approximately flat. At the same time it should be remembered that a laminated spring is not a symmetrical system, and initial deflection should be greater than the amplitude allowed in travelling. The effects of a slight camber on spring friction are probably negligible, and thus for xesthetic reasons springs should not be loaded until they are quite flat.

The coefficient of friction $\mu$, between the plates is probably not a simple constant for all cases. In the tirst plaoc, it is quite different according to whether the springs are dry or lubricated. If the spring leaves are dry or rusted, the force of friction is probably independent of the breadth of the plates, and directly proportional to nip plus load. It will also be independent of the amplitude of the motion. When the springs are lubricated we have, presumably, fluid friotion, and $\mu$ depends on the area and thickness of the film, on the viscosity of the lubricant and on the speed of the motion, which is mostly determined by amplitude. The wider the spring leaves are, the less is the specific juressurc on the lubricant and the further it has to flow under squeeze. Thus, wide springs give a thicker film of lubricant and so less frictional resistance pier unit area. It is true that a wider spring gives a larger shearing area and thus this effect may be neutralised. It all depends on the particular design of spring, and in general we may affirm that wide springs give a greater reserve and less likelihood of producing the conditions of solid friction.

An important phase of spring friction is lubrication and lubricant. Some makers use white lead or paint, some owners use stifl grease, and it is open to question whether they are right in doing so. No matter what lubricant is used, it will be squeezed out in most cases, because the pressure at the spring tips is exceedingly high and the motion has many repetitions during any, journey. How, then, can springs be lubricated? The obvious remedy according to the advertisements is gaiters, and there is little doubt that gaiters or something of the kind are essential. But gaiters cannot lubricate in themselves; they only hold the Iubricant around the spring, and here lies the orux of the matter. The lubricant must be such that it will flow in between the leaves. and to do this effectively it must have a high surface tension and low viscosity.

When a spring is in motion there are thin spaces between the leaves, so thin that the effects of capillarity are very great. If an oil of high surface tension and low viscosity is present when spring blades ease apart, it is sucked in just as liquids rise in a capillary tube. The inference is clear; greases are useless except as rust preventers, because they are squeezed out in time and they are not drawn back. If greases are used they should be renewed from time to time by prizing open the blades. Following 
out this line, the best oil seems to be purely mineral oil--a heary paraffin - everyone knows how paraffins creep. From this arises, perhaps, an interesting corollary. In bearings and other continuously-working surfaces, it has been shown by Wells and Southcombe that surface tension is a thing to be avoided and killed by the addition of free fatty acids-so-called germ oils. In discontinuous surfaces it appears desirable to use purely mineral oils. Water, apart from its rusting effects, is an excellent lubricani for springs as all the old stage goach and carriage builders knew, and it has a very high surface tension and low viscosity. If a satisfactory gaiter could be designed, it seems possible that a solublo oil with soap and water would be an excellent spring: lubricant.

In the earlier part of this paper the treatment of the strength and deflection of springs was confined to the true cantilever or so-called quarter-elliptic spring because it is fundamental to all plate springs. If this is once grasped, any of the various madifications such as elliptic, three-quarter-elliptic, semi-elliptic and full or floating cantilever, can be readily treated. It may be asker why, then, are there so many varieties of springs? The reason is often a mixture of ignoranco, of taste, and of expedience in regard to matters not directly concerned with suspensions. In any elastic system the energy that can be stored in it varies as the square of the stross and as the volume of the material. Thus, if $f$ be the stress induced, the energy stored per unit volume is $f^{2} / 7 \mathrm{E}$ where $\mathrm{E}$ is the modulus of elasticity and $k$ is a constant depending on the kind of stress distribution. Thus, for a bar in tension or compression or shear the stress is uniform and $k=2$. For a bar in torsion $k=4$, and for a simple bar bent under transverso load $k=18$. For a bar which is bent by a pure couple, so that the bending moment is the same at all cross-sections, $k=-6$. Here we see one justification for the laminated spring, and a reason why, as a store of energy, the spring with many leaves is superior to that with few.

The spring problem in essence, or at any rate one important side of it, is the absorption of energy. A second aspect of this arises in the dissipation of some of the energy absorbed. The dissipation oocurs in the form of heat generated by the friction between spring plates, the absorption oocurs in the straining of the metal and in friotion. It has been found in practice that springs which carried their load quite well when dry, broke very quickly when cleaned and greasod, and this is easily explained by two causes; friction between plates absorbs energy, leaving less work for the metal of the springs to do, and friction between plates transforms the action of a spring more or less from $n$ independent thin beams of thickness $t$ to one beam $n$ times as thick and $n^{2}$ times as stiff and $n$ times as strong. The gradations between the two extremes depend on the condition of the plato surfaces, and their number, lubrication and nip. 
'T'o regard a vehicle spring as a store of energy is useful in many ways, but it does not represent all the facts and it may be misleading; questions of impulse and momentum arise, as we have already indicated. Dr. Lanchester's treatment of suspensions is very practical and simple. $\mathrm{He}$ prescribes a certain range of frequency which ensures softness, and he lays down an energy absorption not exceeding $6 \mathrm{ft}$. $-1 \mathrm{~b}$. per lb. of steel in the springs. This is a good rough guide, but the simplicity of its statement and the eminence of its author have led many to follow it too slavishly. The energy that can be safely absorbed by a spring depends on the form of the spring and on the material of which it is made. For well-made modern springs of high-grade welltreated alloy steel, Dr. Lanchester's figure might very safely be doubled.

The study of springs has probably suffered from many attempts at simplicity of statement. The problem is extremely complex, and beyond broad principles it is improbable that any general results can be derived. As an example we may consider the diagrams given by $\mathrm{Mr}$. Remington in his paper on Springs, * from which the first two columns of Table IV. are derived:-

TABLE IV.

\begin{tabular}{c|c|c|c|c}
\hline $\begin{array}{c}\text { Loads 1b. } \\
=W .\end{array}$ & $\begin{array}{c}\text { Frequency per } \\
\text { minute }=\mathrm{P} .\end{array}$ & $\mathrm{P}^{2} \mathrm{~W} / 10^{4}$. & $\begin{array}{c}\mathrm{P}^{2}(\mathrm{~W}+30) \\
10^{\mathbf{3}}\end{array}$ & Remarks. \\
\hline & & $3 \cdot 92$ & $4 \cdot 50$ & Nine-b]aded spring, \\
200 & 140 & $5 \cdot 38$ & $5 \cdot 7$. & in. wide, 52 in. \\
400 & 116 & $5 \cdot 08$ & $5 \cdot 35$ & long. \\
600 & 92 & $4 \cdot 62$ & $4 \cdot 82$ & \\
800 & 76 & $4 \cdot 62$ & $4 \cdot 77$ & \\
1000 & 68 & $5 \cdot 92$ & $5 \cdot 04$ & \\
1200 & 64 & & & \\
\hline
\end{tabular}

The third column should be proportional to the stiffness of the spring if the latter had no weight, and the fourth column shows the stiffness on the assumption of a virtual spring mass of $30 \mathrm{lb}$ The results show that the effective stiffness of the spring in question varied as much as 25.4 per cent of the mean value. Whether this variation is due to friction, nip, change of form an inadvertent forcing by the experimenter is difficult to say, but the figures show how much variation may be expected on a car where springs are assembled under manufacturing conditions.

We have seen that almost every type of plate spring can be considered as built up of quarter-elliptic springs, and thus the elastio and frictional constants may be deduced for any type of spring. One further principal aspect of the subject of springs

* See Proc. I.A.E., Vol. XVI., Part II., p. 187. 
remains, therefore, to be considered, namely, their arrangement on a car. Almost every week a new arrangement of springs is patented; sometimes the springs are transverse, as on the Furd, sometimes torsion tubes are employed, and often various springs are geared together so as to interact; as well-known examples of interaction, we have a number of anti-rolling devices. The number of spring arrangements proposed is so great that detailed discussion of them all is impossible.

In the conventional suspension each of the four springs is independent of the others, so that an impulse on one wheel does not seriously affect the other three. In many of the patented systems one spring cannot be deflected without automatically, deflecting another. In general, the result of these inter-connections is constraint, and in many cases Lord Rayleigh's generalisation of Delaunay's and Kelvin's theorems is applicable, namely, that "adding constraint to a system increases the apparent inertia of the system." The value of new devioes and arrangements, however, cannot be stated in general terms. The value of any. suspension depends on the car body to which it is applied, and unles the dynamical constants of the chassis are known, and the relative position of attachment of the spring system is stated, no judgment is possible as a rule. It has been seen that tyres and springs react on one another, so that in effect no suspension can be completely judged without reference to the tyres.

The main thing for the inventor of suspensions to realise is that the sum total of his efforts can result only in affecting the stiffness, inertia and friction of the car considered as a system. If the stiffness is made variable, as in certain cam-operated springs, or as in some conventional springs improperly shackled, the frequency depends on the amplitude, and a new set of problems arises involving elliptic functions; the experience of the trade is against springs of increasing stiffness. The inertia of a car qua suspensions may be susceptible of treatment, but it is unlikely that one treatment will be generally applicable to all cars. The friction of suspensions is probably the most fruitful line of work, but to make this feasible the laminated spring must be abolished. In the laminated spring there are too many variables and too many sources of error, and, worst of all, there is almost inevitably solid friction. The promising line of work on springs is to use a frictionless spring of the helical or torsion-tube type in combination with a hydraulic damper or shock-absorber. The diffculties in the way of such a suspension are not in any way formidable.

It is a fact of experience that fairly good riding properties may be obtained from the conventional types of springs, and it is of interest to examine the rirelative advantages of the usual ty]es. Here it should be observed that all springs are equivalent dy namically as springs if they have the same elastic and frictional properties. 
Firstly, we have the semi-elliptic spring, which is deservedly popular. Its main advantages are lateral strength, ease of attachment, absence of rotation of spring-seat as the spring deflects, lateral and torsional rigidity, including small effects of slack shackles, and the ability to take torque reaction-the so-called Hotchkiss drive. Under ease of attachment may be included the consideration that with four semi-elliptio springs the chassis is borne at eight points, so that frame stresses are kept small. There is also a cortain measure of safety with semi-elliptios in case a spring breaks. The main disadvantages of the semi-elliptic springs are higher unsprung weight and inability to absorb. horizontal shooks; the latter is probably the more important in many cases. A moot point is the Hotchkiss drive. While this is an advantage in regard to simplicity, there are many experienced designers who imply that a spring should not be asked to perform. two functions. The fact remains that the Hotchkiss drive is used on good cars and it can be justified in principle. Torque reaction if constant has the effect of imposing initial stress so that one half of the spring (the front half) is stressed more than the other, see Appendix G. It should therefore be necessary to use extra elips on one half of the spring, and it might be of advantage to seat the spring eocentrically. It would be useful to have observations from practioe on the relative liability to fracture of the two halves of the spring. One great gain of the Hotohkiss system lies in the possible effeot of torque variations in reducing spring friction.

Next, we may consider the quarter-elliptio or true cantilever spring, the main advantages of which are low unsprung weight and neatness. Lateral rigidity is fairly good, and the spring can be inclined so as to absorb horizontal shocks. The points against the quarter-elliptio spring are, the large local bending moment at the point of attachment to the frame, the large amount of dead spring steel at this clamping point and the sense of insecurity in the ordinary type should the spring break. The rotation of the axle casing due to torque or deflection can be corrected br suitable design and need not be emphasised.

The semi-elliptic cantilever or full floating cantilever has the. advantages of low unsprung weight and ability to absorb horizontal shocks without much localised bending moment in the frame. The trunnion bearing, while a source of expense, server a useful purpose in permitting small oscillations without much friction. The main drawback of the floating cantilever, apart from lateral weakness which can be corrected, is the additire effect of slackness in shackles. This can be seen very readily br allowing a lateral clearance at shackles of any amount C. With the semi-elliptio springs the total side-play is $\mathrm{C}$, whereas with the floating cantilever the total side play is $\mathrm{C}\left(3+b^{\prime} a\right)$ where $a$ and $b$ are the lengths of the anchored and free ends of the spring. Thus. for the same amount of shackle play the side-play 
of the chassis is at least three times as great in the floating cantilever as in the semi-elliptic or quarter-elliptic spring.

Three-quarter-elliptic springs call for little remark except that if the quarter-spring is properly designed there is a good absorption of horizontal shocks.

Transverse springs, as used in the Ford car, are cheap and have low unsprung weight. They require torque rods, however, and they do not absorb horizontal shocks. They have an advantage in regard to anti-rolling since the attachment to the chassis mayy. be high and the rolling stiffness can be made large. The double flexure in most transverse springs leads to excessive friction, and while the spring ends can be carried into the wheels, thus reducing: the bending moment in the axle, it is difficult to obtain slow periods of oscillation.

Opportunity may here be seized to rebut a pernicious fallacy which is graining ground in the automobile industry. It has been stated in a respectable journal that it is good to load laminated springs out of centre, because the unequal frequencies of the two parts tend to damp one another. For practical purposes a car spring under a given load has only one frequency, and thus the above-stated reason has no foundation at all. It is good to use laminated springs eocentrically in some cases, as in the Lanchester front springs, but for objects totally different from those adduoed in the fallacy. The reasons are mostly kinematio, and sometimes they might be concerned with horizontal shocks. It is possible that an eccentric laminated spring may have more friction than a centric spring, but this is doubtful and difficult to perceive. Until definite experimental evidence can be given on this point a sceptical attitude is to be recommended.

\section{Part VIII.-Trres.}

In order to gain clear ideas on the part played by tyres in the suspension of a vehicle, it is neoessary to examine the nature of tyxe efficacy. In doing so we may justifiably ignore all but elastic tyres, and in the first place we are led to consider pneumatic tyres.

Most perople ascribe the efficiency of pneumatic tyres to the resilience of the enclosed air, and in doing so they commit an error, for the chief value of the pneumatic tyre lies in the flexibility of the thin wall which the pneumatic principle permits. When a pneumatic tyre is under load, the contained air is compressed only very slightly, so slightly that the pressure may be assumed constant. The elasticity of the tyre is due to change of form just as the mechanical advantage of the toggle joint is due to form.

A theory of the matter was given by Prof. Archibald Sharp in the Encyclopædia Britannica, 11th Edition. He assumes that the tread is an ellipse, which is probably very near the truth, but 
quite unnecessary as an assumption; all that need be considered is the general form of the tread area. If this remains of the same, i.e., geometrically similar, form, no matter what the deflection of the tyre may be, then the load-deflection curve is a straight line. If the tread area varies in form a straight-line law is not to be expected, though it may pocur.

If the tread area be any symmetrical figure with semi-axes $a$ and $b$, the tread area will be $7 a b$ where $k$ is some constant if the shape of the tread area is constant. Assume that the tyre is circular in section as well as in the periphery so that the deflection $\delta$ can be written

$$
\delta=a^{2} / D=b^{2} / d
$$

or

$$
a=\sqrt{ }(\delta \mathrm{D}) \text { and } b=\sqrt{ }(\delta, l) \text {. }
$$

The area of the tread is $k a b$ or

$$
k a b=k \delta \sqrt{ }(\mathrm{D} d) .
$$

Thus, if $k$ is a constant the area of the tread varies as the deflection $\delta_{\text {. }}$ and if the prassure is assumed constant the tyre load is pressure $\times$ area, which varies as the deflection.

This linear law is borne out very closely by a variety of experiments. The directors of a well known tyre company have given the author a number of load-deflection curves for tyres of various sizes, and these analysed lead to the values in Table $V$. Thu first line gives the tyre dimensions, the second the range of load under which it was tested. The first column gives inflation pressure in $\mathrm{lb}$. per iq. in. and the remaining numbers are stiffnesses

\begin{tabular}{|c|c|c|c|c|c|}
\hline $\begin{array}{c}\text { Tyre Size. } \\
\text { Range of Load. }\end{array}$ & $\begin{array}{l}26 \times 2 \frac{1}{2} \\
0-4 \mathrm{cwt}\end{array}$ & $\begin{array}{c}710 \times 90 \\
0-200 w t .\end{array}$ & $\begin{array}{c}760 \times 90 \\
0-20 \text { cwt. }\end{array}$ & $\begin{array}{l}895 \times 150 \\
0-20 \mathrm{cwt} .\end{array}$ & $\begin{array}{l}915 \times 175 \\
0-20 \mathrm{cwt} .\end{array}$ \\
\hline $\begin{array}{c}\text { Inflation Pressure, } \\
\text { lb. per sq. in. } \\
30 \\
35 \\
40 \\
45 \\
50 \\
60 \\
70\end{array}$ & $\begin{array}{r}7190 \\
8020 \\
9750 \\
10910 \\
13000 \\
- \\
-\end{array}$ & $\begin{array}{c}12636 \\
\overline{14532} \\
- \\
1 \overline{6} \\
\overline{2} \\
21480\end{array}$ & $\begin{array}{l}11580 \\
\overline{14220} \\
\overline{17070} \\
\overline{22+50}\end{array}$ & $\begin{array}{l}16250 \\
\overline{20050} \\
\overline{2} \\
23550 \\
-\overline{-} \\
29700\end{array}$ & $\begin{array}{l}18050 \\
- \\
21900 \\
\overline{24810} \\
2 \overrightarrow{29700}\end{array}$ \\
\hline
\end{tabular}
in $\mathrm{lb}$. per ft. of defleation.

TABLE $V$.

In Table VI. are given those loads in owt. which would deflect the same tyre by one-eighth of the tyre section diameter. This fraction is that recommended by Mr. Paull, of the Dunlop Com-. 
pany; whom the author has to thank for instructive and interesting: onversations on the subject.

TABLE VI.

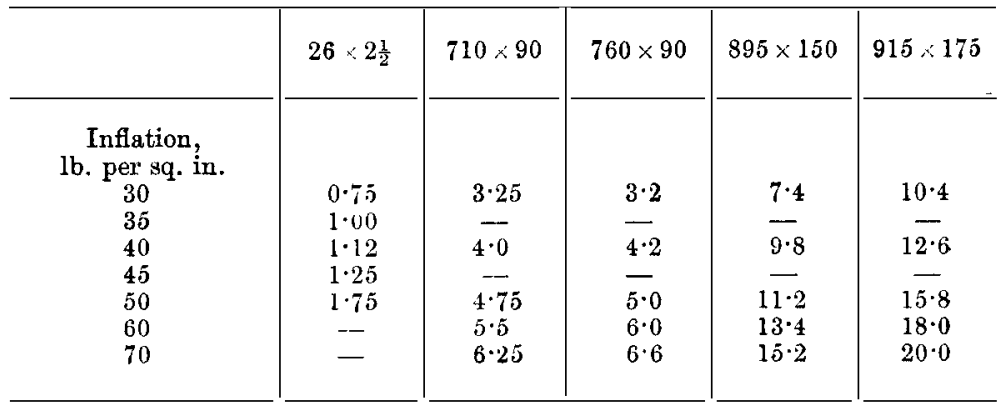

The Tables and information supplied by various makers are very different in arrangement, and to get general laws a variety. of Tables have been analysed. The Goodyear Company's Tables, for example, show for each tyre size an ideal load and inflation pressure from which the following formulæ for inflation pressure have been deduced.

For canvas tyres:--

lb. per sq. in. $=p_{i}=17 \cdot 5+10 d$ where $d=$ diameter in in.

For cord tyres:-

lb. per sq. in. $=p_{i}=12 \cdot 5+10 d$ where $d=$ diameter in in. For practical purposes we may take the mean $p_{i}=15+10 d$, so that the ideal inflation pressure is 10 times the section in inches plus 15. This should be a handy rule for garages.

The ideal loads per tyre from the Goodyear Tables may be expressed as

$$
\mathrm{W}_{i} \mathrm{lb} .=32 \cdot 4 d^{2 \cdot 24}
$$

so that the ideal load increases more rapidly than as the square of the tyre section. Here we see the need for large tyres for largo loads.

For any given inflation pressure the variation of permissible loal with diameter may be deduced from the Goodyear Table and expressed thus

$$
W=c p d^{1 \cdot 48}
$$

where $W$ is the load in $l b$.

$p$ is the inflation pressure in $\mathrm{lb}$. per sq. in.

$d$ is the section diameter in in.

and $c$ is a constant being 1.63 for canvas tyres and 1.81 for cord tyres.

The foregoing is a brief résumé of some important tyre facts based on makers' actual experience and recommendations. It. 
agrees generally with the predictions of theory, namely, that the deflection of a tyre varies as the load and inversely as the inflation pressure; we may now deduce a further result of much value. At the outset, from one allowable assumption we showed that the load

$$
\begin{aligned}
W & =p \text {.area of tread } \\
& =p k a b=p 7 i \delta \sqrt{ }(d \mathbf{D})
\end{aligned}
$$

The stiffness is thus:- $-\mathrm{W} / \delta$ or

$$
\left.s=W_{/} \delta=p\left(l^{o}\right) \% \sqrt{ } \mathrm{I}\right)
$$

But the Goodyear Table gives a permissible load $W=c p d^{1 \cdot 48}$, and if $\delta$ is made proportional to $d$ as the tyre makers recommend, wo have the Goodyear stiffness

$$
s=\mathrm{W} / \mathrm{o}=c_{1} p d^{0 \cdot 48}
$$

Both results show that for a given inflation pressure the stiffness varies as the pressure and as the square root of the tyre section. If, now, we take the car designer's problem and assume a definite load to be carried by a tyre which is to satisfy the tyre maker's recommendation that it must not be deflected more than one-eighth of the section, we see that the inflation pressure will be inversely as $d^{1 \cdot 5}$. Hence the chassis designer perceives that the stiffness of the tyro under a given load is inversely as the section diameter of tho tyre.

In Part VI, of this paper, Tables wore given showing quantitatively the effect, qua suspension, of fitting large tyres. It has been objected that large tyres are more expensive, but in the absence of exact tests this may be doubted, for the wearing surface is larger and the big tyre is less sensitive to overloading. This is part of a general principle in almost every branch of engineering; if any structure or machine is worked up to its maximum, even occasionally, its life is greatly reduced, e.g., fatigue of steel, small engines, human beings.

In connection with tyre size, an examination on the following lines was attempted:-

The load which a tyre will carry may be written

W varies as $p d^{1 \cdot 5}$

Now for a given cover stress the thickness $t$ of the cover will be $t$ varies as $p d$

and the weight of material $R$ in the aover will be

$\mathrm{R}$ varies as $t d$ or $t$ varies as $\mathrm{R} / d$

from which by elimination

so that

$p$ varies as $\mathrm{R} / d^{2}$

\section{$\mathrm{W} / \mathrm{R}$ raries as $1 / \sqrt{ } d$}

that is, the load that aan be carried by a given weight of cover is inversely as the square root of the tyre section. This result was gratifying for the following reasons. The London buses were ROWELL. 
barred from using giant pneumatios on aceount of the danger of collapse and capsizing due to tyre bursts, and it seems feasible to use a series of smaller tyres in parallel, e.g., in place of one 7 in. tyre, three 4 in. tyres. The idea appears to have been used in France some fifteen years ago. Secondly, in order to see whether' smaller tyres are cheaper load-carriers than larger tyres, ws the foregoing calculations indicated, the catalogue prices of one company and the ideal loads recommended by another company for cord tyres of the same size were compared. This was justified because no other data suitable were at hand, and, besides, the leading makers, on acoount of severe competition, bear very close comparison - at least, in their published Tables. However, the result of the eomparison was astonishing, and may be expressed thus:-

$$
\mathrm{C}=1 \cdot 11+0 \cdot 987 \mathrm{~W}
$$

where $\mathrm{C}$ is the cost in $£$ of a tube and corer and $W$ is the ideal load in cwt. The points lay exactly on a straight line, excepting. that for the $80 \mathrm{~mm}$. tyre, which was catalogued at $£ 411 s .9 d$. instead of $£ 511 s$. 0d. as given by the formula. The nett result is that the cost of a tube and cord cover for all sizes above $90 \mathrm{~mm}$. inclusive was $22 s$. plus as many $£$ as there are owt. in the load. Thus, on a cash basis one big tyre is slightly cheaper than the equivalent number of smaller tyres. This is, of course, not really surprising, since paoking, handling and selling as well as labour costs are probably more important than the material used. The difference in cost is, however, not serious and does not exclude the solution for the London bus unless skidding and turning should prove to causie excessive wear. The advantage of the multiple small tyre as against the giant pneumatic is that spare wheels or rims are easily carried and itted.

In the suspension problem, two factors stand out and dominate the design, which is fixed in regard to inertia, etc. by fashion, prejudice, and convenience. These two factors are stiffness, which should be kept small, and friction, which should be neither too large nor too small. We have seen that to reduce tyre stiffness there are only two courses open; the chassis designer must use larger tyres, or the tyre maker must develop a cover which will endure greater flexure, in proportion to the tyre section, without injury. A secondary point in connection with tyre stiffness is connected with the tread pattern. We have assumed a tread area of constant similar form, and this leards to a straight load-deflection line, but actual deflection diagrams are not quite straight. The divengence is probably not important, however, and in any case it is the problem of the tyre maker.

Little more need be said of tyres from the suspension standpoint except to compare solid and pneumatic tyres and to emphasise their different qualities. Many, and indead most, people assert thit the great value of the pneumatic tyre is that it is soft and resilient and that it drinks or swallows minor obstacles. This 
is, of course, futility. The main value of the pneumatio tyre is its friction, and its second value is its flexibility and lack of inertia. This may be seen at a glance from Fig. 23, which is taken from Enoch's article referred to in the bibliography. The Figuro shows that the pneumatic tyre of comparable size is less than half as stiff as the solid tyre and it absorbs by friotion ten or twenty times as much energy. The pneumatic tyre is built up of layers which rub on one another, and in this respect it is like a laminated spring. The solid tyre is a homogeneous substance and has only molecular friction, as in the helical spring. The load-deflection diagram for the pneumatic tyre is practically a straight line, and for the solid tyre it is a curre. For small loads the curve and straight line coincide, and thus we see one reason why a light ear might run on solid tyres. But, and here we have an astounding example of how the Goddess of Luak

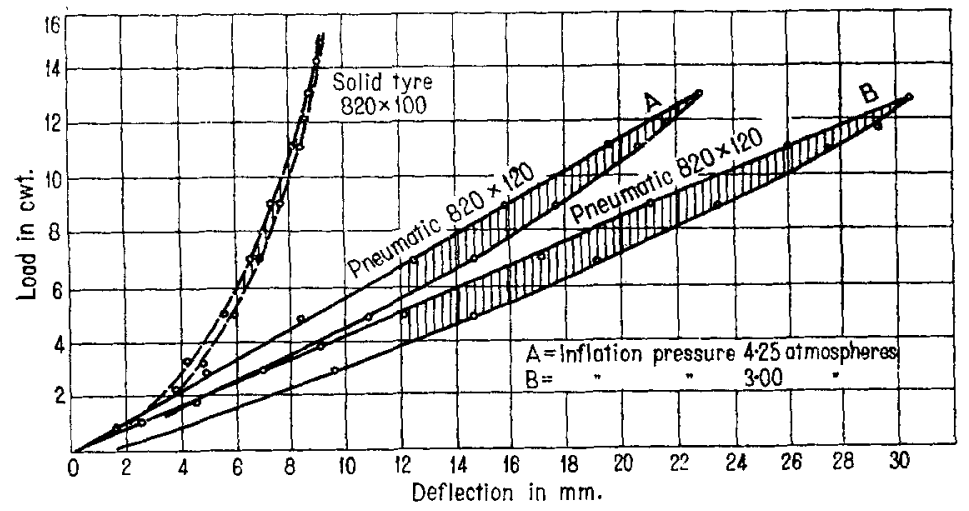

Fig. 23 .

stands helpfully at the elbow of the designer, the solid tyre could not be used satisfactorily on a heavy vehicle without laminated springs. No wonder the early cyoles were called "boneshakers."

An example of how the same Groddess fails, may be seen in the pneumatio tyre. With one hand she gives frietion, due to the rubbing of the fabrio layers or cords against one another, and with the other hand she adds that consequent heat which destroys those fabrics and cords. It would appear that the racing tyre, which requires friction and yet coolness, is a very nice matter of adjustment. For touring, a tyre of quite different characteristics might be better, in spite of many advertisements by tyre makers.

\section{PART IX.-CushtoNs.}

The rôle played by cushions has been indicated in Part VI. Here, we are conoerned with the main practical applications. $33(2)$ 
The chief requisites are softness and friction, but these are not all. To gain softness we require springs of adequate resilience, and to obtain friction we must have sufficient hair or kapok or other fibrous substitute, and the air passages must be so arranged that damping occurs. It is impossible to specify these factors it detail, but it should be very easy for an intelligent body-builder to notice whether cushions lack springs or hair or both. The great value of having cushions well damped is that resonance is almost impossible, and the value of deep springs is that shocks are not violent.

These are the general facts regarding cushions; there are, however, a few special points to be noted. Firstly, the general contour of the seats should be such that the weight of the body is distributed evenly. By having low seats the legs and feet are borne by the floor, whereas when seats are too high the weight of the leg and foot hangs from the knee and puts a load on the under surface of the thigh, thus compressing arteries, etc. By having reolining cushions some of the weight is taken on the shoulders and back and this relieves other parts of the body. Good cushions properly stuffed are naturally a great aid in distributing pressure, and since seats cannot usually be made to measure, the quality of the cushions becomes very important.

In connection with weight distribution, the feet present a problem. If the seating is too upright, pitching of the car is felt acutely, the feet become hot and the circulation becomes restricted. As the body is reclined, the pitching effects are taken up more effectively by the back cushions, but the feet are thrown up and down on the floor of the car. It may be possible to ameliorate this by means of a sprung foot-board. At present, in most cars, a hard boot is left to rest on a hard floor, and this would be bad enough in itself, but the rest of the body is suspended on springs which vibrate, and the boot must inevitably hammer on the floor, the knee joints are flexed, muscles are jerked and the result is needless fatigue and discomfort.

A further aspect arises from another consideration. Last year, in Paris, the author had an opportunity of discussing a certain car with a number of people, and there was unanimous complaint about the glazing of jackets. One man, who had fitted loose covers to correct this glazing, found that his coat-linings were rapidly worn through. The explanation, in general terms, is that the seat cushions were not damped enough, and the back cushions not reclined enough. Thus, the seat was bouncing up and down and sliding the passenger against the back. The solution here seems to lie in general springing of the seat. In many cars there is not enough clearance for this beneath the cushions, but in some saloons it should be easy to arrange separate seats on tubular sprung pillars; a reclining spring could also be fitted as in office chairs. In some omnibuses there is ample room for this general springing, and need for its application. The seat cushicns are 
so flexible and the posture so erect that an unwary passenger is liable to severe blows under his shoulder blades, or if he turns round his elbow is rapped on the window sill, oocasionally important buttons are unduly stressed.

The sum of all this is to indicate the need for springing all parts of upholstery in harmony, and, if possible, for springing the seat as a whole. To sum up-Damp down the oscillations by adequate filling, study posture and padding to distribute the load and, if possible, devise a softly-sprung foot-board or leg-rest.

\section{Acknowledgments.}

The sources drawn upon by the author have been stated in the text, and a short bibliography of writings on the subject is attached. Many of the results in these papers have not been embodied, others, notably in Professor Reissner's article, had been already worked out in Part IV. There remains, therefore, the duty of thanking the Council of the Research Association of British. Motor and Allied Manufacturers for permission to read this paper, which is based on some of the reports issued to Members of that Association during the past two and a half years.

\section{Bibliograpity.}

H. Reissner .... Bemerkungen zur Abferderung der Motorwagon (Der Motorwagon, 20 June, 1921).

P. Lemaire .... Remarques sur la Suspension des Vehicules (La Technique Moderne, Jan. 1921).

P. Enoch ...... Untersuchungen über die Beanspruchung und Abnutzung von Kraftwagenreifen (Der Motorwagon, 10, 20, 30 Sept. 1921).

H. Lamb ....... Dynamical Theory of Sound.

D. Landau and Journal, Franklin Institute, April, Dec. 1918, P. L. Parr... Jan. and Feb. 1919.

D. Landau ..... The Commercial Testing of Leaf Springs (Horseless Age, 30 Oct. 1912).

Influences affecting the Fundamental Deflection of Leaf Springs (Journal, S.A.E.).

Leaf Springs (Sheldon Axle Co., 1912).

W. L. Holt and Power Losses in Pneumatic Tyres (Bureau of P. L.Wormeley Standards, Paper 213, 1922).

A. Sharp ....... Encyclopædia Britt., 11th Edition, Art. Tyres. 


\section{APPENDIX A.}

\section{AMPLITUDE RATIOS AND ENERGY PARTITION IN AN ELASTIC SYSTEM WITH TWO DEGREES OF FREEDOM.}

Let the co-ordinates of the system be $x$ and $y$, then the kinetic and potential energies $\mathrm{T}$ and $\mathrm{V}$ can be expressed by the equations

$$
\begin{aligned}
& 2 \mathrm{I}=\mathrm{A} \dot{x}^{2}+2 \mathrm{H} \dot{x} \dot{y}+\dot{\mathrm{B} y} \dot{y}^{2} \\
& 2 \mathrm{~V}=2 \mathrm{~V}_{1}+a^{2}+2 h x y+b y^{\prime}
\end{aligned}
$$

where $a, b$, and $h$ are stability or elasticity coefficients. The equations of motion are

$$
\begin{aligned}
& A \ddot{x}+H \ddot{y}+a x+h y=0 \\
& \Pi \ddot{x}+H \ddot{y}+h x+b y=0
\end{aligned}
$$

using a speed factor $i s z$ we have

$$
(\mathrm{A} x+\mathrm{H} y)(h x+b y)=(\mathrm{IL} x+\mathrm{B} y)(a x+h y) .
$$

This gives a quadratic in $x / y$ thus

$$
\left.\left(x^{2} / y^{2}\right): \mathrm{A} h-a \mathrm{H}\right)-(x / y)(a 13-\mathrm{A} b)+b \mathrm{H}-\mathrm{B} h=0
$$

the product of the roots is

$$
-(b \mathrm{H}-\mathrm{B} h) /(a \mathrm{H}-\mathrm{A} h)
$$

when $\mathrm{H}$, i.e., when $x$ and $y$ are so chosen that the kinetic energy is expressed by squares of velocities, as in equations (19a), the product of the roots is $-B / A$, i.e., the ratio of the inertia coefficients, or, as we found, $K^{2}$. If, on the other hand, $x$ and $y$ are so chosen that the potential energy is expressed by squares of displacements, i.e., $h=0$, the product of the roots is $-b / a$, i.e., the ratio of the stability coefficients, or, as we found, the ratio of the spring stiffnesses. These two results can be written briefly

$$
x_{1} r_{2} / y_{1} y_{2}=-\mathrm{B} / \mathrm{A} \text { or }-b / a
$$

according as the kinetic or potential energy is a function of squares only. The suffixes of $x$ and $y$ denote the modes.

Now if this last equation be squared and multiplied by $A^{2} / \mathrm{B}^{2}$ or $a^{2} / b^{2}$ we have an energy relation thus

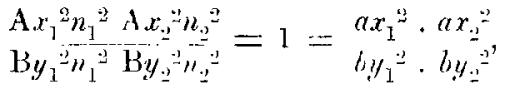

observing that in these elastic systems the onergy is alternatively kinetic and potential and that both are proportional to the square of the amplitudes and the kinetic energy varies also as the square of the frequency, we can interpret the last equations thus:-

"The energy ratio in one mode is the reciprocal of the energy ratio in the other mode when the energy is a function of squares."

In the car this leads to two important corollaries, namely:-

1. The pitching energy divided by the bouneing energy in one mode is the reciprocal of the corresponding ratio in the other mode; and

2. The energy absorbed in the front springs divided by that abiorbed in 
the rear springs is the reciprocal of the corresponding ratio in the other mode.

These two statements make clear a great variety of car phenomena. In particular they explain why the $\mathrm{K}^{2}=a b$ law is related to the springs and why it is not universally applicable.

If the motion is to maintain its character it will be sufficient and probably necessary that the dissipation should be proportional to the square of the amplitude, and this implies fluid friction. But, as may be seen in Part VII. and Appendix $\mathrm{E}$, the friction of laminated springs is mostly solid friction, and thus with laminated springs there is almost certainly a change in the type of motion. In practice this is not very serious because the damping is rapid, but the popularity of spring Iubrication and hydraulic shock-absorbers goes to show that the offect is unpleasant. In any case there is abundant evidence to show that spring friction is of the first importance in suspensions. (See Phil. Mag., Aug. 1922, p. 382.) 


\section{APPENDIX B.}

INFLUENCE OF BODY-FORM ON AXIE POSITION.

The nature of the variation in axle position to suit different types of body can be illustrated by simple geometrical analogy. Assume that the car body

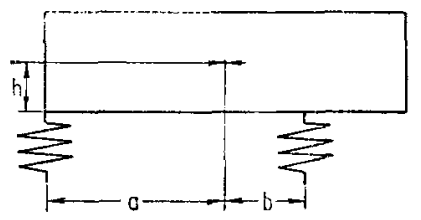

FIG. 24.

can be represented by a solid prism, Fig. 24, then it can be shown that the effective radius of gyration squared is something of the form

$$
\mathbf{K}^{2} \cong\left(a^{2}+4 h^{2}\right) / 3
$$
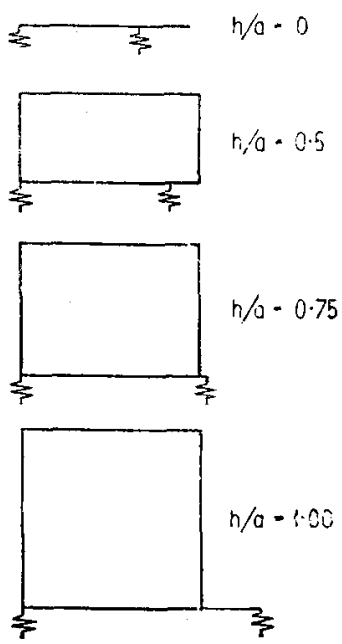

FIG. 25. 
and if this is made equal to $a b$ we have

$$
b / a=1 / 3+(4 / 3)\left(h^{2} a^{2}\right)
$$

or in a table we have the values

\begin{tabular}{c|c|c|c|c|c}
\hline$h / a$ & 0 & $\frac{1}{4}$ & $\frac{1}{3}$ & $\frac{3}{4}$ & 1 \\
\hline$b / a$ & 0.333 & 0.417 & 0.867 & 1.083 & 1.667 \\
\hline
\end{tabular}

These values are shown graphically by scale diagrams in Fig. 25 . It is assumed that the front spring is under the leading edge of the prism, and it will be appreciated that the solid prism considered bears only rough and qualitative comparison with actual car bodies, which, as a rule, have the masses further from the centre of gravity and thus proportionately larger. The two extreme cases, however, bear comparison with the empty brewer's flat and the fully-loaded pantechnicon. A two-seater coupé is also comparable. 


\section{APPENDIX C.}

\section{MORE GENERAL THEORY.}

The car simply considered has six degrees of freedom in the plane of its motion, see Fig. $26 ; m_{5}$ and $m_{6}$ are the passengers and $s_{5}$ and $s_{6}$ are the stiffnesses of the cushions. The double of the kinetic energy is:-

$$
\begin{aligned}
& 2 \Gamma=m_{1} \dot{x}_{1}{ }^{2}+m_{3} \dot{x}_{3}{ }^{2}+m_{5} \dot{x}_{5}{ }^{2}+m_{6} \dot{x}_{6}{ }^{2} \\
& +\mathrm{M} z^{2}+\mathrm{M} z^{2} \dot{\theta}^{2} \\
& \text { where } z=\left(a \dot{x}_{4}+b \dot{x}_{2}\right) / \mathrm{L} \text {. } \\
& \dot{\theta}=\left(\dot{x}_{4}-\dot{x}_{2}\right) / \mathrm{L}
\end{aligned}
$$

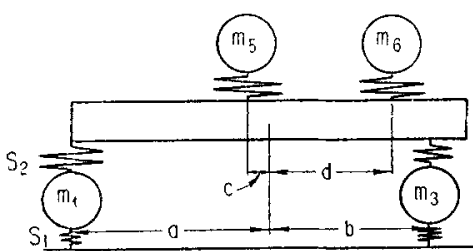

FIG. 26.

and the double of the potential energy, ignoring gravity, is:-

$$
\begin{gathered}
2 \mathrm{~V}=2 \mathrm{~V}_{0}+s_{1} x_{1}^{2}+s_{3} x_{3}^{2}+s_{0}\left(x_{2}-x_{1}\right)^{2}+s_{4}\left(x_{4}-x_{3}\right)^{2} \\
+s_{5}\left(x_{5}-x_{5}^{\prime}\right)^{2}+s_{6}\left(x_{6}-x_{6}^{\prime}\right)^{-2} \\
\text { where } x_{5}^{\prime}=\left\{x_{2}(b+c)+x_{4}(a-c)\right\} / \mathbf{I} \\
\left.x_{6}^{\prime}=\left\{x_{2}(b-a)+x_{4}^{\prime} a+c\right)\right\} / \mathrm{L}
\end{gathered}
$$

The equations of motion are given by:-

Thus:-

$$
\frac{d}{d t} \cdot \frac{d \mathrm{~T}}{d x_{r}}+\frac{d \mathrm{~T}}{d x_{r}}=0
$$

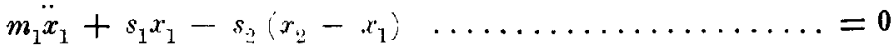

$$
\begin{aligned}
& b \mathrm{M}\left(a x_{4}+\ddot{\left.b x_{2}\right)}\right) / \mathrm{L}^{2}-\mathrm{M} / \ddot{k}^{2}\left(\ddot{x}_{4}-\ddot{x_{3}}\right) / \mathrm{I}^{2}+s_{2}\left(x_{2}-x_{1}\right) \\
& \left.-(b+c) s_{5}: x_{5}-\left[(b+c) x_{2}+(a-c) x_{4}\right] / \mathrm{L}\right\} / \mathrm{L} \quad a_{3} \\
& \left.-(b-a) s_{i \mathrm{i}} ; x_{6}-\left[(b-d) x_{2}+(a+d) x_{4}\right] / \Gamma_{1} ; \mathrm{I}_{1} \ldots=\mathbf{b}_{0} 0\right]
\end{aligned}
$$




$$
\begin{aligned}
& m_{3} \ddot{x}_{3}+s_{3} x_{3}-s_{4}\left(x_{4}-x_{3}\right) \ldots \ldots \ldots \ldots \ldots \ldots \ldots \ldots \ldots \\
& a \mathrm{M}\left(a x_{4}+\ddot{x_{2}}\right) / \mathrm{L}^{2}+\mathrm{M} k^{2}\left(\ddot{x_{4}}-\ddot{x}_{2}\right) / \mathrm{L}^{2}+s_{4}\left(x_{4}-x_{3}\right) \\
& \quad-(a-c) s_{5}\left\{x_{5}-\left[(b+c) x_{2}+(a+d) x_{4}\right] / \mathrm{L}\right\} / \mathrm{L} \\
& \quad-(a+d) s_{6}\left\{x_{6}-\left[(b-d) x_{2}+(a+d) x_{4}\right] / \mathrm{L}\right\} / \mathrm{L} \ldots=0 \\
& m_{5} \ddot{x}_{5}+s_{5}\left\{x_{5}-\left[(b+c) x_{2}+(a-c) x_{4}\right] / \mathrm{L}\right\} \ldots \ldots=0 \\
& m_{6} \ddot{x}_{6}+s_{6}\left\{x_{6}-\left[(b-d) x_{2}+(a+d) x_{4}\right] / \mathrm{L}\right\} \ldots \ldots \ldots=0
\end{aligned}
$$

Rearranging these equations with amplitudes $A_{r}$ and a speed factor $i n$, wo have the eliminant:-

$$
\begin{aligned}
& s_{1}+s_{3}-m_{1} n^{2} ;-s_{3} \quad ; \quad ; \quad ; \quad ; \\
& -s_{2} \quad ;\left[s_{2}+\left\{s_{5} \beta_{1}{ }^{2}+s_{6} \beta_{2}{ }^{2}-n^{2} \mathbf{M}\left(b^{2}+k^{2}\right)\right\} / \mathbf{L}^{2}\right] ; ; ; \quad ; \quad ; \\
& 0 \quad ; \quad 0 \quad ; \quad s_{3} s_{4}-m_{3} n^{2} \quad ; \quad ; \quad ; \quad ; \\
& \left.0 \quad ;\left[s_{5} \alpha_{1} \beta_{1}-s_{6 \alpha_{2}} \beta_{2}-n^{2} \mathbf{M}\left(a b-k^{2}\right)\right] / \mathrm{L}^{2} ;-s_{4} ; \downarrow ; ; \quad ;\right\}=0 \\
& {\left[s_{4}+\left\{s_{5} \alpha_{1}{ }^{2}+s_{b} a_{2}{ }^{2}-n^{2} \mathrm{M}\left(a^{2}+k^{2}\right)\right\} / \mathrm{L}^{2}\right]} \\
& 0 \\
& 0 \\
& ;-s_{5} \beta_{1} / \mathrm{L} ; 11 ;-s_{5} \alpha_{1} / L ; s_{5}-m_{5} n^{2} ; \\
& \left.; \quad s_{6} \beta_{2} / \mathrm{L} ; 0 ;-s_{t} \alpha_{2} / \mathbf{L} ; 0 ; s_{6}-m_{6} n^{2} ;\right)
\end{aligned}
$$

where

$$
\begin{array}{ll}
\alpha_{1}=a-c & a_{2}=a+d \\
\beta_{1}=b+c & \beta_{2}=a-b
\end{array}
$$

This determinant is symmetrical, and thus to save space only the lower left half is shown. Wach row is identical with the corresponding column.

The product of the roots is:-

$$
\mathrm{P}=s_{1} s_{2} s_{3} s_{4} s_{5} s_{6} /\left(m_{1} m_{3} m_{5} m_{6} \mathrm{M}^{2} k^{2} / \mathrm{L}^{2}\right)
$$

and the sum of the roots is:-

$$
\begin{gathered}
\mathrm{S}=\left(s_{1}+s_{2}\right) / m_{1}+\left(s_{3}+s_{4}\right) / m_{3}+s_{5} / m_{5}+s_{6} / m_{6} \\
\mathrm{~L}^{2}\left[\left(s_{2}+s_{4}\right) k^{2}+s_{22} a^{2}+s_{4} b^{2}+\left(a^{2}+k^{2}\right)\left(s_{5} \beta_{1}^{2}+s_{6} \beta_{2}^{2}\right)\right. \\
+\left(b^{2}+k^{2}\right)\left(s_{5} a_{1}^{2}+s_{6} a_{2}^{2}\right) \\
\mathrm{M}\left(a^{2}+k^{2}\right)\left(b^{2}+k^{2}\right)
\end{gathered}
$$

put $\mathrm{K}^{2}=a b$ and we have:-

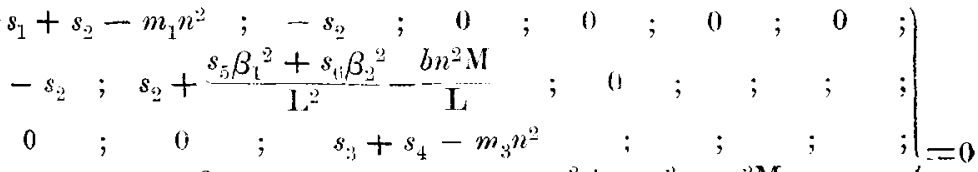

$$
\begin{aligned}
& 0 \quad ; \quad \frac{s_{5} a_{1} \beta_{1}-s_{6} u_{2} \beta_{2}}{\mathrm{I}^{2}} ;-s_{4} ; s_{4}+\frac{s_{5} a_{1}{ }^{2}+s_{6^{2}} \alpha^{2}{ }^{2}}{\mathrm{~L}^{2}}-\frac{a n^{2} \mathrm{M}}{\mathrm{I}^{2}} ; ;
\end{aligned}
$$

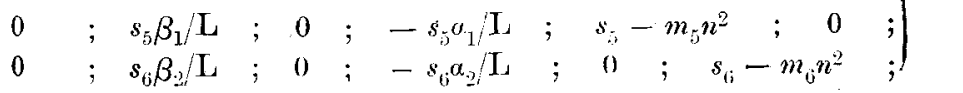

Now put

$$
d-b=\beta_{3}=0 \therefore \alpha_{2}=\mathrm{L}
$$


and the determinant becomes

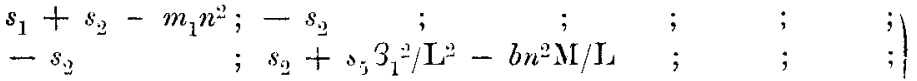

$$
\begin{aligned}
& 0 \\
& \left.\begin{array}{c}
11 ; s_{3}+s_{4}-m_{3} n^{2} ; \quad ; \\
; s_{5} a_{1} \beta_{1} / \mathrm{L}^{2} ;-s_{4} ; s_{4}+s_{6}+s_{5^{2}} \mu^{2} / \mathrm{L}^{2}-a n^{2} \mathrm{M} / \mathrm{L} ;
\end{array}\right\}=0 \\
& \text {; }-s_{5} \beta_{1} / L_{1} ; 0 ;-s_{5} \alpha_{1} / \mathrm{L}_{3} ; s_{5}-m_{5} n^{2} ; 0
\end{aligned}
$$

making

$$
s_{5}=m_{5}=0=s_{15}=m_{i j}
$$

we have:-

$$
\begin{aligned}
& s_{1}+s_{2}-m_{1} n^{2} ;-s_{2} \quad ; 0 \quad ; 0 \\
& -s_{2 .} \quad ; s_{2}-b_{2}: \mathrm{M} / \mathrm{L} ; 0 \quad 0 \quad ; 0 \\
& 0 \quad ; \quad 0 \quad ; s_{3}+s_{4}-m_{3} n^{2} ;-s_{4} \quad ;=0 \\
& \left.0 \quad ; \quad 0 \quad ;-s_{4} \quad ; s_{4}-a n^{2} \mathrm{M} / \mathrm{L}\right)
\end{aligned}
$$

which represents the empty vehicle.

Roturning to the main determinant and ignoring $s_{5} m_{5} s_{6} m_{6}$, we have:-

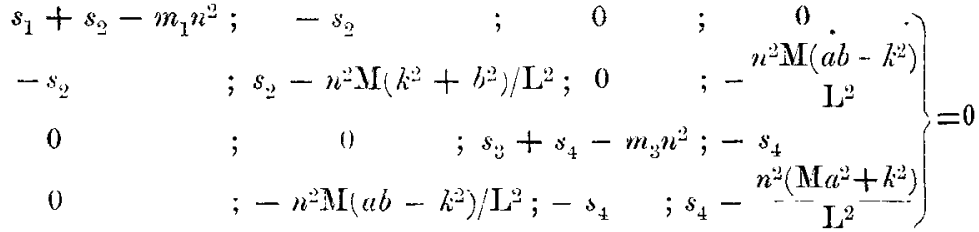

$$
\begin{aligned}
& \text { or }
\end{aligned}
$$

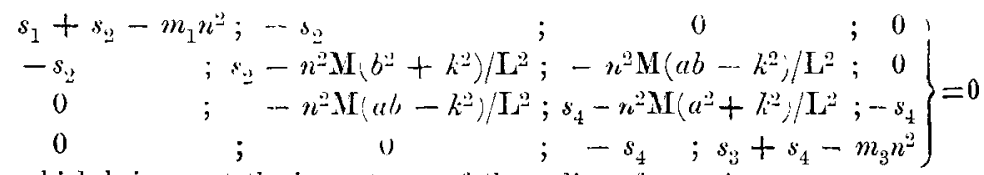

which brings out the importance of the rarlius of gyration.

If

$$
\begin{aligned}
& k^{2}=a b
\end{aligned}
$$

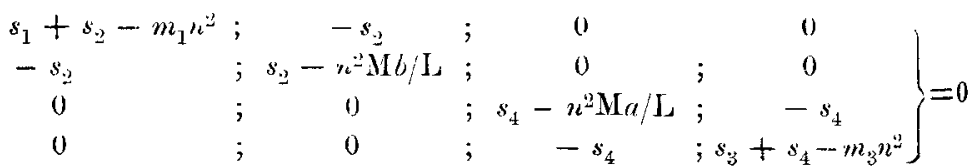

These determinants show, the nature of the influence of the various factors on the behaviour of the system, but the problem even in this simplified form is clearly too complicated for general deductions or working formulx for the designer. In a system with two degrees of freedom, i.e., two springs, the author has been able to deduce general relations on amplitude ratios and on energy partition, but for more complieated systems generalisation appears to be impossible; at least, this is the view of a very eminent mathomatician whom the author has consulted. At the same time two useful results emerge which are fairly general and which should be -iseful to the 
designer. There are two equations for the sum and product of the roots of the frequency equation. It will be seen that these are related very simply to the frequencies of the component parts when they are isolated or given individnal freedom.

A further word is necessary on the general problem. The suspension of a car is too complex for brief statement, but it is not too complex for improvement. Thus, keeping in mind the general ideas outlined, the designer can by rational experiment try various effeets, and by trying these one at a time see how his particular car is affected. The chief factors that will be found operative in any one car are softness and friction. Softening springs, tyres and cushions slows down the system and makes it less harsh throughout. Adding friction, especially if it be of the right kind and not excessive, makes for comfort and adaptability. If the system is adequately damped, resonance is less likely and less violent. Here it should be added that friction in any one part helps all the other parts except in cases of resonance, when the portion lacking in friction will be liable to excessive oscillations. This may he seen very clearly in cushions or in cycle saddles, and it shows the value of the cantilever cycle saddle and of ample horse-hair in cushions.

It is appropriate in this general section to recall the method of dynamieal similitude or models. The basis of the method lies in the adjustment of forces, lengths, masses and times, such that their ratios $\Pi, \lambda, \mu$ and $\tau$ satisfy the equation $\Pi=\mu \lambda / \tau^{2}$ together with the gravity relation $\Pi=\mu$ so that $\lambda=\tau^{2}$.

The advantage of the dynamical model is that it permits experiment of an accurate kind indoors and it has been very instructive in a negative way. The shortcomings of the model are due to two main causes. The first is that the friction in the car, which is a most important factor, cannot be readily reproduced to scale, and secondly, the problem involves so many variables that an experimental solution would be unlikely, at least in general terms. The main use of the model would appear to lie in the examination of the effeet of alterations, and even here it has many shortcomings and no advantage save expense in comparison with the actual car.

The suspension problem seems so intimately. bound up with steering, braking and engine, i.e., especially badly balanced engines, that the actual car, or a special experimental car with provision for adjustments, seems preferable to the model. This is especially clear when it is considered how widely the distribution of weight varies in the cars of various makers. 


\section{APPENDIX D.}

\section{SPRINGS WITH FLUID FRICTION.}

If the resistance in a spring is due to fluid friction the equation of free motion may be written:-

$$
m \ddot{x}+\mathrm{F} \dot{x}+s x=0
$$

or

where

$$
\ddot{x}+2 k x+n^{2} x=0
$$

and

$$
2 k=\mathrm{F} / \mathrm{m}
$$

Tho solution of this equation is:-

$$
n^{2}=s / m
$$

where

$$
x=\mathrm{A} e^{-k t} \cos n^{1} t
$$

$$
n^{1}=\sqrt{ }\left(n^{2}-k^{2}\right)
$$

one arbitrary constant is suppressed because the time zero can be chosen at will.

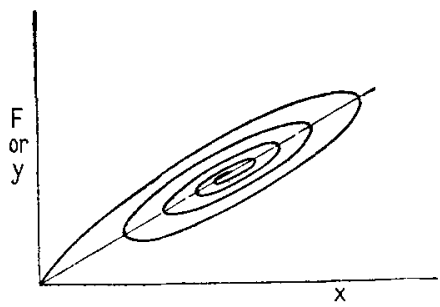

FIG. 27.

Equation (2) gives the displacement and the corresponding force is easily obtained from (1). The time can be eliminated, and thus an equation connecting the force and displacement. Thus if $x$ is the displacement from the equilibrium position and $y$ represents the force exerted by the spring per unit mass we have:-

$$
\begin{aligned}
y= & \mathrm{A} e^{-k t}\left\{\left(n^{2}-2 k^{2}\right) \cos n^{1} t-2 n^{1} k \sin n^{1} t\right\} \\
& =\mathrm{R} A e^{-k t} \cos \left(n^{1} t+\epsilon\right) \ldots \ldots \ldots \ldots \ldots
\end{aligned}
$$

where

$$
\epsilon=\tan -1 \cdot 2 n^{1} k /\left(n^{2}-2 k^{2}\right)
$$

and

$$
\mathrm{R}=\sqrt{ }^{\prime}\left\{2 n^{1} k^{2}+\left(n^{2}-2 k^{2}\right)^{2}\right\}
$$


Equations (2) and (3) may be rewritten for convenience thus:-

$$
\begin{aligned}
& x=a e^{-k t} \cos n^{1} t \\
& y=b e^{-k t} \cos \left(n^{1} t+\epsilon\right) \\
& y / b-(x / a) \cos \epsilon=-e^{-k t} \sin n^{1} t \sin \epsilon \ldots \ldots \ldots \ldots \text { (4) }
\end{aligned}
$$$$
(x / a) \sin \epsilon=-e^{-i t} \cos n^{1} t \sin \epsilon \ldots \ldots \ldots \ldots \ldots \text { (5) }
$$

Square and add and

$$
y^{2} / b^{2}-(2 x y / a b) \cos \epsilon+x^{2} / a^{2}=e^{-2 k t} \sin ^{2} \epsilon \ldots \ldots \text { (6) }
$$

which gives an elliptic or Lissajous spiral of the type shown in Fig. 27. If the vibration is forced, the foree-displacement characteristic becomes an ellipse or a family of ellipses. 


\section{APPENDIX E.}

\section{SPRINGS WITH SOLID FRICTION.}

Suppose we have a dry bar sliding through a dry hole as in Fig. 28. Then whichever way the bar slides there is a constant frictional force

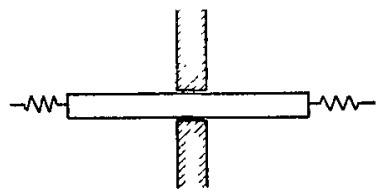

FIG. 28

opposing it, say F. The elastic force exerted by the springs is proportional to the displacement from mid position, say $c^{2} x$ where $x$ is the displacement.

Then if $m$ is the mass of the bar the equation of motion is

$$
m \ddot{x}+c^{2} x \pm \mathrm{F}=0
$$

wherein the sign of $\mathrm{F}$ depends on the direction of motion; when $\dot{x}$ is positive the positive sign is used before $\mathbf{F}$. Substitute

$$
x=\mathrm{X} \mp \mathrm{F} / c^{2}
$$

and the differential equation above becomes

$$
m \ddot{\mathbf{X}}+c^{2} \mathbf{X}=0
$$

the solution of which is

$$
\mathrm{X}=\mathrm{A} \cos (c t / \sqrt{ } m+\epsilon)=x \pm \mathrm{F} / c^{2}
$$

measure time from the instant when $x=\mathbf{A}$, say the moment of extreme deflection to the right, then

$$
x_{0}=\mathrm{A}-\mathrm{F} / c^{2}
$$

The return swing then takes place about the point $x=\mathbf{F} / c^{2}$ and the next forward swing takes place about the point $x=-\mathrm{F} / c^{2}$.

The motion is plotted on a time base in Fig. 29 and the true amplitudes measured from the position of equilibrium if there were no friction are:-

$$
\begin{aligned}
& x_{0}=\mathrm{A}-\mathrm{F} / \mathrm{c}^{2} \\
& x_{1}=-\left(\mathrm{A}-3 \mathrm{~F} / \mathrm{c}^{2}\right) \\
& x_{2}=\left(\mathrm{A}-5 \mathrm{~F} / \mathrm{c}^{2}\right) \\
& x_{3}=-\left(\mathrm{A}-7 \mathrm{~F} / \mathrm{c}^{2}\right) \\
& x_{4}=\left(\mathrm{A}-9 \mathrm{~F} / \mathrm{c}^{2}\right), \text { etc. }
\end{aligned}
$$

Thus the amplitudes decrease in arithmetical progression. Now using Mr. Baillie's definition of decrement as the ratio of each amplitude to the 
next one we see why the deorement becomes large for smail amplitudes. To make this olear we may assume $x_{0}=12$ and $\mathrm{F} / c^{2}=1$, then in a table we have:-

\begin{tabular}{|c|c|c|c|}
\hline & & Decrement. & \\
\hline$x_{0}=12$ & $\ldots \ldots$. & $1 \cdot 2$ & $\ldots$ \\
\hline$x_{1}=10$ & $\ldots \ldots$ & $1 \cdot 25$ & $\ldots \ldots$ \\
\hline$x_{2}=8$ & $\ldots \ldots \ldots$ & $1 \cdot 33$ & $\ldots \ldots$ \\
\hline$x_{3}=6$ & $\ldots \ldots \ldots$ & $1 \cdot 50$ & $\ldots \ldots \ldots$ \\
\hline$x_{4}=4$ & $\ldots \ldots \ldots$ & $2 \cdot 00$ & $\ldots \ldots \ldots$ \\
\hline$x_{5}=2$ & $\ldots \ldots \ldots$ & 00 & $\ldots \ldots \ldots$ \\
\hline$x_{6}=0$ & & & \\
\hline
\end{tabular}

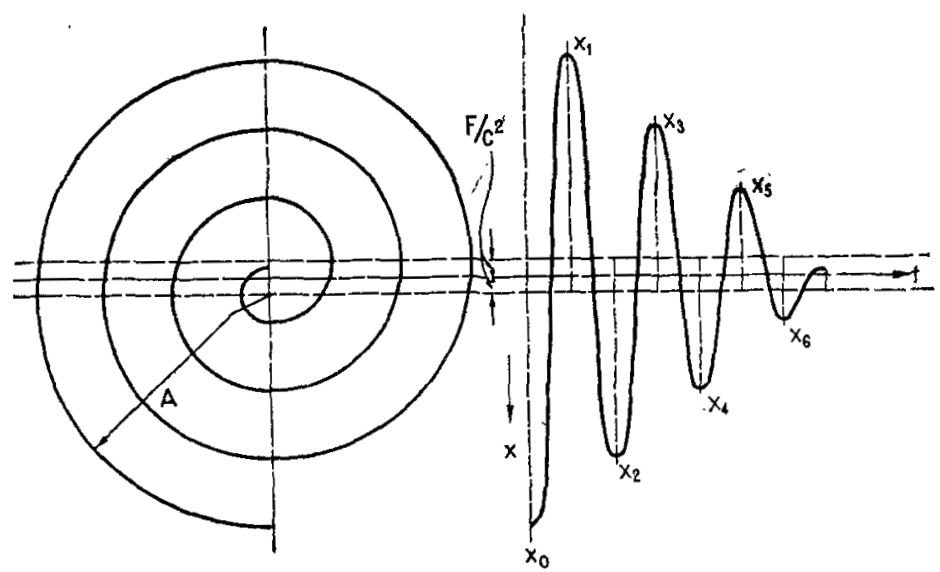

Fig. 29.

Putting the matter more generally, the amplitude is a linear function of the time, and if the time is measured backwards from the moment of coming to rest we have $x=a t$; the decrement is thus $i=\frac{u(b+t)}{a t}$ where $b$ is the periodic or semi-periodic time.

This becomes $\delta=1+b / t$ a hyperbola agreeing very well with $\mathrm{Mr}$. Baillie's experimental curves. The outstanding fact is that even in his well greased spring, there is evidently solid friction far in excess of the fluid Priction.

It may be remarked that vibrations under solid friction may be projected from a rotating vector the end of which describes a form of spiral. (See Fig. 29. and Phil. Mag., July, 1922, p. 284.) 


\section{APPENDIX F.}

\section{SPRING FRICTION EXPERIMENTS.}

Mr. Baillie in his paper on Springs mentions his diffeulty, in connection with the zero, in obtaining deflections and decrements accurately, and this difficulty is a general one in all damped elastic systems, e.g., galvanometers, torsion balances, etc.

Because spring friction is of fundamental importance in suspensions and as it can be determined most easily by means of oscillations, the following method of kurmounting Mr. Baillie's difficulty has been worked out.

Assume that there is both solid and fluid friction present according to the law. Resistance $=\mathbf{F}+k v$ where $v$ is the velocity of deflection. Then the equation of motion is

$$
m \ddot{x}+l i \dot{x}+c^{2} x \pm \mathrm{F}=0
$$

write

and we have the solution

$$
x=\mathrm{X} \mp \mathrm{F} / c^{2}
$$

$$
x=\mp \mathrm{F} / c^{2}-\mathrm{A}_{0} e^{-k t_{i}^{\prime} 2 m} \cos n^{\mathrm{I}} t
$$

where

and

$$
n^{1}=\sqrt{ } /\left(n^{2}-k^{2} / 4 m^{2}\right)
$$

$n^{2}=c^{2} / m$.

Note that solid friction has no effect on the frequency; write

and put

$$
2 \pi / n^{1}=\mathrm{T}
$$

$$
k_{\pi} / m n^{1}=\lambda
$$

The stiffness of the spring $c$ is known from static tests; we have to determine $\lambda$ and $F$ and the true zero position.

Suppose all readings of deflections are taken from a datum distant $\mathbf{E}$ from the true zero and let $R_{i}$ be the reading corresponding to the $i$ th swing. Then writing $\mathbf{F} e^{2}=\phi$ and $-\lambda / 2=\delta$ we have the relations

$$
\begin{aligned}
& \mathbf{R}_{0}=\mathrm{E}-\phi-\mathbf{A}_{0} \ldots \ldots \ldots \ldots \ldots \ldots \ldots \\
& \mathrm{R}_{1}=\mathrm{E}-\phi+\mathrm{A}_{0} \\
& \mathrm{R}_{2}=\mathrm{E}+\phi-\mathrm{A}_{0} \delta^{2}+2 \phi \delta \\
& \mathrm{R}_{3}=\mathrm{E}-\phi+\mathrm{A}_{0} \delta^{2}-2 \phi_{\delta}-2 \phi \delta^{2} \ldots \ldots \ldots
\end{aligned}
$$

Subtracting (1) from (2) and

$$
R_{1}-R_{0}=A_{0}(1+\delta)
$$

By elimination of $\mathrm{E}, \tau$, and $\mathrm{A}_{0}$ from equations (1) to (4) we have

$$
\delta=\left(\mathrm{R}_{1}-\mathrm{R}_{3}\right) /\left(\mathrm{R}^{2}-\mathrm{R}_{0}\right) \ldots \ldots \ldots \ldots
$$


Thus the logarithmic decrement is determined, and by substitution in (5) we obtain the true value of the first swing. The solid friction term $p$ which may be called the arithmetic decrement follows from (2) and (3) thus:-

$$
2 \phi=\frac{\mathbf{R}_{2}-\mathbf{R}_{1}}{1+\delta}+\mathbf{A}_{0} \delta \text {. }
$$

Equation (1) will then give $\mathrm{E}$ if required. 


\section{APPENDIX G.}

\section{SECONDARY STRESSES IN SPRINGS.}

The following is a brief examination of some secondary stresses in springs with the object of determining the order of their magnitude so that their relative importance may be estimated.

The-stresses considered are due to the following actions:-

1. Thrust due to the reaction of the car body against. being propelled.

2. Torque due to the reaction against the drive.

3 . Thrust due to the reaction of the brakes.

4. Torque due to the reaction of the brakes.

5. Torsion of springs due to twisting of the road plane as when one wheel is lifted or dropped.

It will be seen that 1 and 2 are almost identical with 3 and 4 but reversed.

The thrust in a top leaf is the most simple of these secondary stresses; there are two main conditions in which it may be usefully discussed. Suppose a car weighing $30 \mathrm{cwt}$. and driven by an engine of $40 \mathrm{~h} . \mathrm{p}$. at 30 miles per hour or $44 \mathrm{ft}$. per second. This implies a gradient. The total horizontal force on the car is $40 \times 550 \mathrm{lb}=500 \mathrm{lb}$. or the thrust on each spring is $250 \mathrm{lb}$. Assume a single top leaf of $2 \mathrm{in}$. by $\frac{1}{3}$. or an area of $0.5 \mathrm{sq}$. in., the total stress due to this load is thus $500 \mathrm{lb}$. per sq. in. or less than a quarter of a ton per sq. in. This is clearly an insignificant addition of stress.

Now take the thrust due to applying the brakes. This is limited by the adhesion of the wheels on the road which is hardly ever more than 0.8 and which under conditions of rear-wheel braking is always reduced by kinetic reactions. Assume the total axle load as $18 \mathrm{cwt}$, and the thrust becomes per spring $0.8 \times 9 \times 112 \mathrm{lb},=806 \mathrm{lb}$, which, for the ridiculously flexible spring assumed, means a maximum stress of $1,612 \mathrm{lb}$. per sq. in., or less than three-quarters of a ton per sq. in. This is clearly unimportant as an addition of stress.

As regards the torque due to driving or braking we may dismiss the stresses due to engaging the clutch in comparison with those due to applying the brakes. Thus suppose the wheels braked so that the road force per wheel is $806 \mathrm{lb}$. as above. Then with 30 -inch wheels the braking torque is $806 \times 15 \mathrm{lb}$.-in., and this is transmitted to the spring shackles, which we may reasonably assume to be $40 \mathrm{in}$. apart, producing reactions equal to $\frac{806 \times 15}{40} \mathrm{lb}$. $=302 \mathrm{lb}$.

We assumed an axle load of $18 \mathrm{cwt}$. or a spring load of $9 \mathrm{cwt}$. or a shackle. load of $4.5 \mathrm{cwt}$. or $504 \mathrm{lb}$.

Thus it is elear that the effect of applying the brakes is to induce forces of a magnitude comparable with the normal loading. Fig. 30 shows the chief forces. It will be seen that the effect of a road drag of $806 \mathrm{lb}$. adds $302 \mathrm{lb}$. to the rear shackle and relieves the front shackle of a like amount.

The conditions as regards stress are, in the rear half of the spring, as though the load were increased by 60 per cent, and it should be remarked 
that the kinetic reaction tends to relieve the stress as soon as it begins to occur.

An overload of 60 per cent beyond the normal static loading is in no way alarming, the ordinary dynamic overload on a rough road is often 100 per cent more than the static and most springs are designed for at least this addition. But consider the brakes applied on a rough road, and it is at once apparent that fracture is possible, though here again the road grip may be mitigated by road irregularities. A further contingency may be considered. Suppose a car descending a hill which is followed by a sharp ascent. Assume the radius of curvature of the road contour at the bottom of the valley to be $200 \mathrm{ft}$., then for a speed of 30 miles per hour the centripetal acceleration involves an additional load on the springs of 30 per cent. It will be seen that the torque reaction due to brakes may assume an undesirably high value. If springs fail due to this cause the fracture should occur in the rear half of the spring, and it is desirable to have the views of spring makers and chassis builders on this point. If springs failed in the front half and the failure were due to this torque reaction, it would indicate either that starting stresses were high which is unlikely with the usual eluteh and transmission, or that the forward rebound clips were insufficient.

So much for torque and thrust. There remains now the twisting of the

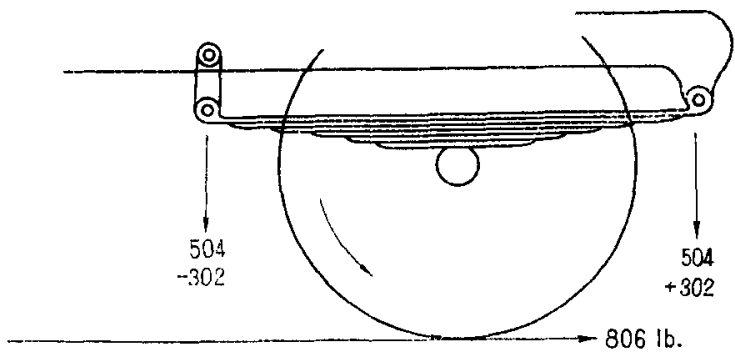

Fig. 30.

springs about an axis parallel to their length. The formulse for the torsion of a rectangular prism are derived in text-books of elasticity and they have been verified experimentally. The stress is greatest at the end of the minor axis, and there it has the value $f=4.5 \mathrm{~T} / a b^{2}$ where $\mathrm{T}$ is the twisting mornent and $a$ and $b$ are the long and short sides of the rectangle. The angular deflection per ineh of length is

$$
d \phi / d l={ }_{j}^{4} \cdot f \cdot \frac{1+b^{2} / a^{2}}{b}-
$$

where $G$ is the modulus of shear elasticity. In a plate spring $b / a$ is about $\frac{1}{\xi}$, so that $b^{2} / a^{2}$ may be neglected and the formula is simplified to

$$
d \phi / d l=4 f / 5 \mathrm{G} b
$$

Thus for a given angle of twist the maximum shearing stress is independent of the width of the plates and varies as the plate thickness and as the angle of twist.

If there were but one plate and the half-length of the spring were $20 \mathrm{in}$., then assuming a shear stress of $20,000 \mathrm{lb}$. per sq. in. and $G=12 \times 10^{6} \mathrm{lb}$. per sq. in. and the plate thickness $=0.25 \mathrm{in}$.

$$
d \phi=20 \cdot \frac{4}{5} \cdot \frac{2}{300}=0.107 \text { radians. }
$$


This would be ample for any road irregularities. But suppose there are plates and the twisting moment is the same, then the stress in any plate is $1 / n$th of that for the single plate, and consequently the angle of twist is $1 / n$th if the twisting moment is the same.

Iii the laminated spring the twisting moment allowable is limited by the master leaves and the angular twist is limited by the shorter leaves. This may be seen by considering a spring of 10 leaves with equal spacing and a half-length of 20 in., see Fig. 31 . Let a twisting moment $T$ be applied at the end and suppose that the angular deflection for a single leaf would be $\phi$. The deflection up to the first step is clearly $\phi / 10$, for the next step it is $\varphi / 20$, and the total deflection is clearly

$$
\begin{aligned}
& 0 \cdot 1 \phi(1+1 / 2+1 / 3+1 / 4+1 / 5+1 / 6++1 / 10) \\
& \text { or about } 0 \cdot 29 \phi
\end{aligned}
$$

For 15 leaves we have $0.22 \phi$,

$$
\begin{array}{lll}
\text { for } 20 \quad, & & 0 \cdot 18 \phi, \\
\text { and for } n, & , & (\phi / n)(1+1 / 2+1 / 3 \ldots+1 / n) .
\end{array}
$$

With a single leaf $0.25 \mathrm{in}$. thick and a $5 \mathrm{ft}$. track the permissible wheel deflection is $6.4 \mathrm{in}$. For a ten-leaved spring this is reduced to $1.85 \mathrm{in}$. and

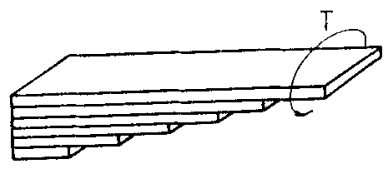

Fig. 31.

for a twenty-leaved spring the allowable deflection is only $1.15 \mathrm{in.}$. If thicker leaves or shorter steps are used the conditions become worse.

There seems little doubt that torsion of leaves is an important factor and well worthy of attention. Probably the usual practice of using more than one master-leaf is a result of torsion effects.

At the same time it is right to point out some mitigating circumstances. In the first place, the foregoing calculations assume perfect contact acrose leaf ends, whereas even with good clipping there must be a little yield. Secondly, when a wheel passes over a hump or hollow it rarely moves without the vehicle moving with it, and thus the relative motion of axle and frame - the torsion of the spring-is reduced by inertia effects. Thirdly, the fastenings, shackles, frame and axle casing, all yield and ease the stress on the spring. Fourthly, the torsional deflections are easily obviated by universal shackles or hasps. The main conclusions are that the thrust or pull in the master-leaf due to driving or braking is of no importance, the bending moment due to torque reaction is worthy of consideration because, in conjunction with other forces, it may cause failure, and the stresses due to twisting of the springs are probably the most important of all the secondary stresses. There is a common view in the motor industry that wide plates are good for anti-rolling because they resist torsion, but it would appear that this view is not correct, for when a plate is four or more times as wide as it is thick there is very little gain in stiffness by increasing the width. This follows at once from the fact that the stresses at the ends of the axes are inversely as the axes, and thus the integral of the stress squared is little affected by areas remote from the central point. 


\section{APPENDIX H.}

\section{$\longrightarrow$ \\ ON TORSION AND ANTI-ROLLING.}

Taking a rear axle with two quarter-elliptic springs we know that for a deflection if of each spring the load must be

$$
\mathrm{W}=\mathrm{En} a b^{3} \delta / 6 \mathrm{~L}^{3}
$$

The angle of torsion is $2 \delta / D$ where $D$ is the distance apart of the springs. The torque necessary to produce this deflection in each spring would be

$$
\mathrm{T}=\frac{2 \delta}{\mathrm{T}} \quad \frac{\mathrm{G}}{\mathrm{I}} \cdot \frac{10}{9} \cdot \frac{a^{3} b^{3}}{a^{2}+b^{2}}\left(\begin{array}{l}
n \\
r=n \pm 1 / r \\
r=1
\end{array}\right)
$$

Thus the reaction due to the torque of both springs is

$$
\mathrm{F}=\frac{4 \delta}{\mathrm{D}^{2}} \cdot \frac{\mathrm{G}}{\mathrm{L}} \cdot \frac{10}{9} \cdot \frac{a^{3} b^{3}}{a^{2}+b^{2}}\left(\frac{n}{n_{1} \Sigma^{2} / r}\right)
$$

The ratio of $F$ to $W$ measures the importance of torsion for anti-rolling. This ratio is

$$
\mathrm{R}=\frac{80}{3} \cdot \frac{\mathrm{G}}{\mathrm{E}} \cdot \frac{\mathrm{L} \dot{2}^{2}}{\mathrm{D}^{2}} \cdot \frac{a^{3}}{a\left(a^{2}+b^{2}\right){ }^{\prime \prime} \Sigma^{2},}
$$

We see that since $b^{2} / a^{2}$ may be ignored the ratio is independent of the width of the leaves. For semi-elliptic springs the problem is identieal since each half of the semi-elliptic acts as a quarter-elliptic spring. 


\section{APPENDIX J.}

\section{$\longrightarrow$ \\ THEOREM ON MASS RATIOS.}

Suppose three elastic bodies $m_{1} m_{2} m_{3}$ in line (Fig. 32) and suppose $m_{1}$ to move with velocity $v_{1}$, what are the conditions under which $m_{3}$ has a maximum or minimum velocity?

The fundamental principles are:-

1. The momentum is unchanged by impact.

2 . The relative velocity after impact is $-e$ times that before impact. Applying these and eliminating the intermediate velocities we have the velocity of $m_{3}$ as

$$
v_{3}=\left\{m_{1} m_{2} v_{1}(1+e)^{2}\right\} /\left(m_{1}+m_{2}\right)\left(m_{2}+m_{3}\right)
$$

Assuming that the impulse $m_{1} v_{1}$, i.e., the unsprung weight times the velocity of bounee, is fixed, we have to examine $m_{2} /\left(m_{1}+m_{2}\right)\left(m_{2}+m_{3}\right)$,

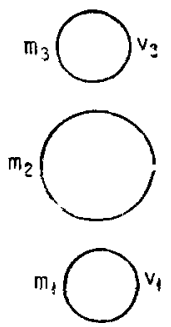

Frg. 32,

and when the differential coefficient of this expression is equated to zero we have the equation

$$
m_{1} m_{3}=m_{2}^{2}
$$

or in words, the weight of the body is the geometric mean of the weights of wheel and axle and of passenger.

This result is clearly true only for impulsive systems and it cannot be extended precisely even by analogy to elastic systems, but in certain conditions of springs and tyres and cushions the suspension of a car approaches the impulsive condition, and then the equation $m_{1} m_{3}=m_{2}^{2}$ might be expected to hold good more or less. The main point of interest here lies in the fact that in the light car the proportions of the masses are more in agreement with the above equation than are the proportions in big cars, and this may offer one explanation of the fact that a light car cannot be made as comfortable as a heavy car. Other explanations involving arguments of a more direct kind arise from Appendix $O$ and Part $V$. 


\section{THE DISOUSSION.}

Mr. J. WAT'l, in opening the discussion, said: 'The author advocates the retaining of an "intelligent invalid " to test out springing systems, and there is much truth in his contentions. I fully believe that I myself am not physically aware of the discomfort of many suspension systems, because when on the road I incline instinctively to concentrate on the mechanical aspect. For example, when motor cycling, if I hit a bad stretch of road I do not consciously notice the discomfort so much as the fact that I am possibly overstressing the frame or some other structural part. I therefore agree that an engineer who is driving regularly cannot pass so valuable a criticism on the comfort of a car as can someone who treats the velicle simply as a means of providing transport or pleasure. To all designers there is food for thought in the point the author raises regarding double pendulum effect. There is no doubt that the adjustment of the relation between the spring deflections (front and rear) and the wheel positions, so that the mast desirable combination is obtained, is a point worthy of the most careful consideration.

I should like to ask if the figures regarding the dimensions of the values in the vertical columns below the tyre sizes in Table VI. are in ewt. I might remark in passing that this Table of tyre deflections affords information useful in many ways, particularly. in connection with the computation of inertia stresses in various structural parts. In conclusion I feel that the Institution is to be congratulated on having been given the opportunity of putting on record this very valuable dissertation on springs, and I feel that in the future this paper will come to be recognised as a classic.

Mr. G. McDonald: Shock-absorbers have lately been very much to the fore, but I have not heard whether anything has been done in connection with their application to commercial vehicles; perhaps, however, the damping of springs by inter-leaf friction has been carried sufficiently far in commercial vehicles to obviate their use. To my mind the suspension problem will be very closely linked up with the multi-wheeled vehicles which are receiving so much attention just now. I have boen very much impressed with some of the similes used by the author; he has a happy knack of bringing home most of the points he is trying to make by a reference to something in nature.

Mr. J. D. Parkes: I would like to enter a plea for pure unadulterated mathematics in dealing with a problem of this sort. We may struggle along for years to get a result which, given the necessary facts, can be deduced mathematically in a few minutes, and the author, apart from any other value which his statements 
(Mr. J. D. Parkes.)

may have, has done us signal service in giving us so much of the mathematies of the subject.

The two main points which he has stressed are:-

(1) The effect of friction between the leaves of a laminated spring; and

(2) The effect of the nip between individual leaves.

The effect of friction is to some extent admitted whenever spring leaves are greased, but the mathematical results on the suspension as a whole are not so commonly understood or realised. The question of nip, in my opinion, is of extreme importance in its effect: on the life of individual leaves, and therefore of the spring as a whole. It is a matter of actual experience that in some springs, as built by the makers, the lower leaves are stressed very nearly, to their elastic limit as soon as the centre bolt is pulled up, without the application of any load to the spring at all. To proportion accurately the nip between this extreme limit and the opposite case in which the leaves open badly on a rebound, is a problem which, so far as I am aware, has hardly been touched, except by. Mr. Landau in his classic papers on road springs in goneral.

The Chairman: I think the first part of the paper is most instructive, and that it is most useful to try and find out in the first place what constitutes a comfortable car. I take it that the equations which the author has given for fore-and-aft oscillation of a car apply equally to oscillation sideways. Normally, the centre of gravity will be on the centre-line of the car, but when the car is only loaded on one side this will not be so, and this may be the reason why some cals are much more comfortable when they are fully loaded than with only the driver aboard. I think probably this paper could be extended to the question of the breakage of parts due to vibration, and if we went into it far enough we should probably find that the period of these parts corresponds. with the period of the springs or some other part of the vehicle. The author attached great importance to damping, and I should like to ask him if he has considered the form of the damping curve. That is to sav, in the ordinary spring friction we get very, slight damping at the beginning of the oscillation and very severe damping when the oscillation is at its maximum. Would some other form of damping be better or worse?

I am glad the author has taken up Mr. Landau's method of calculating out springs, which is an enormous advance on the work previously done on the question. Much of the calculation work done on springs previous to $\mathbf{M r}$. Landau's papers was, I think, very far from the mark, and I would like to urge upon those who are buying springs that they should be sure that they really do get what they are asking for. We have found that a great many failures of springs have been due to the material not being what we thought it was. There is just one slight criticism I would like to make. If the author had given us Tables showing what the various symbols which ho uses refer to, it would have helped a 
great deal in reading the paper. For instance, he uses $m$ in one place for mass, and in another place he uses it as a constant.

Mr. Bonn: I would like to ask the author if any experiments have been made with a view to determining the effect on vibration of pulling a car, so eliminating the effect of the drive of the engine. Regarding equal roots, page 479 , what would be the effect of designing a car symmetrically with six wheels, two wheels being at the centre of oscillation?

Mr. Rowel. in replying on the discussion, said: The instructive questions that have been asked, coming from practical people engaged in the Industry, are a great incentive, encouragement and help to anyone working in more abstract fields. At the same time it must be emphasised that the paper has been produced in close touch with modern practice. My position in the Research Association gives me almost unrivalled opportunities for discussion of such matters with men who are daily doing the world's work.

In a paper of this kind, the first essential, in my opinion, is to clear the air of a great many misconceptions that have grown up round the subject, due to the great complexity of the problem. When there are dozens of variables in a problem, a busy man cannot be expected to lay his finger on the precise effect of each one. Thus the leading object of the paper is to separate the main variables and give signposts so that designers and drivers may more consciously study these variables in their application to vehicles.

In reply to Mr. Watt, the values in Table VI. are in cwt., and a note to this effect has been inserted in the preceding paragraph.

$\mathrm{Mr}$. Macdonald's interesting suggestion of shock-absorbers on commercial vehicles may well be borne in mind by progressive designers, but only if they proceed on original lines. Lorry springs at present have many leaves and much friction, so that damping: is not seriously needed. Moreover, the drivers of such vehicles are usually hardened professionals who are paid to stand the racket.

I am much indebted to Mr. Parkes for his voice in the wilderness defending mathematics as a useful tool. The automobile is one of the most complex assemblies of problems in engineering, and whereas the turbine designer, the bridge engineer and many other specialists readily admit the need and value of mathematica? analysis, there is a deplorable tendency in the automobile world to belittle and decry any computations less crude than arithmetic.

$\mathrm{I}$ am in full agreement with $\mathrm{Mr}$. Parkes on the importance of friction and nip, and each of these aspects is at present under investigation by the Research Association. The phenomena, however, aro very complicated, and designers must not expect the results in a brief and chatty note.

Mr. Henderson raises many very interesting points. The equations given apply generally to rolling motion of the car and. as he suggests, unequal loading may, especially in very light cars, produce undesirable contitions. The main effect of full loading is, 
(Mr. Rowell.)

however, to slow down the natural frequencies of the car and to decrease the ratio of unsprung to sprung weight. Breakage due to vibration is certainly relevant to the general problem of suspension. Some time a.go I was asked to trace out the cause of a very happy result. A four-cylinder engine was found to idle so smoothly that the driver went to the starting handle thinking that the engine had stopped. I was able to show that this was almost wholly due to tyre inflation pressure. Motor cycles give a very clear illustration of this and the sensitive rider can do a great deal for his comfort by adjusting tyre pressures. At certain speeds which vary with tyre pressure a motor cycle "goes to sleep." The form of the damping curve is most important, and very minute variations alter seriously the character of a suspension. This has been investigatied recently by the Research Association, and the results will be available for publication in due course. Spring materials are certainly vital in spring design and not less dominant is the heat-treatment to which the steel is subjected. Fortanately, makers of springs are becoming alive to these matters, and the entire subject is being investigated on a very complete scale by the Government Springs Committee and the Research Association.

I have only one point of disagreement with all the speakers, and I regret I cannot see my error. Mr. Henderson asks for a list of symbots, and if the paper were one dealing with mere formula or design, that would be proper, but in dealing with principles I doubt the wisdom of such a step. In the first place the meaning of the symbols is carefully made clear just before the symbols are used, in many cases the symbols are shown in the illustrations. This saves the reader from carrying a long list in his memory or from turning frequently to the desired list. But this is not all. In a long paper, the choice of notation is a most important and diffeult matter, because it must be symmetrical and the symbols available are limited-many indeed are already attached by usage to well-known quantities and it is not advisable to change them. Thus $M$ is used for mass in the earlier parts of the paper, and in the chapter on springs it is used for bending moment; $p$ is used for tyre pressure and also for road wave frequency - both are conventional, and little confusion can result in the mind of the reader.

Various experiments of the kind mentioned by Mr. Bonn have been made, but mostly in private laboratories. On a perfectly flat road a car will oscillate, due to fluctuations of engine torque or faulty balance of wheels, but these troubles are easily remedied. A symmetrical car on six wheels would tend to pitch more gently than a similar car sprung on four points. In the sense of Part V. of the paper the system would have two degrees of freedom with two frequencies. "If these were equal the dynamical conditions would be essentially the same as for the four-wheeled car, as demonstrated experimentally by me before the members in Glasgow. The important principle to be kept in mind, and one 
which is not made clear, so far as I know, by previous writers, is that in a system of multiple frequency, any one frequency can be brought out by an appropriate disturbance. This is the most general view of resonance, and it is the view contemplated in Part II. on comfort. As everyday examples we have the dinner gong. Strike it with a flannel-covered mallet and it gives a dull sound; strike it with a steel key and a metallio note is given, simply beaause the impact of the key is more rapid and brings out the higher overtomes of the gong. "Similarly with an engine detonating-the high-speed blow on the eylinder wall makes it ring in a high note. 